DOE/ER82911-1

\title{
LARGE AREA FILTERED ARC DEPOSITION OF CARBON AND BORON BASED HARD COATINGS
}

\author{
Final Report
}

For Period September 4, 1999 - September 5, 2003

Rabi S. Bhattacharya

UES, Inc.

4401 Dayton-Xenia Road

Dayton, OH 45432-1894

December 2003

Prepared for

THE U.S. DEPARTMENT OF ENERGY

Contract No. DE-FG02-99ER82911

\begin{abstract}
NOTICE
This report was prepared as an account of work sponsored by the United States Government. Neither the United States Department of Energy, nor any of their employees, nor any of their awardees, subcontractors, or their employees, makes any warranty express or implied, or assumes any legal liability or responsibility for the accuracy, completeness, or usefulness of any information, apparatus, product or process disclosed or represents that its use would not infringe privately-owned rights.
\end{abstract}




\section{FOREWARD}

This document is a final report covering work performed under Contract No. DE-FG0299ER82911 from the Department of Energy under a Small Business Innovative Research (SBIR) Phase II Program. The research covered in this report was performed by the Materials Laboratory at UES, Inc. The Ohio State University was a subcontractor on this project (Dr. Rajiv Shivpuri). Dr. Shivpuri oversaw several graduate students who completed their thesis under this project. Besides the principal investigator the author of this report, Dr. Rabi Bhattacharya, other key UES personnel who were actively involved in this project include: Dr. Satish Dixit, Dr. A. K. Rai, and Mr. Boris Brodkin. Ms. Jan Clark of UES has provided excellent administrative support throughout this Phase II Project. 


\section{TABLE OF CONTENTS}

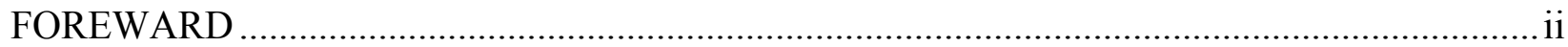

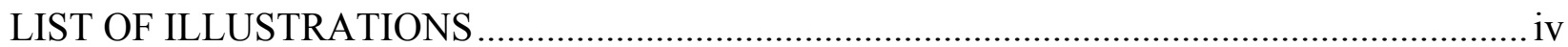

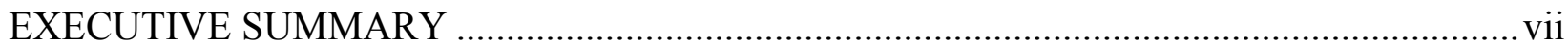

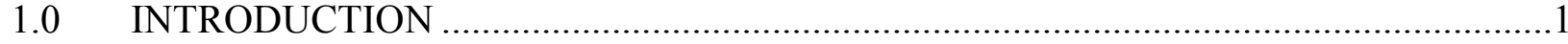

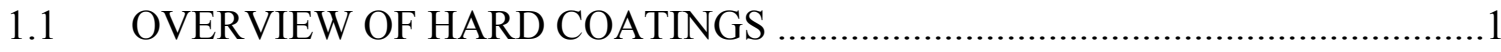

1.2 OVERVIEW OF MACHINING PROCESS ……………................................

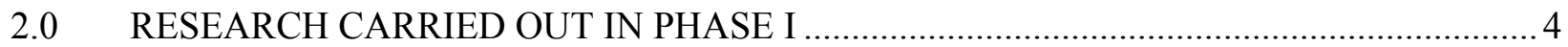

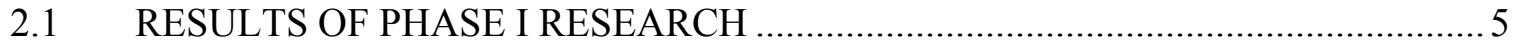

2.1.1 Experimental Description ..........................................................................5

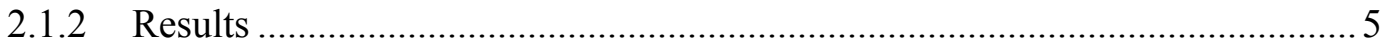

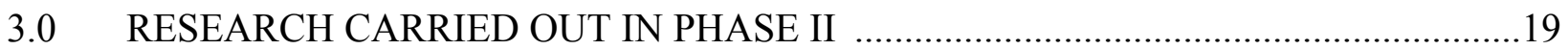

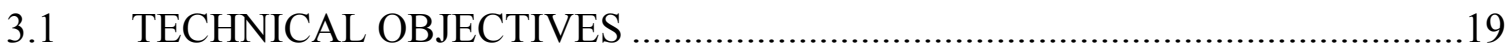

3.2 RESULTS OF PHASE II RESEARCH AND DEVELOPMENT ..........................20

3.2.1 Selection of Coating Materials and Coating Design ...................................20

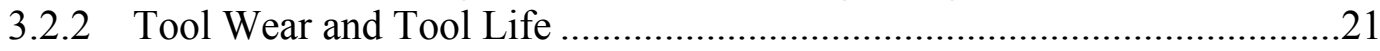

3.2.3 Selection of Substrate Materials and Heat Treatment................................24

3.2.4 Substrate Surface Preparation and Deposition of Coatings .......................25

3.2.5 Boron and Carbon Based Coating Development ......................................28

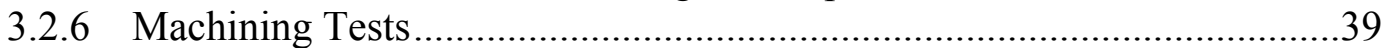

3.2.6.1 End Milling of AISI H13 ...........................................................

3.2.6.2 End Milling of Ti-6Al-4V............................................................48

3.2.6.3 End Milling of Al-Si Alloy ..........................................................57

3.2.7 FEM Analysis of Coating Behavior in Milling of Hardened Die Steel.....62

3.2.8 Temperature Distribution in Coating Layer and Substrate .........................68

3.2.9 Summary of FEM Simulation.................................................................69

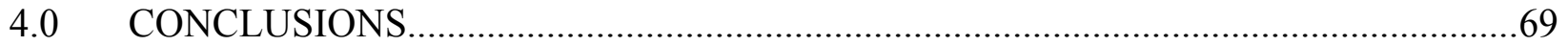

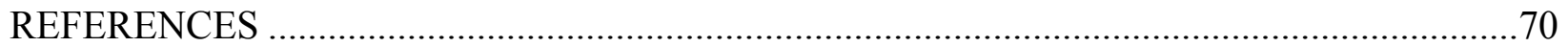


Figure

Figure 1

Figure 2

Figure 3

Figure 4

Figure 5

Figure 6

Figure 7

Figure 8

Figure 9

Figure 10

Figure 11

Figure 12

Figure 13

Figure 14

Figure 15

Figure 16

Figure 17

Figure 18

Figure 19

Figure 20

Figure 21

Figure 22

Figure 23

Figure 24

Figure 25

Figure 26

Figure 27

Figure 28

Figure 29

Figure 30

Figure 31

Figure 32

Figure 33

Figure 34

Figure 35

Figure 36

Figure 37

Figure 38

Figure 39

\section{LIST OF ILLUSTRATIONS}

Wear of coated cutting tools during high speed milling of $\mathrm{H}-13$

workpiece hardened to $52 \mathrm{HRC}$...........................................................................

Hot hardness as a function of temperature for various PVD coatings .................... 3

AES Profiles of Sample \#216 ............................................................................

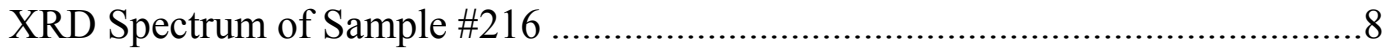

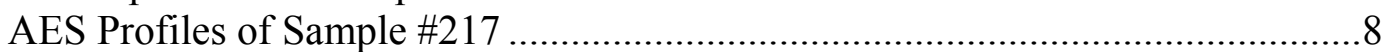

XRD Spectrum of Sample \# 217 ..................................................................... 9

XRD Spectrum of Sample \#218 .................................................................. 10

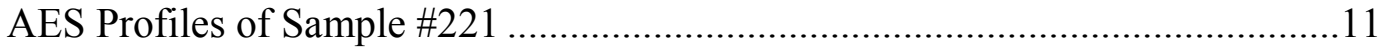

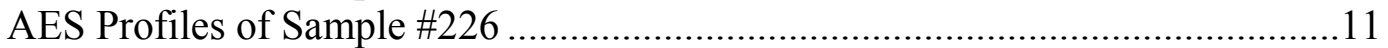

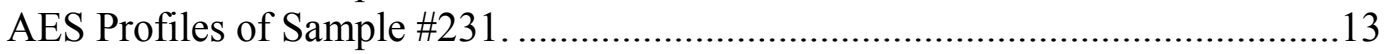

XRD Spectrum of Sample \#231 ....................................................................13

Transmission Electron Micrographs of Sample \#231: (a) Electron Diffraction

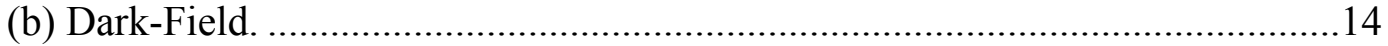

Raman Spectra of Samples \#221, \#231, \#240 and \#247 .......................................15

Optical Micrographs of Samples \#221, \#231, \#240 and \#247 ...............................16

Load Displacement Curves for Sample \#216 .....................................................18

Load Displacement Curves for Sample \#217 ....................................................18

Wear Test Results: Crater Diameter as a Function of Time for Various

Coatings

A schematic of the gradual wear modes in cutting tools (shown for a single

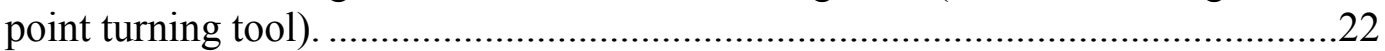

Features of a single point tool wear in turning (ISO Standard) ..........................23

Curves of tool flank wear and time of cutting for different cutting speeds. ..........23

Tool lives from Figure 20 plotted against cutting speed on a log-log graph ..............24

Schematic of the Large Area Dual Filtered Cathodic Arc Deposition System......27

Surface morphology of direct arc and filtered arc TiN coating..........................27

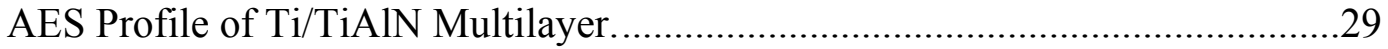

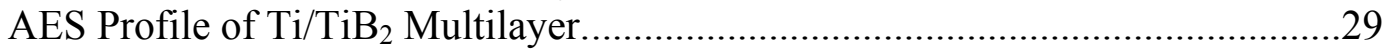

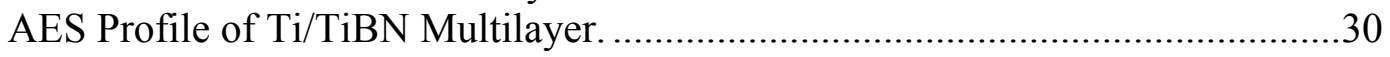

AES Profile of TiBN/Ti Multilayer. ...................................................................30

AES Profile of TiAIN/TiBN Mutilayer on TiAlN Base Layer.............................31

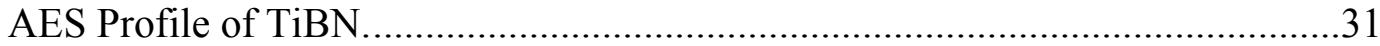

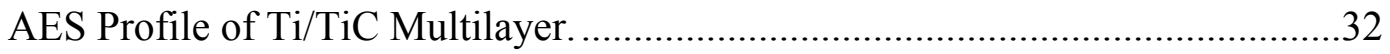

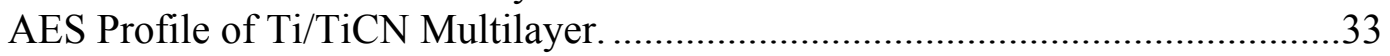

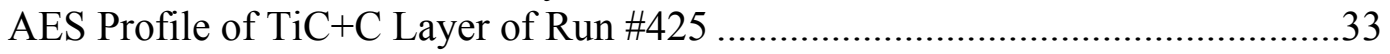

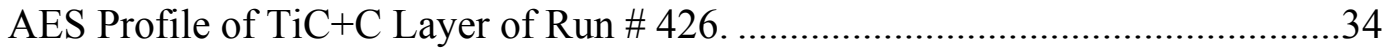

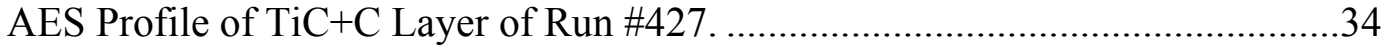

AES Profile of B Doped TiC+C Layer on Run \#676. ........................................35

Adhesion Judgment of PVD-Layers using Mercedez Test...................................36

Mercedez Test Results for Boron Based Coatings: (a) Run \#386 Ti/TiB 2 ,

(b) Run \#460 Ti/TiB 2 Multilayer and (c) Run \#461 Ti/TiBN Multilayer..............37

Cutter Body and Cutter Parameters. .................................................................40

Kistler's Stationary Dynamometer........................................................... 41 
Figure

Figure 40

Figure 41

Figure 42

Figure 43

Figure 44

Figure 45

Figure 46

Figure 47

Figure 48

Figure 49

Figure 50

Figure 51

Figure 52

Figure 53

Figure 54

Figure 55

Figure 56

Figure 57

Figure 58

Figure 59

Figure 60

Figure 61

Figure 62

\section{LIST OF ILLUSTRATIONS (Continued)}

Tool lives of different coatings during experiments (250 SFPM (RPM=673), feed rate: IPT=0.008; IPM=5.092).

Progression of wear at cutting speed of 250 SFPM (feed rate: IPT $=0.008$;

$\mathrm{IPM}=5.092$ ).

Tool lives of different coatings during experiments (350 SFPM (RPM=891), feed rate: IPT=0.008; IPM=7.13).

Progression of wear at cutting speed of 350 SFPM (feed rate: IPT $=0.008$;

IPM=7.13).

Tool lives of different coatings during experiments (450 SFPM (RPM=891),

feed rate: $\mathrm{IPT}=0.008$; IPM=9.166).

Progression of wear at cutting speed of 450 SFPM (feed rate: IPT $=0.008$;

IPM=9.166).

Tool lives of different coatings during experiments (120 SFPM (RPM=305), feed rate: $\mathrm{IPT}=0.008$; IPM=2.44).

Progression of wear at cutting speed of 120 SFPM (feed rate: $I P T=0.008$;

IPM=2.44).

Tool lives of different coatings during experiments (180 SFPM (RPM=458),

feed rate: IPT=0.008; IPM=3.664).

Progression of wear at cutting speed of 180 SFPM (feed rate: IPT $=0.008$;

IPM=3.664).

Tool lives of different coatings during experiments (240 SFPM (RPM=611),

feed rate: $\mathrm{IPT}=0.008$; IPM=4.884).

Progression of wear at cutting speed of 240 SFPM (feed rate: IPT $=0.008$;

IPM=4.884).

Tool lives of different coatings during experiments (300 SFPM (RPM=764),

feed rate: $\mathrm{IPT}=0.008$; IPM=6.11).

Progression of wear at cutting speed of 300 SFPM (feed rate: IPT $=0.008$;

IPM=6.11).

Worn out edges at 2600 SFPM: (a) $\mathrm{TiB}_{2}$, (b) TiBCN, and (c) TiAlN.

Tool lives of different coatings during experiments (2200 SFPM

(RPM=5600), feed rate: $\mathrm{IPT}=0.01$; IPM=112, 2 inserts on cutter)

Progression of wear at cutting speed of 2200 SFPM (feed rate: IPT=0.01;

IPM=112, 2 inserts on cutter).

Tool lives of different coatings during experiments (2600 SFPM

(RPM=6620), feed rate: IPT=0.01; IPM=132.4, 2 inserts on cutter).

Progression of wear at cutting speed of 2600 SFPM (feed rate: IPT $=0.01$;

IPM=132.4, 2 inserts on cutter).

Face Milling Process.

FEM models: a) FEM model for overall operation; b) sub-model for a

interest location on cutting tool rake face.

Comparison of Cutting Forces.

Stress distribution under different coatings at cutting speed of $76.2 \mathrm{~m} / \mathrm{min}$ (250 SFPM). 


\section{LIST OF ILLUSTRATIONS (Continued)}

Figure

Page

Figure 63 Stress distribution under different coatings at cutting speed of $137.6 \mathrm{~m} / \mathrm{min}$ (450 SFPM)

Figure 64 Temperature distribution under different coatings at cutting speed of $76.2 \mathrm{~m} / \mathrm{min}$ (250 SFPM).

Figure 65

Temperature distribution under different coatings at cutting speed of $137.6 \mathrm{~m} / \mathrm{min}$ (450 SFPM).

Table

Page

Table 1

Deposition Parameters of Coatings..............................................................6

Table 2

Indentation Parameters

Table 3

Hardness and Young's Modulus

Table 4

Coating Type: $\mathrm{TiB}_{2} / \mathrm{TiBN} / \mathrm{TiB}$

Table 5

Coating Type: $\mathrm{TiC}+\mathrm{C}$

Table 6

Table 7

Table 8

Test Conditions and Procedure.....

Nano Indentation Results

Machining Center Parameters

Table 9

Table 10

Coatings Tested for Machining.

CNMG 433 MR4 Parameters.

Table 11

Wear data for cutting speed of 250 SFPM $(R P M=673)$, feed rate: $I P T=0.008$;

$\mathrm{IPM}=5.092$

Table 12

Wear data for cutting speed of 350 SFPM $(R P M=891)$, feed rate: IPT $=0.008$; IPM=7.13

Table 13

Wear data for cutting speed of 450 SFPM $(R P M=891)$, feed rate: IPT $=0.008$;

IPM=9.166

Table 14

Wear data for cutting speed of 120 SFPM $(R P M=305)$, feed rate: IPT=0.008; IPM=2.44

Table 15

Wear data for cutting speed of 180 SFPM $(R P M=458)$, feed rate: $I P T=0.008$; IPM=3.664

Table 16

Wear data for cutting speed of 240 SFPM $(R P M=611)$, feed rate: $I P T=0.008$; IPM=4.884

Table 17

Wear data for cutting speed of 300 SFPM (RPM=764), feed rate: IPT=0.008; IPM=6.11

Table 18

Wear data for cutting speed of 2200 SFPM $(\mathrm{RPM}=5600)$, feed rate: $\mathrm{IPT}=0.01$;

IPM=112, 2 inserts on cutter.....

Table 19

Wear data for cutting speed of 2600 SFPM (RPM=6620), feed rate: IPT $=0.01$; IPM=132.4, 2 inserts on cutter.

Table 20

Cutting Conditions and Tool Geometry.

Table 21

Material Properties

Table 22

Tool Life Comparison for Milling of H13

Table 23

Tool Life Comparison for Milling of H13 


\section{EXECUTIVE SUMMARY}

The primary goal of this project was to develop coatings containing boron and carbon with hardness greater than $30 \mathrm{GPa}$ and evaluate these coatings for machining applications. The project tasks were carried out using the following procedure:

1. Muti-layer hard coatings containing boron and carbon were developed and deposited at UES, Inc. using the proprietary LAFAD (Large Area Filtered Arc Deposition) technology. Hardness of single layers boron and carbon containing coatings varied from 34 to $65 \mathrm{GPa}$. Multilayering, incorporating thin metal layers between boron and carbon containing hard layers, resulted into an increase in toughness and adhesion of these coatings.

2. Machining tests were performed with single and multilayer coated tools. CNMG433MR883 cutting insert geometry was chosen as it is the preferred geometry for high performance machining of ferrous and non-ferrous alloys. KL2IR-1.5-CN4-0 geometry was chosen for tool holder. Hard to machine titanium alloy, aluminumsilicon alloy and H-13 tool steel were chosen as workpiece materials for tool life assessment.

3. The turning and milling tests were run at TechSolve Inc. on a Tongil TNV-80 machining center with a fully instrumented test set up. The test parameters (depth of cut, feed and speeds) were selected to be consistent with the recommendation in the Machinability Handbook. While both flank and rake face wear were measured, flank wear of 0.02 inch was used as the tool life criterion. Both uniform wear and maximum wear at different stages of the machining process were recorded. Tool surfaces were optically examined to characterize the state of the flank surface and cutting edge.

4. Uncoated WC/Co substrate was used as a benchmark for titanium alloy and H-13 tool steel, while commercial PVD deposited TiAlN coating was used as a benchmark for Al-Si alloy machining. These selections were based on the best practices in the machining industry.

The results of the tests indicate the following:

1. The ultra hard TiBN single layer coating performed the best in high speed end milling of hardened tool steels (H-13). It has demonstrated a tool life increase of over $800 \%$ over uncoated $\mathrm{WC} / \mathrm{Co}$ and $25 \%$ higher than the second best candidate: multilayer TiBN/TiN. This performance was outstanding.

2. In the end-milling of highly abrasive Al-Si alloys, the multi-layer TiBN/TiN performed the best ( $40 \%$ increase over the TiAlN benchmark). Performance of single layer TiBN was lower but it also beat the benchmark. The improvement in tool life was lower at higher cutting speeds.

3. In the milling of titanium alloys, monolayer TiBN performed best at lower cutting speeds ( $80 \%$ increase over the uncoated benchmark). However at the higher cutting speeds $\mathrm{TiB}_{2}$ and the uncoated candidates had comparable performance.

In summary, significant increases in tool lives were realized in end milling of $\mathrm{H}-13$ die steel (8X) and titanium alloy (80\%) using the LAFAD deposited ultra hard monolayer TiBN coating. Other coating candidates also provided higher tool lives. However, the increases were not as significant. 


\section{$1.0 \quad$ INTRODUCTION}

\subsection{OVERVIEW OF HARD COATINGS}

Hard coatings are of interest in many engineering applications covering a broad range of industries including the aerospace, automotive, engineering, construction, biomedical, optical and microelectronics. The cutting tool industry has been using a variety of hard coatings available commercially since the early 1970 s [1]. Currently, more than $80 \%$ of all cutting tools are coated with wear resistant coatings and the applications are growing rapidly. The most common coatings are used in the industry are TiN, TiC, TiCN, and $\mathrm{Al}_{2} \mathrm{O}_{3}$ deposited by both Physical Vapor Deposition (PVD) and Chemical Vapor Deposition (CVD) techniques. The hardness of these commercial coatings is usually below $30 \mathrm{GPa}$. Although these coatings have increased the efficiency in the manufacturing industry, particularly in the machining of aluminum and iron base alloys, they have not performed well in machining of hypereutectic AlSi alloys, titanium base alloys, metal matrix composites and other newer exotic materials [2]. This poor performance is because the properties of these coatings such as hardness, toughness, wear resistance, chemical stability, and oxidation resistances are not adequate for machining harder materials. Even for more common steel materials, the productivity can be greatly increased by high-speed cutting using harder coatings, provided these coatings exhibit higher oxidation temperature than the current coatings. It is also desirable to eliminate the use of cooling lubricants completely in order to reduce the environmental impact of hazardous coolant. Harder coatings, in combination with a dry lubricant coating, may allow high speed dry machining which will lead to significant savings of the disposal cost of hazardous coolant. The recycling cost of these coolants represents anywhere from $10 \%-40 \%$ of the total machining cost. Thus, harder, more wear resistant coatings are needed in the machining industry for machining of newer alloys and improving the productivity by high-speed machining of conventional alloys. Also, other industries such as die casting dies, biomedical and aerospace industries can benefit from the availability of reliable, smooth and very hard (>30 GPa) coatings. Wear resistant coatings can increase the life of die-casting dies leading to the overall productivity improvement of $15-20 \%$, and energy reduction of $5-10 \%$ (usage of oil/gas and electricity, environmental effluents and metal scrap and recycling) [3].

Most of the commercial hard coatings to date are produced by either cathodic arc evaporation or CVD. In the cathodic arc process, a high-current, low-voltage arc spot moves at a high velocity around the cathode surface, igniting other arc spots in its wake thus producing a highly ionized metal plasma that transfers coating material from the target to the substrate surface. A significant disadvantage of this method is the formation of droplets, also known as macroparticles, in the cathodic arc jets, which limits the application of the process to surface coatings that do not require high precision or surface finish. These particles also deleteriously influence critical properties of the coatings. For instance, in the case of TiN coating on cutting tools, the presence of Ti particles in the coating compromises the hardness and wear resistance of the coating. Also, the roughness of the coatings on cutting tools produces rough surface finish of the machined surface. Thus, these coatings are not suitable for precision machining. Most of the early hard coatings were applied by CVD at high substrate temperatures around $1000^{\circ} \mathrm{C}$. Such high temperatures are unsuitable for many engineering substrates. 
From the above discussion, it is clear that the industry needs better wear resistant coatings that possess high hardness, $>30 \mathrm{GPa}$, smoothness and low processing temperature. Thus, the objective of this project was to develop coatings that meet the above needs and a coating process that can be easily scalable for large areas and adaptable for complex shapes. The key technical approach was based on developing ultra hard coatings with hardness $>30 \mathrm{GPa}$ using boron and carbon containing materials. The coatings were deposited by using a large area filtered arc deposition (LAFAD) technique in combination with sputtering.

\subsection{OVERVIEW OF MACHINING PROCESS}

Tougher substrate such as WC/Co coated with hard ceramic coatings is increasingly being used to improve the wear resistance and the tool life during machining hard-to-machine materials. However, in high speed machining of titanium alloys, hypereutectic aluminum-silicon alloys and hardened die steel, the tool lives of coated tools are of the order of a few minutes. This leads to loss of productivity due to tool changes and/or the use of low depths of cut, feeds or cutting speeds. The failure of coatings to machine these hard-to-machine materials has primarily been attributed to crater and attrition wear. This in turn could be attributed to insufficient hardness, toughness and poor adhesion properties of the coatings as well as the excessive high temperatures at workpiece-tool interface.

1. High Speed Machining of Hardened Tool Steels: High speed machining (HSM) of hardened tool steels is very attractive for die manufacturing companies because it eliminates the use of EDM (Electric Discharge Machining) and consequently die life reductions associated with the recast white EDM layer. The main limitation in its use is the reduced tool lives realized while machining hardened tool steels. Consequently, HSM has seen increased use of coated carbide inserts. While CVD is the preferred coating technique, PVD (plasma enhanced) is increasingly being used. The application of coated cemented carbides for high speed machining (cutting and milling) of tool steel is very much restricted by the increases in tool temperatures with the increase in cutting speeds. For example, flank wear behavior of uncoated, TiN coated $(1930 \mathrm{HV})$ and $(\mathrm{Al}, \mathrm{Ti}) \mathrm{N}$ coated $(2720 \mathrm{HV})$ cutting tools is shown in Figure 1 [2]. Cutting speed is $600 \mathrm{~m} / \mathrm{min}$ (2000 sfm) for $\mathrm{H}-13$ hot working tool steel hardened to $52 \mathrm{HRC}$ (typical die application). Higher performance of (Al, Ti)N coating system is attributed to higher hot hardness (higher hardness at elevated temperatures, Figure 2), higher oxidation resistance $\left(840^{\circ} \mathrm{C}\right.$ vs. $\left.620^{\circ} \mathrm{C}\right)$ and better bonding to the substrate. The dominant mechanism for tool wear in this application is tribo-oxidation and elevated temperature diffusion. The rule of the thumb in machining hardened steel with ceramics, cermets and CBN are that lower cutting speeds should be used for harder material. Cutting speeds are lowered from 250 $\mathrm{m} / \mathrm{min}(812 \mathrm{sfm})$ to $100 \mathrm{~m} / \mathrm{min}(325 \mathrm{sfm})$ as the hardness increases from 48 to 64 HRC. Typical cutting tools include oxide ceramics (e.g. alumina matrix with zirconia dispersions for high thermal resistance used in both rough and finish turning or continuous cutting at high speeds), mixed ceramics (e.g. finishing and fine finishing turning using TiC, TiN and mixtures for toughness as well as hardness), coatings on ceramics and $\mathrm{Si}_{3} \mathrm{~N}_{4}$ (CVD multi-layer coatings of $\mathrm{Al}_{2} \mathrm{O}_{3}, \mathrm{TiC}$, TiN etc.), and polycrystalline $\mathrm{CBN}$. 


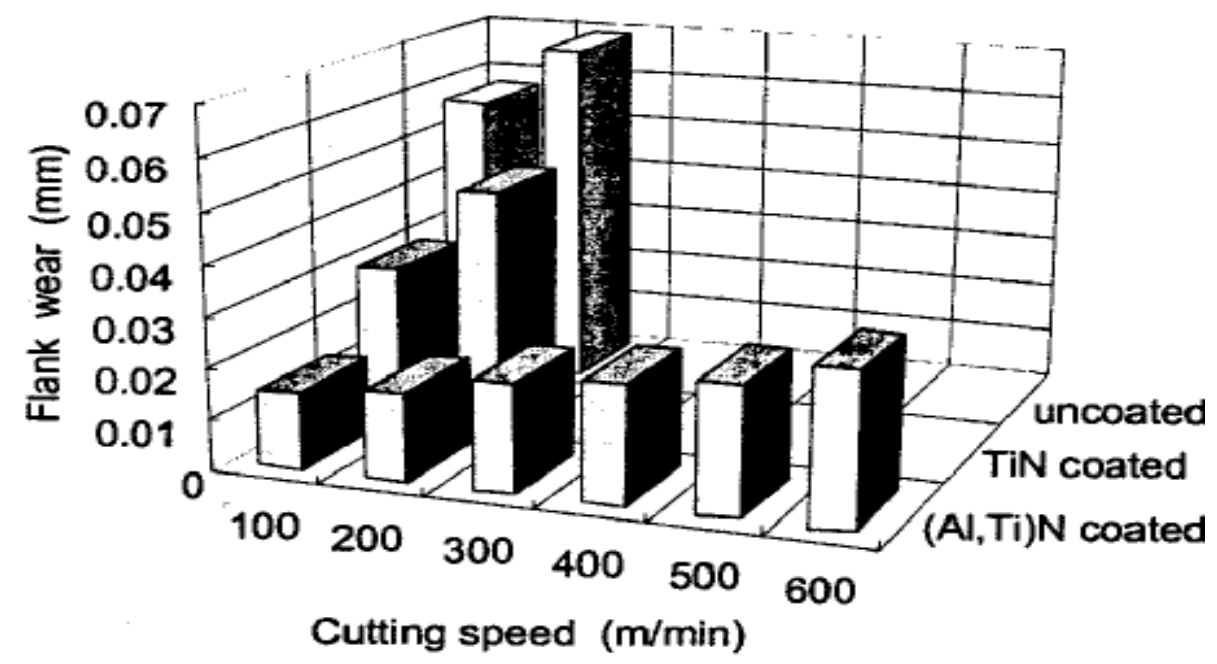
Outside diameter of endmills $10 \mathrm{~mm}$
Work material (hardness) X40CrMoV5-1 (52HRC)
Cutting speed $100-600 \mathrm{~m} / \mathrm{min}$
Feed rate $0.10 \mathrm{~mm} /$ tooth
Depth of cut $a_{p}=10 \mathrm{~mm}$
Width of cut $a_{0}=0.5 \mathrm{~mm}$
Cutting direction Downcut milling
Cutting length $50 \mathrm{~m}$
Remarks Side milling, air blow

Figure 1. Wear of coated cutting tools during high speed milling of $\mathrm{H}-13$ workpiece hardened to $52 \mathrm{HRC}[2]$.

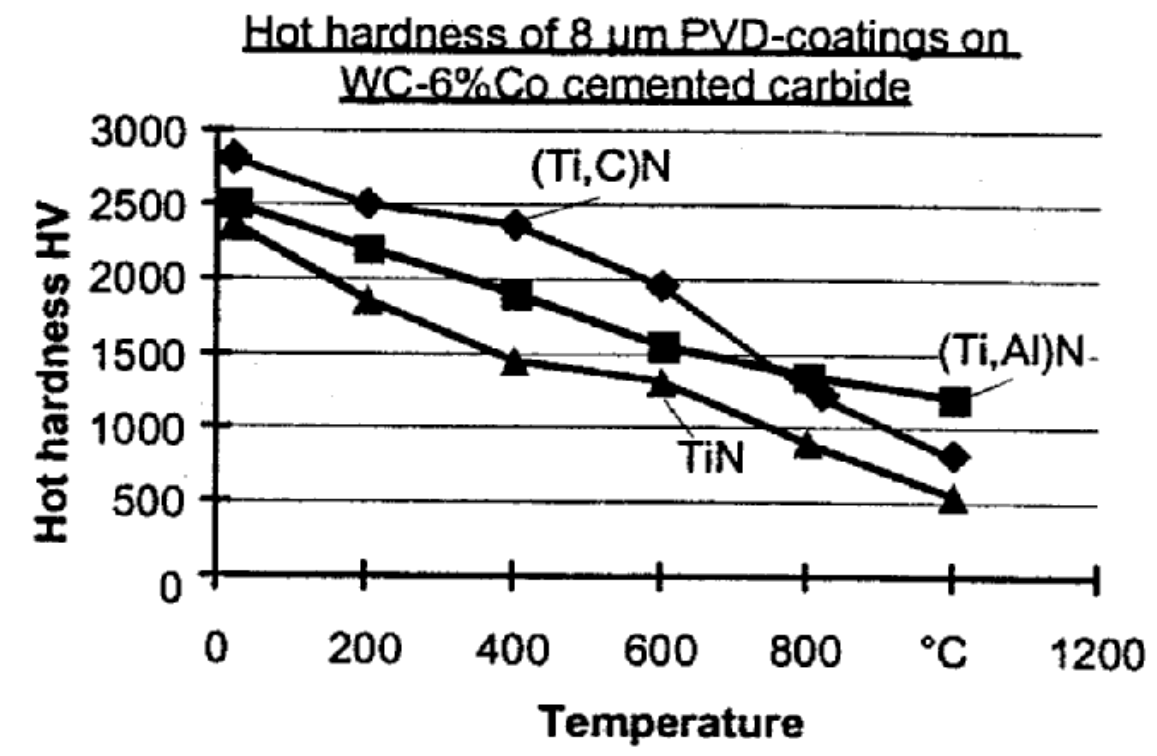

Figure 2. Hot hardness as a function of temperature for various PVD coatings [2]. 
2. Machining of Hypereutectic Al-Si Alloys: Hypereutectic Aluminum Silicon alloys (Si content 17 to 15\%) are increasingly being used in automotive application such as engine blocks due to their low density and excellent wear characteristics. The parts are often manufactured by die casting (390 Al), lost foam casting, hot forging and spray forming processes. Increased silicon content, however, results in formation of inclusions of silicon carbide oxides and nitrides in the aluminum matrix. These inclusions are extremely hard and abrasive in nature which results in severe reductions in cutting tool lives.

3. Dry/Minimum Coolant Milling of Cast Aluminum Alloys: Dry machining has significant ecological and economic advantages over conventional coolant based machining. Because of their high hot hardness and low susceptibility to adhesion and diffusion, $\mathrm{CBN}$ and ceramic based tools make dry machining possible for hard and high speed machining using rotating tools. This is especially attractive in milling where coolant impose additional thermal load on the cutting tool. A typical application is dry face milling of cast aluminum (AlSi10Mg (380/383) alloy) where higher tolerances can be achieved. However due to higher adhesion and diffusion wear, it is essential to use coated tools. Self lubricated PVD $\left(\mathrm{TiN}+\mathrm{MoS}_{2}\right)$ and $\mathrm{PCD} / \mathrm{DLC}$ coatings have shown lower flank wear.

The above examples illustrate the diverse needs for tool coatings to be effective in different machining applications. The coatings should be hard (low abrasive wear), tough (low cracking), high temperature resistance (diffusion barrier), good adherence to the substrate (reduced spalling), poor adherence to the workpiece material (low surface friction) and compatibility with the lubricant.

The purpose of the proposed experimental program is to evaluate the performance of boron and carbon based coating systems in high performance machining applications (high temperatures, high cutting speeds, highly abrasive and adhesive workpiece material and high diffusion (dry cutting)).

To reduce tool wear, superhard ( $>30 \mathrm{GPa}$ ) boron based titanium coatings with low defects and low stress are developed on the carbide cutting tool using the large area filtered arc PVD process. Then the selected coating system candidates are evaluated in a face-milling test carried out at conventional and higher cutting speeds. Extensive machining tests were performed to investigate the performance of different coating developed in Phase I and Phase II in this project during machining different materials, namely die steel $\mathrm{H} 13$, hypereutectic aluminum alloys (Al-Si alloy) and, Ti-6Al-4V. The developed coatings show significantly reduced wear compared to commercially available coatings in face milling hypereutectic aluminum. A FEM model of TiBN and TiBN/TiN coated cutting tool in face milling of $\mathrm{H} 13$ steel is also developed. FEM model of the milling process are used to explain the wear behavior. Based on both the experimental and numerical analysis, an evaluation for different coatings during cutting processes is reached.

\subsection{RESEARCH CARRIED OUT IN PHASE I}

The purpose of the Phase I project was to develop a process for depositing ultra hard coatings containing boron and carbon. The approach was to use a novel filtered cathodic arc deposition 
technology available at UES. This technology provides a "plasma immersed" environment using powerful arc plasma sources and auxiliary anodes to provide highly ionized plasma surrounding the part. The coating materials selected for Phase I included $\mathrm{TiB}_{2}, \mathrm{TiB}_{2} / \mathrm{TiBN}$ composite, DLC and TiC/DLC composite.

\subsection{RESULTS OF PHASE I RESEARCH}

\subsubsection{Experimental Description}

The experiments were conducted using the filtered cathodic arc system at UES, equipped with two magnetron sputter sources. Titanium and carbon cathodes were used to generate arc plasma. Boron and titanium diboride cathodes were used in the magnetron sources to produce boroncontaining coatings. The deposition chamber was initially evacuated to a pressure of $7 \times 10^{-4} \mathrm{~Pa}$ prior to introducing gas such as nitrogen, argon or methane. The substrates were mounted on a variable speed rotary (two-axis) substrate holder that can be biased to a desired voltage using either a DC or RF power.

The substrates were made from H-13 steel, heat-treated to a hardness of HRC 46, M50 steel and silicon. The samples were cleaned ultrasonically first in acetone and then in methanol and blowdried with dry nitrogen. The deposition chamber and the samples were degassed by heating in vacuum at $200^{\circ} \mathrm{C}$ for one hour prior to deposition. The samples were sputter etched for $5 \mathrm{~min}$. in dense argon plasma created by extracting electrons from the filtered arc sources using auxiliary anodes and keeping the deflecting magnetic coil turned off. After sputter etching, a thin layer $(\sim 100$ $\mathrm{nm}$ ) of Ti was deposited from the filtered arc prior to the deposition of all Ti-based coatings. This was done with the presumption that it will enhance the bonding of Ti-based coatings with the substrates. The gas pressure in the chamber during depositions varied from $4 \times 10^{-2}$ to $1 \times 10^{-1} \mathrm{~Pa}$.

The coatings were characterized for thickness, composition, hardness and adhesion. The thickness was characterized by both surface profilometry and Calotest equipment. In Calotest measurement, a small crater was put in the sample using this instrument that rotates a steel ball coated with fine abrasive. The thickness of the coating can then be measured from the crater edge using a calibrated optical microscope. This technique without the abrasive was used for relative wear resistance measurement of various coatings. Auger Electron Spectroscopy (AES) in combination with sputtering was used for composition analysis. X-ray Photoelectron Spectroscopy (XPS) was used for analysis of the selected coatings containing both B and N. Raman spectroscopy was used to analyze carbon-containing coatings. Limited Transmission Electron Microscopy (TEM) was used for microstructural analysis. The hardness and the modulus of the coatings were measured by using a nanoindenter.

\subsection{2 $\underline{\text { Results }}$}

Table 1 summarizes the deposition parameters for all the coatings that were selected for detailed characterizations based on their visible appearance of uniformity and adherence. 


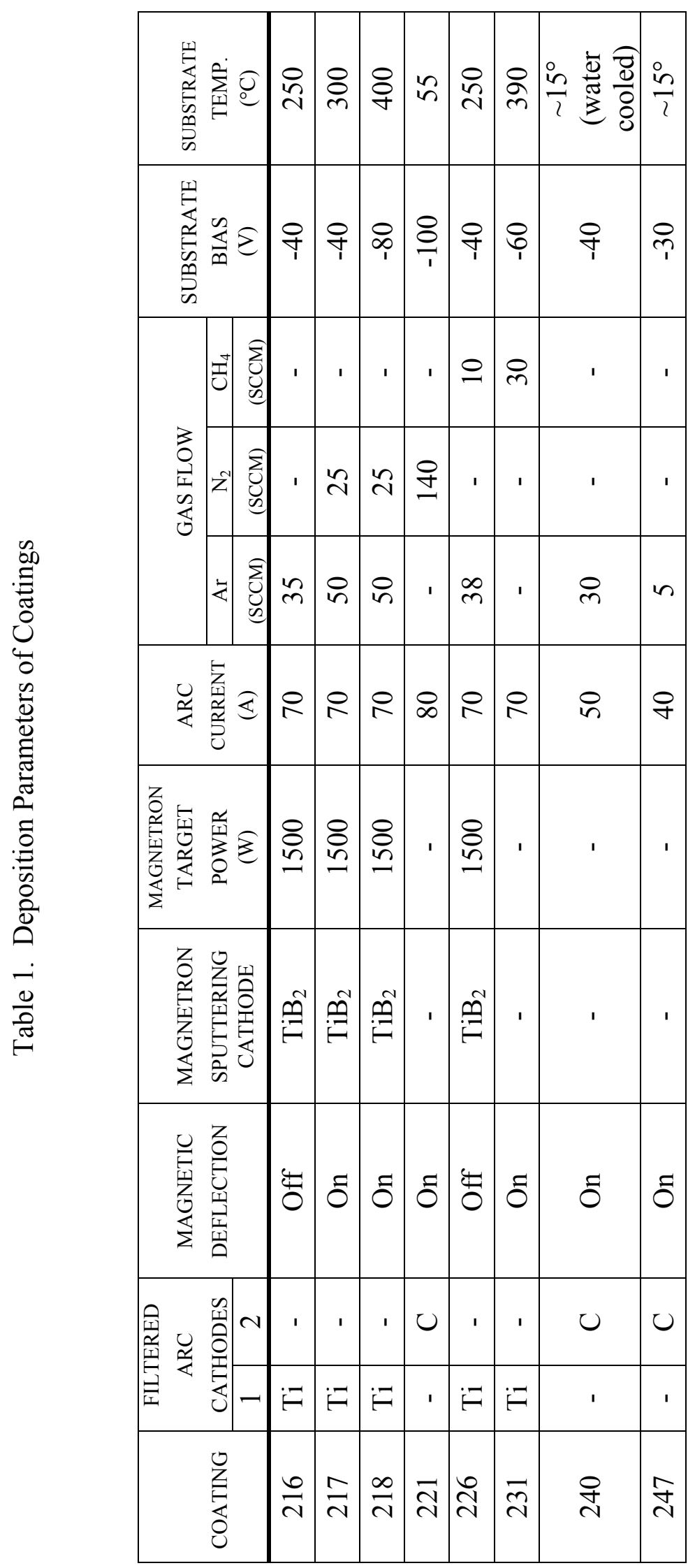




\section{Boron-Based Coatings $216\left(\mathrm{TiB}_{2}\right), 217\left(\mathrm{TiB}_{2}+\mathrm{N}\right)$ and $218\left(\mathrm{TiB}_{2}+\mathrm{N}\right)$}

The coating 216 was deposited by RF sputtering of $\mathrm{TiB}_{2}$ target in a plasma immersion mode. The plasma was created by using electrons from the Ti arc in an Ar pressure. The coating was 0.7 micron thick. Figure 3 shows the AES profile indicating a composition of the coating close to $\mathrm{TiB}_{2}$, as expected. The background carbon level was rather high, $\sim 10 \%$. We believe this has originated from the cracking of oil vapor back streaming from the oil diffusion pump. The x-ray diffraction pattern, Figure 4, shows strong (001) and (002) peaks of $\mathrm{TiB}_{2}$ indicating the presence of highly crystalline and textured hexagonal $\mathrm{TiB}_{2}$.

The coating 217 was deposited by flowing Ti arc plasma into the chamber in the presence of sputtered $\mathrm{TiB}_{2}$ in an $\mathrm{Ar}+\mathrm{N}_{2}$ atmosphere. The coating was about 3.27 micron thick. Figure 5 shows the AES profile of this coating. The composition is predominantly $\mathrm{TiB}_{2}$ with less than $5 \%$ $\mathrm{N}_{2}$ incorporated in it. The level of $\mathrm{C}$ is somewhat less, $(<10 \%)$, as compared to that in coating 216. It should be noted here that there is a strong overlap of the Ti LMM and N KLL Auger peaks. This creates difficulty in the quantitative analysis of the coatings. For samples containing just Ti and N, we have used a method based on published studies to quantify AES data [4]. For pure $\mathrm{Ti}$, the peak at $\sim 385 \mathrm{eV}$ has only a small positive portion. The $\mathrm{N}$ intensity in $\mathrm{TiN}$ then can be determined from the positive going part of the peak. Since, we do not have a $\mathrm{TiB}_{2}$ standard; we do not know what the Ti LMM spectrum for this compound looks like. Thus, it has been difficult to quantify the $\mathrm{N}$ level using AES. We have explored XPS to analyze $\mathrm{N}$ in these coatings. Figure 6 shows the x-ray diffraction spectrum of this coating. A solid solution of crystalline $\mathrm{TiB}_{2}$ with $\mathrm{N}$ was found to be present.

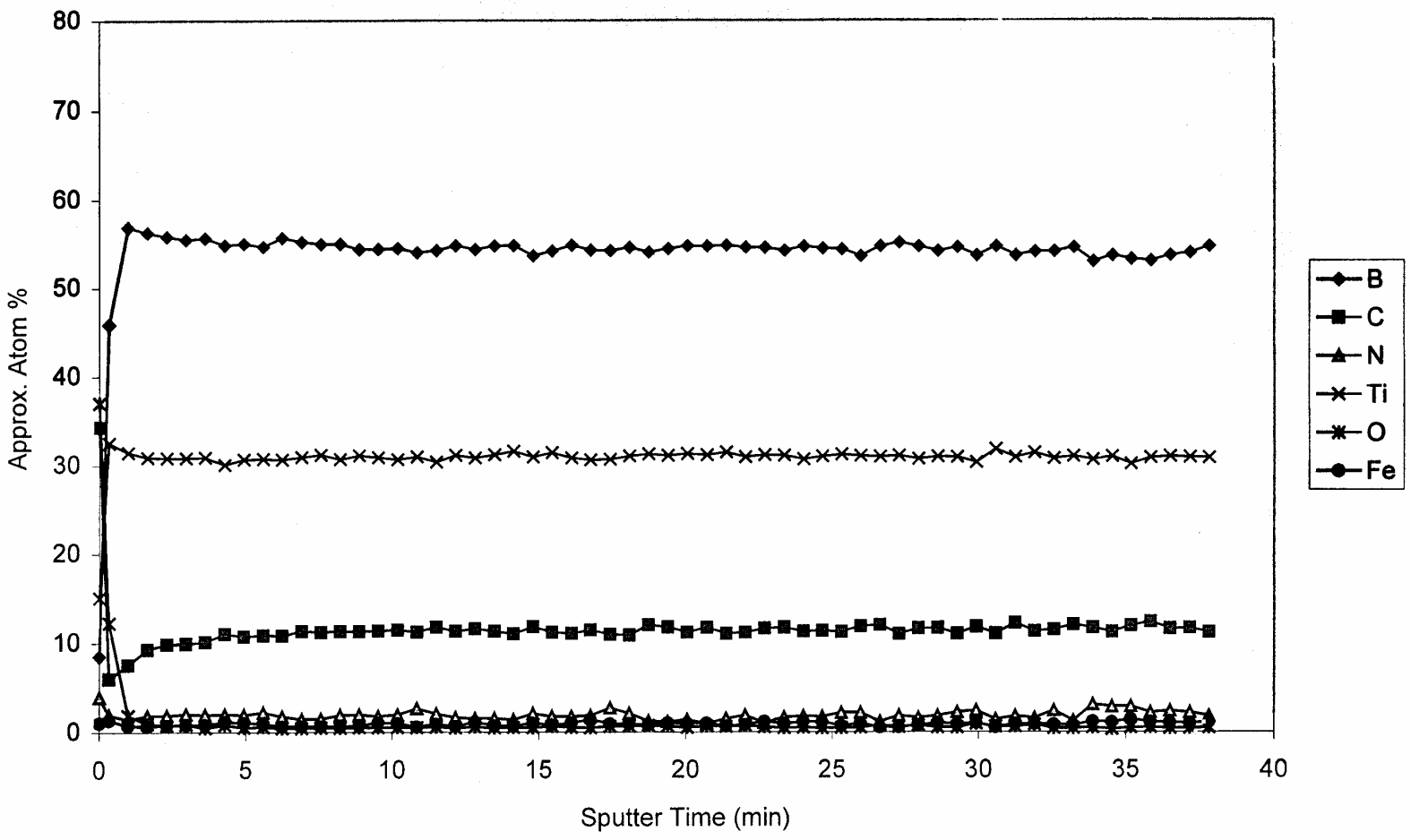

Figure 3. AES Profiles of Sample \#216. 


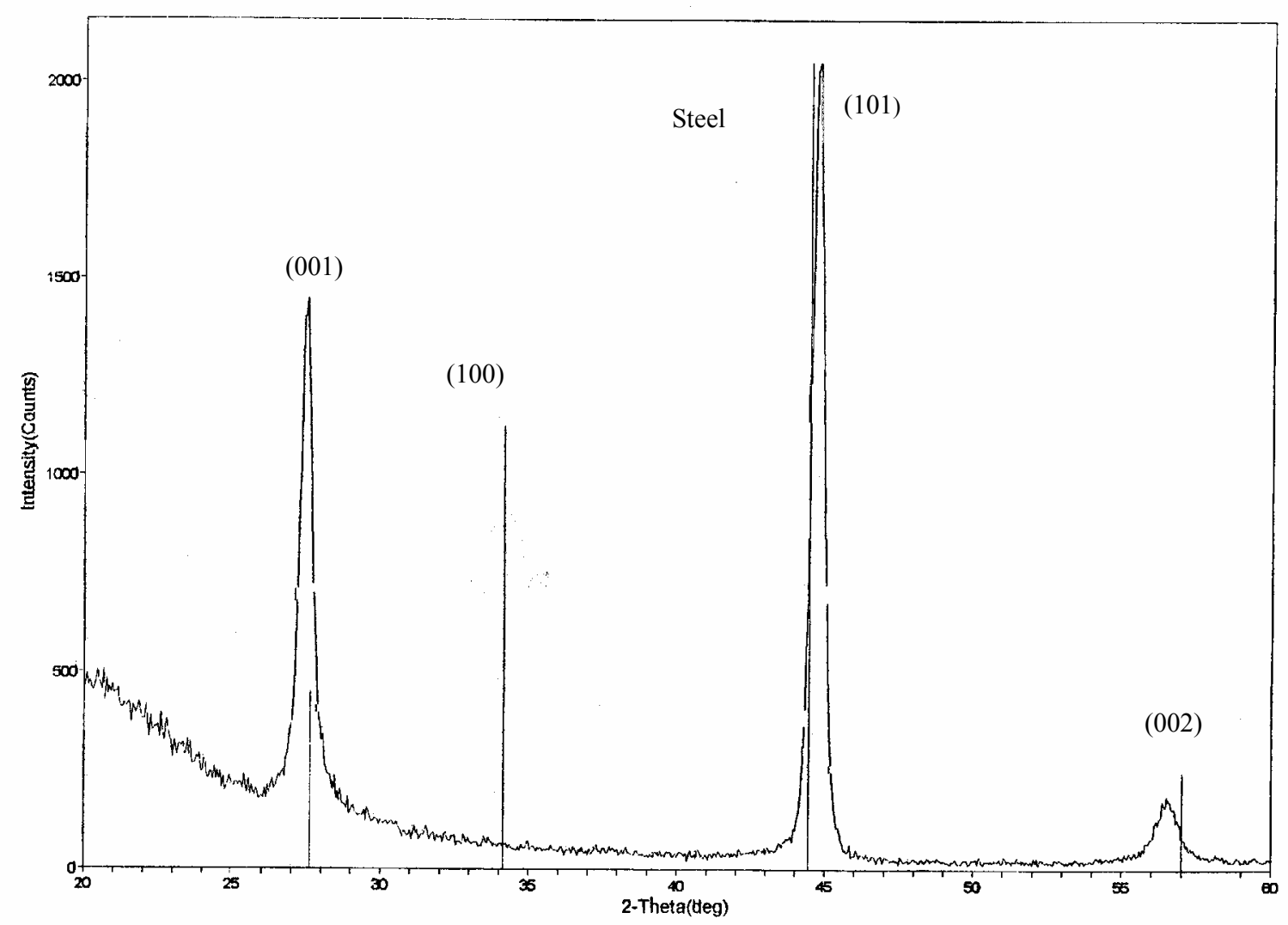

Figure 4. XRD Spectrum of Sample \#216.

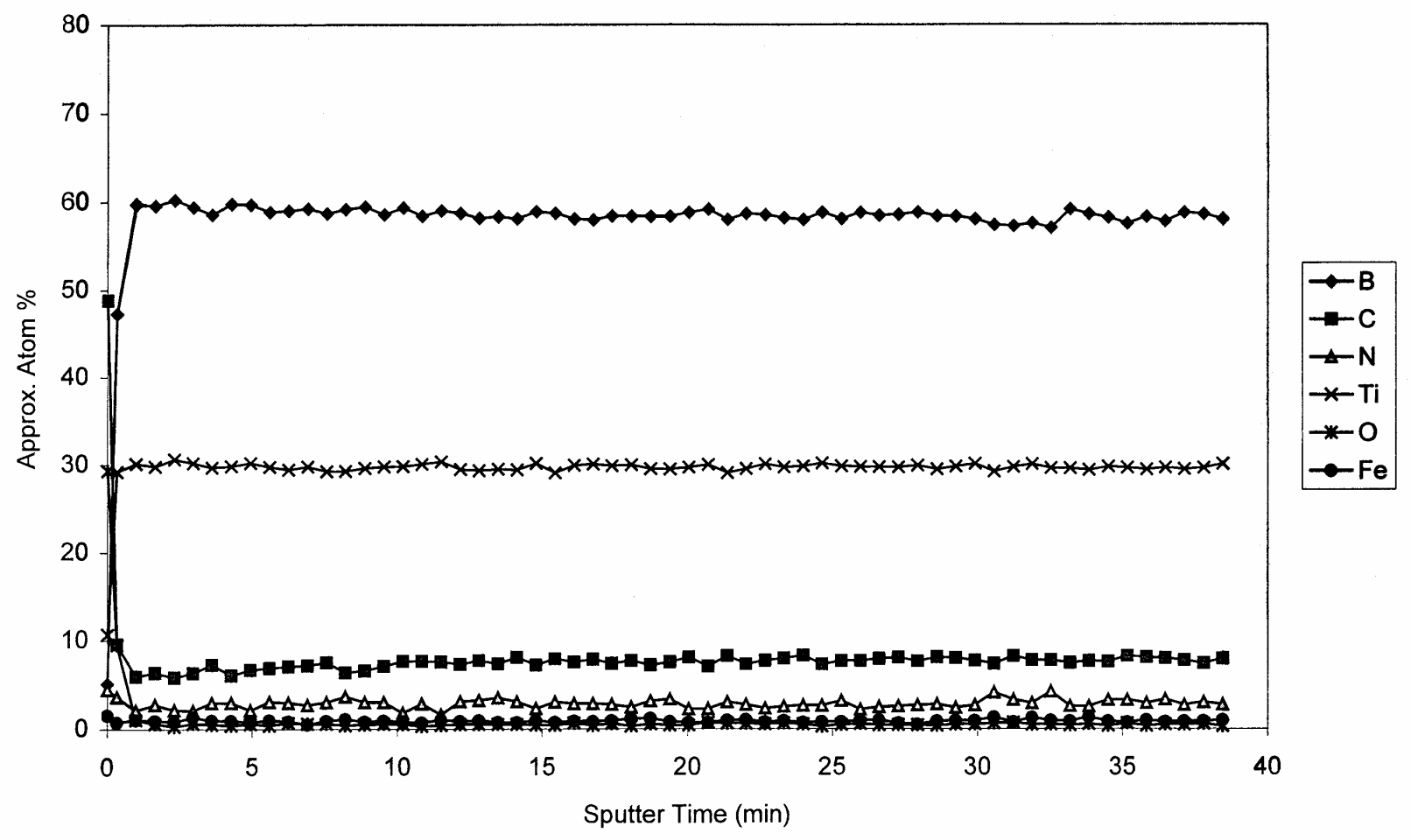

Figure 5. AES Profiles of Sample \#217. 


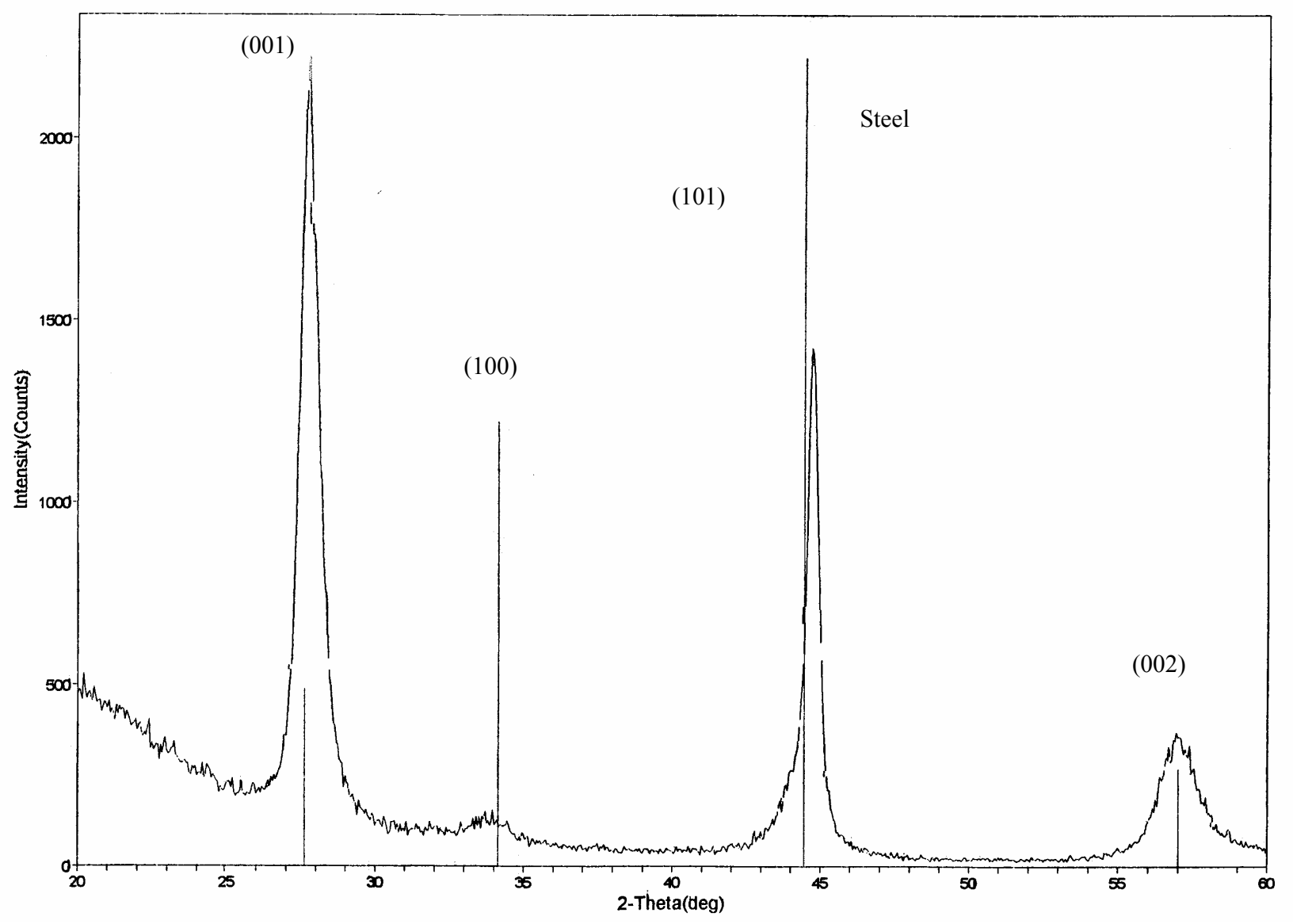

Figure 6. XRD Spectrum of Sample \# 217.

The coating 218 was deposited under similar conditions as 217 with the exception of higher substrate bias voltage, $-80 \mathrm{~V}$, as compared to $-40 \mathrm{~V}$ for 217 . The coating was about 1.3 micron thick. Not much difference is observed in the composition of this coating as compared to the previous one. However, the x-ray diffraction spectrum shows a predominantly amorphous microstructure (Figure 7). 


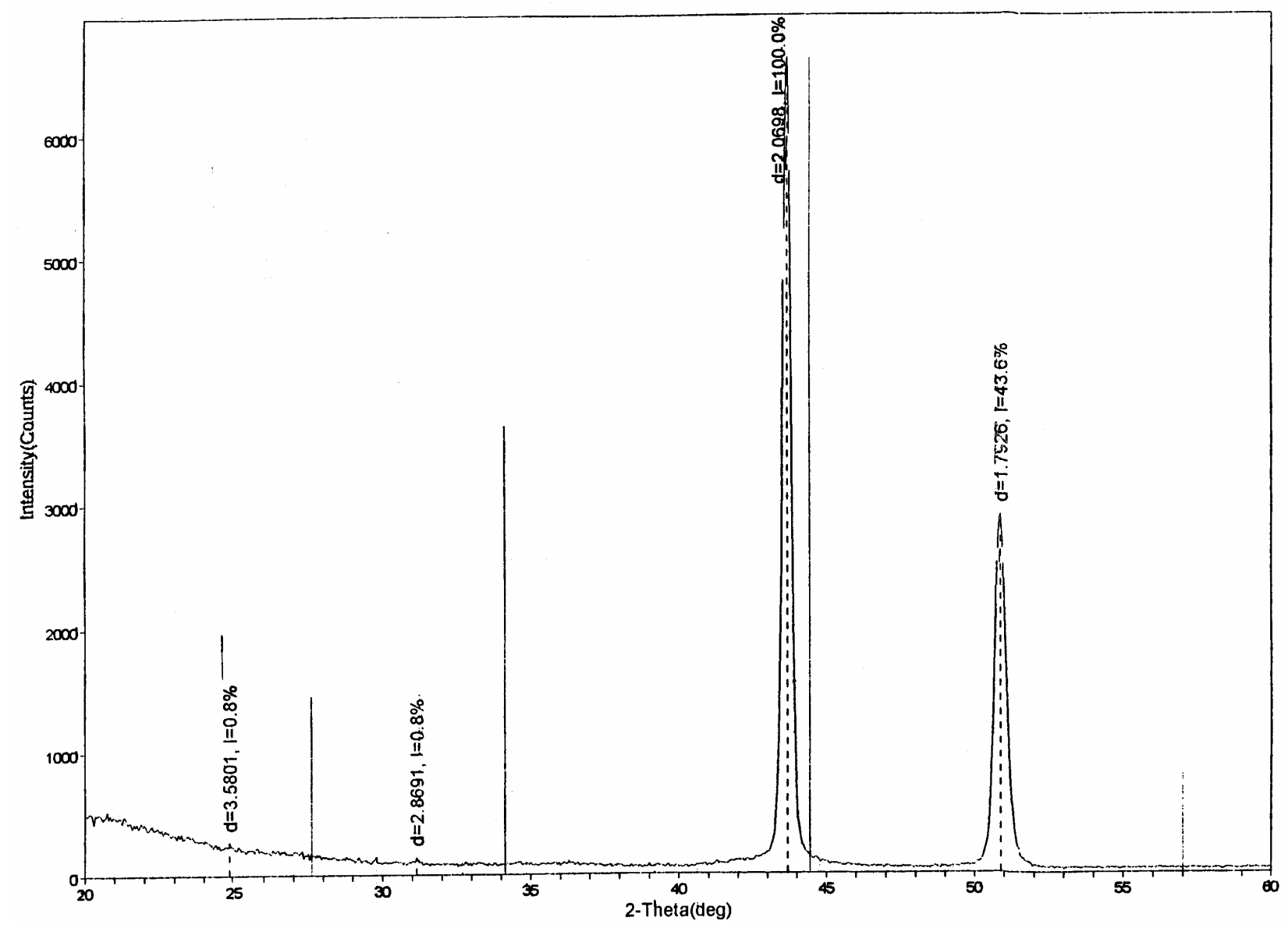

Figure 7. XRD Spectrum of Sample \#218.

\section{Carbon-Based Coatings $221\left(\mathrm{C}_{\mathrm{x}} \mathrm{N}_{\mathrm{y}}\right), 226\left(\mathrm{TiB}_{2}+\mathrm{C}\right), 231(\mathrm{TiC}+\mathrm{C}), 240$ (DLC) and 247 (DLC)}

The coating 221 was made by allowing $\mathrm{C}$ arc plasma in a $\mathrm{N}_{2}$ environment to be intersecting the substrate held at room temperature $\left(\sim 23^{\circ} \mathrm{C}\right)$. After a short run of $15 \mathrm{~min}$., the temperature of the substrate increased to $55^{\circ} \mathrm{C}$ and a coating of thickness 0.2 micron was deposited on both steel and Si substrates. Similar attempts without any gas or with Ar failed in depositing a $\mathrm{C}$ coating. The AES analysis of coating 221 is shown in Figure 8. It is clear that the coating is mostly $\mathrm{C}(\sim 85 \%)$ with some $\mathrm{N}(\sim 10 \%)$ in it. X-ray diffraction did not show any peaks thus indicating an amorphous microstructure.

Coating 226 was deposited by sputtering of $\mathrm{TiB}_{2}$ in a plasma immersion mode in the presence of $\mathrm{Ar}$ and $\mathrm{CH}_{4}$ gas mixture. Figure 9 shows the AES profiles of this coating. The composition of $\mathrm{B}$ and $\mathrm{C}$ appears to vary with thickness. About $25 \% \mathrm{C}$ has been incorporated in this coating. X-ray diffraction spectrum shows two peaks at $2 \theta=27^{\circ}$ and $55^{\circ}$. $\mathrm{TiB}_{2}(001)$ and (002) should be located at $27.5^{\circ}$ and $57^{\circ}$, respectively. Thus, if these can be identified as due to $\mathrm{TiB}_{2}$, then $\mathrm{C}$ in solution must be responsible for these shifts. 


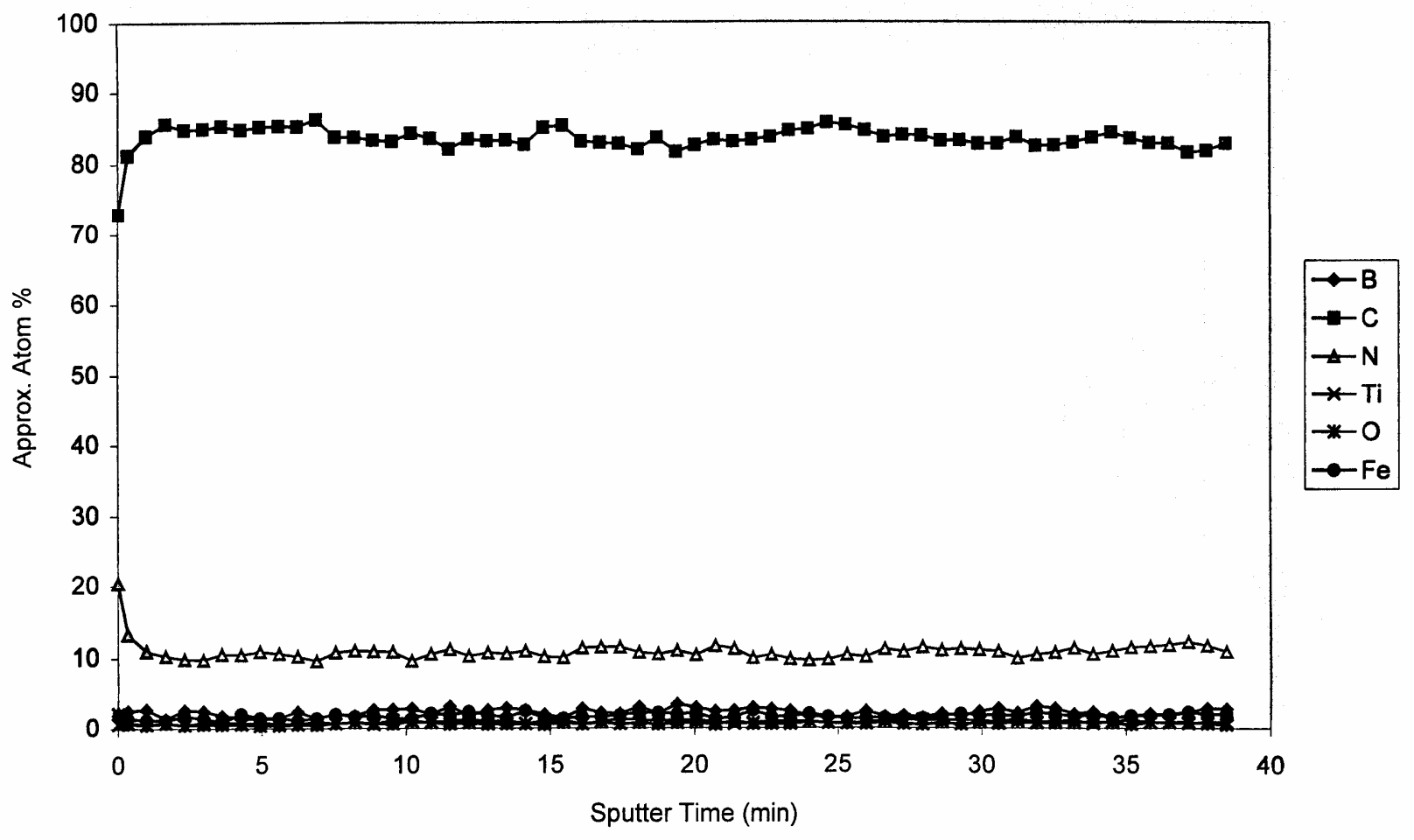

Figure 8. AES Profiles of Sample \#221.

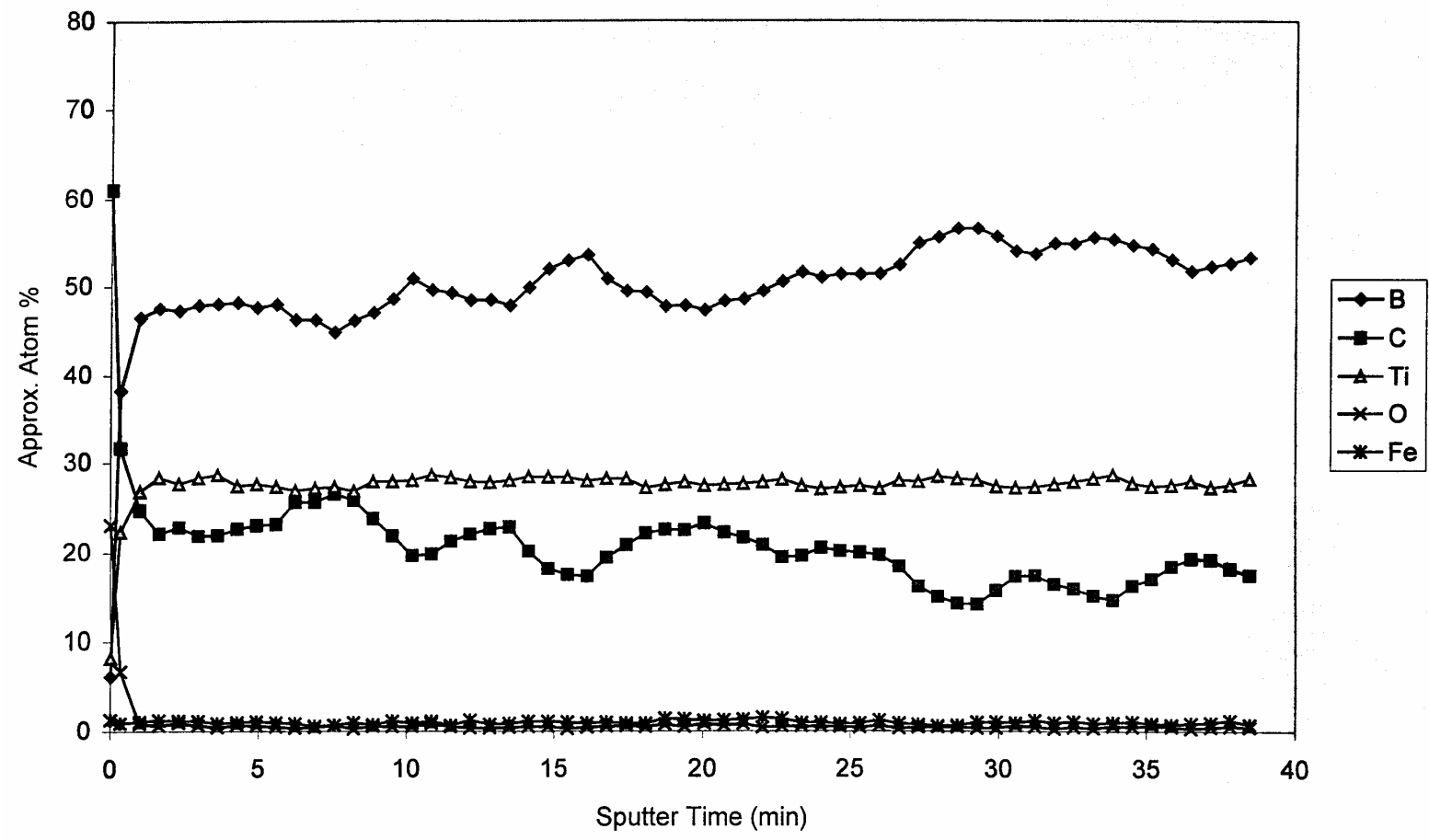

Figure 9. AES Profiles of Sample \#226. 
Coating 231 was deposited from filtered arc using Ti under $\mathrm{CH}_{4}$ gas. AES profiles show about 60\% C and 39\% Ti (Figure 10). X-ray diffraction spectrum shows TiC peaks (Figure 11). An unidentified peak around $59^{\circ}$ is also visible. Transmission electron microscopy of this coating on Si revealed a nanocrystalline microstructure. Figure 12(a) represents a typical selected area diffraction (SAD) pattern of the coating. Discontinuous distribution of intensity along the observed diffraction rings indicated the highly textured nature of the small crystallites present in the coating. The d-spacings of the observed diffraction rings matched very well with that of the known $\mathrm{d}$-values of $\mathrm{TiC}$ thus indicating the formation of $\mathrm{TiC}$ phase in the coating. The excess carbon as evidenced from the AES results must be in the form of amorphous microstructure since there is no extra spot or rings representing crystalline form of carbon. The size of the TiC crystallites as determined from the dark-field micrograph, Figure 12(b), is in the range $5-100 \mathrm{~nm}$.

Coatings 240 and 247 were deposited by using carbon cathodes in the filtered arc sources and water-cooled substrate.

\section{Raman Analysis of the Carbon Containing Samples}

The DLC coatings produced by Large Area Filtered Arc Deposition (LAFAD) process are inherently very hard due to their intrinsic compressive stresses. This partially lays a restriction on the thickness of the coating, limiting it to a micron or so. Also, since the carbon arc plasma is almost $100 \%$ in an ionized state, the resulting DLC film may have less graphitic content. Raman spectroscopy is very sensitive to the graphite content and hence the resulting film from the filtered arc deposition process could have less intense Raman signatures [5]. Indeed this has been observed in the overall Raman spectra shown in Figure 13, where in the films showing DLC character (samples 240 and 247) have intensities below 2000 counts viz. those with higher graphitic content (samples 221 and 231). The spectra recorded span almost the complete range from $200 \mathrm{~cm}^{-1}$ to $1900 \mathrm{~cm}^{-1}$.

Samples 240 and 247 were deposited on silicon substrates using pure graphite target as the source material and substrates were held at cold finger. This enabled the energetic carbon ions to condense in the form of a diamond like network. These samples show a broad hump at $620 \mathrm{~cm}^{-1}$ with an intensity of about 460 counts, which is characteristic of a fully ionized hydrogen-free DLC film [6]. Both the films show a broad ' $G$ ' band centered around $1550 \mathrm{~cm}^{-1}$ and a deconvoluted ' $\mathrm{D}$ ' band around $1380 \mathrm{~cm}^{-1}$ which are characteristic features of DLC films [7]. The intensity ratios of the ' $D$ ' to ' $G$ ' bands for both 240 and 247 samples are 0.52 and 0.51 respectively, indicating good $\mathrm{sp}^{3}$ coordination in the coatings.

The film 221 is a carbon coating deposited by FA process in nitrogen environment relatively at higher temperatures of about $150^{\circ} \mathrm{C}$ to $200^{\circ} \mathrm{C}$. The nitrogen incorporation has resulted into a broad and intense peak with a shift of ' $G$ ' band to lower wavenumber of $1520 \mathrm{~cm}^{-1}$ from $1550 \mathrm{~cm}^{-1}$ and the ' $\mathrm{D}$ ' band still remaining at $1380 \mathrm{~cm}^{-1}$. The relative intensity of ' $\mathrm{D}$ ' to ' $\mathrm{G}$ ' peaks within the envelope is about 0.85 which indicates good DLC character. The FWHM is about 370 wavenumbers indicating a high degree of amorphization in the film. However, the hardness is about $<30 \mathrm{GPa}$, indicating that the film is nitrogen deficient. 


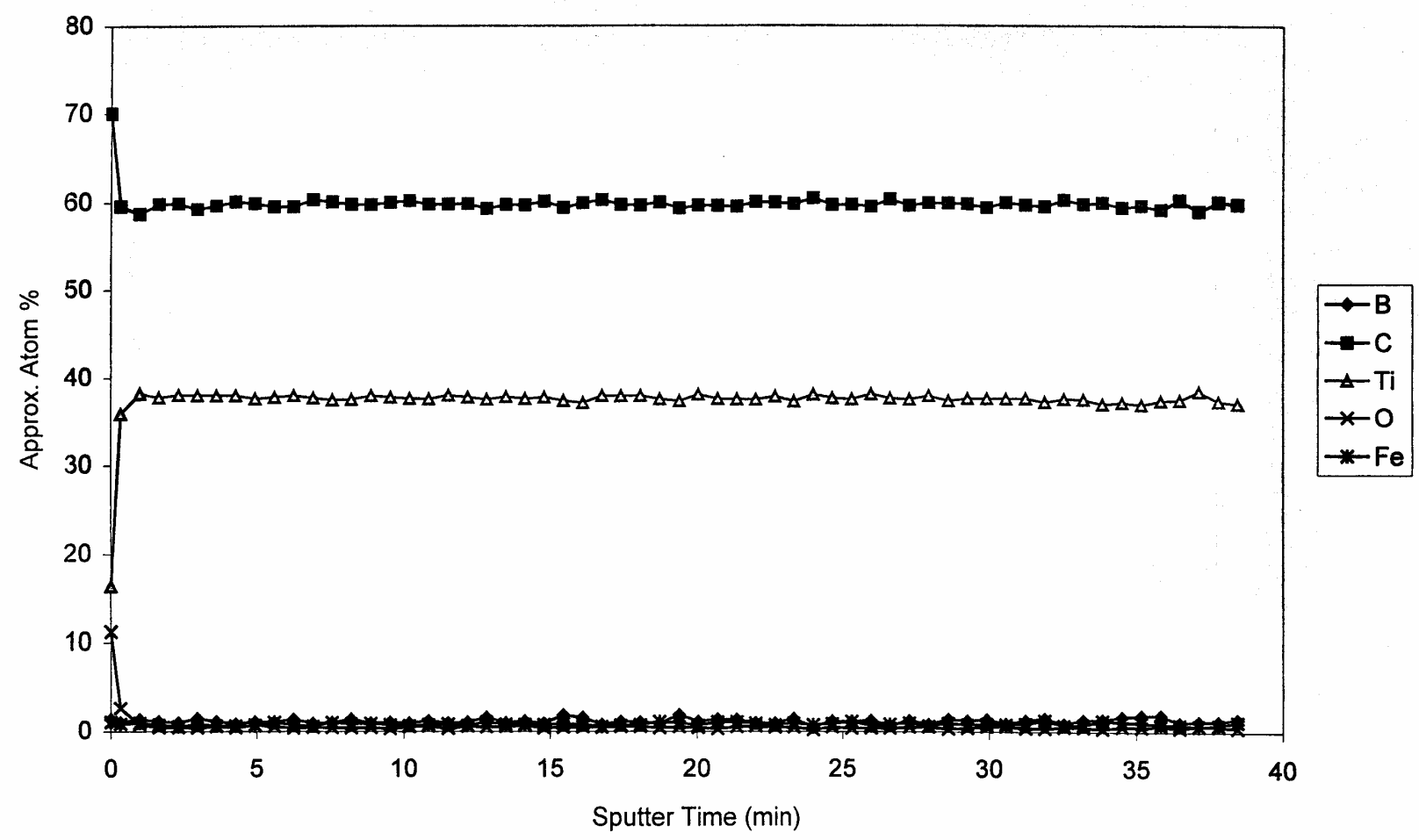

Figure 10. AES Profiles of Sample \#231.

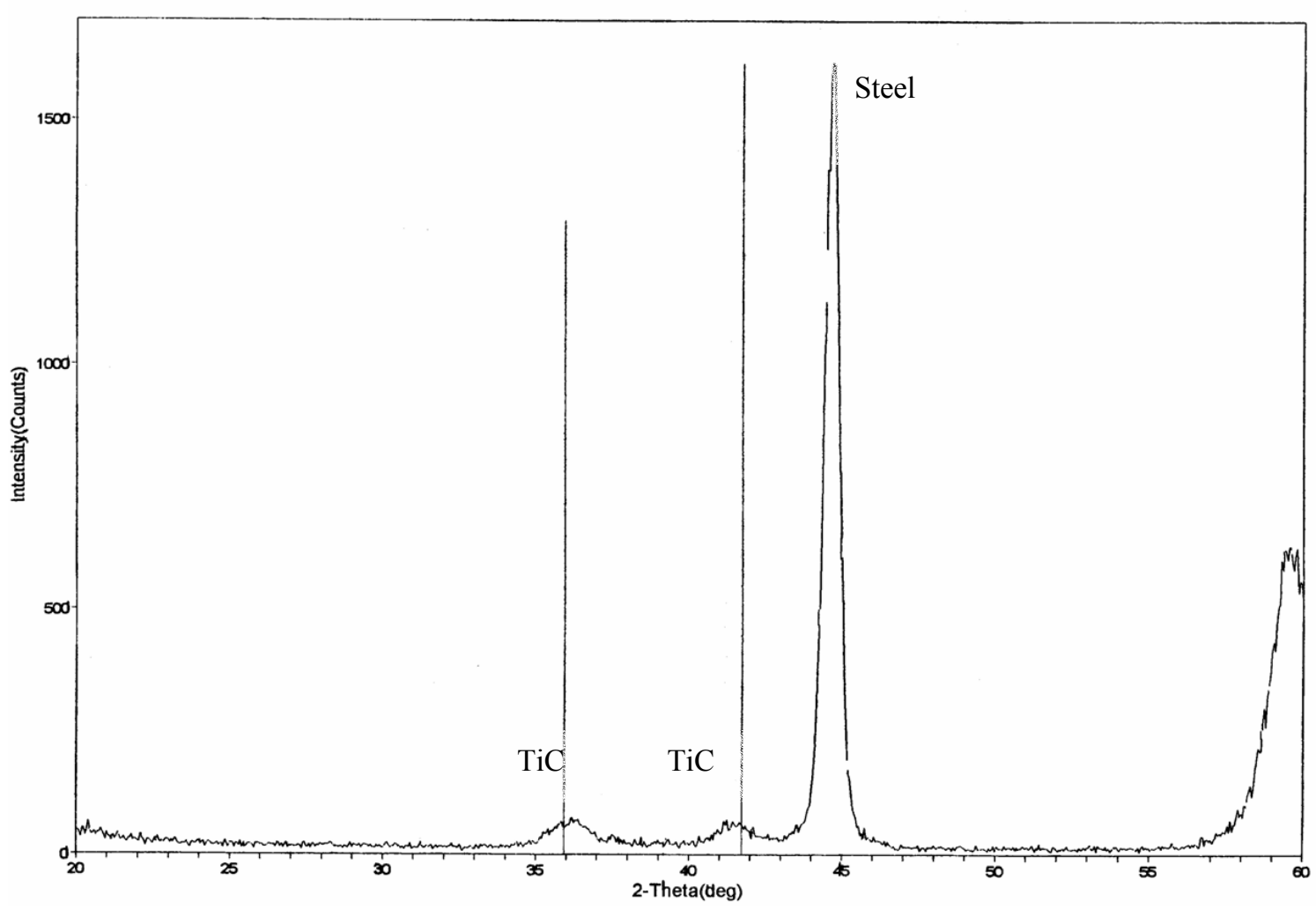

Figure 11. XRD Spectrum of Sample \#231. 


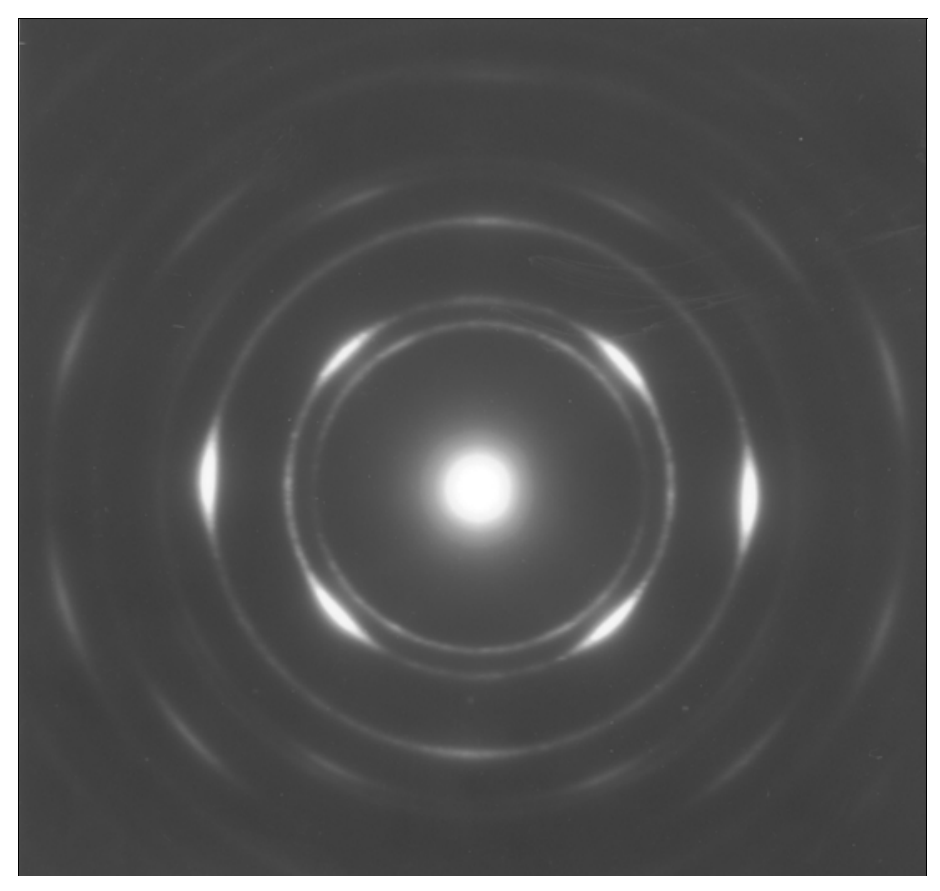

(a)

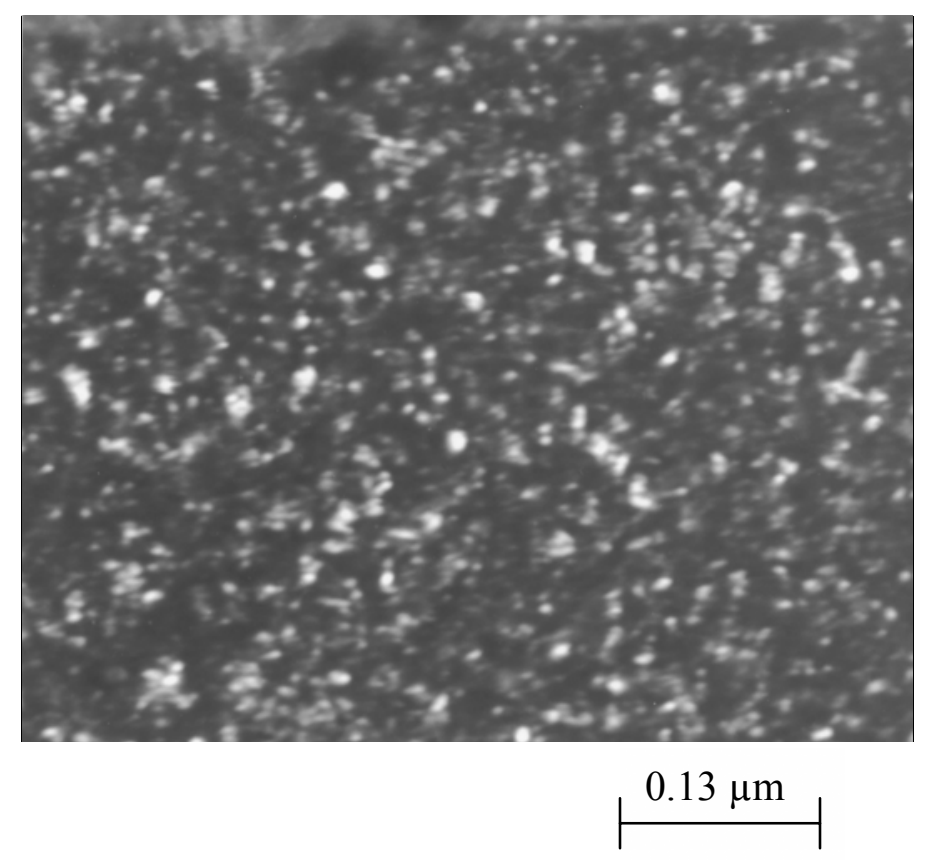

(b)

Figure 12. Transmission Electron Micrographs of Sample \#231: (a) Electron Diffraction (b) Dark-Field. 


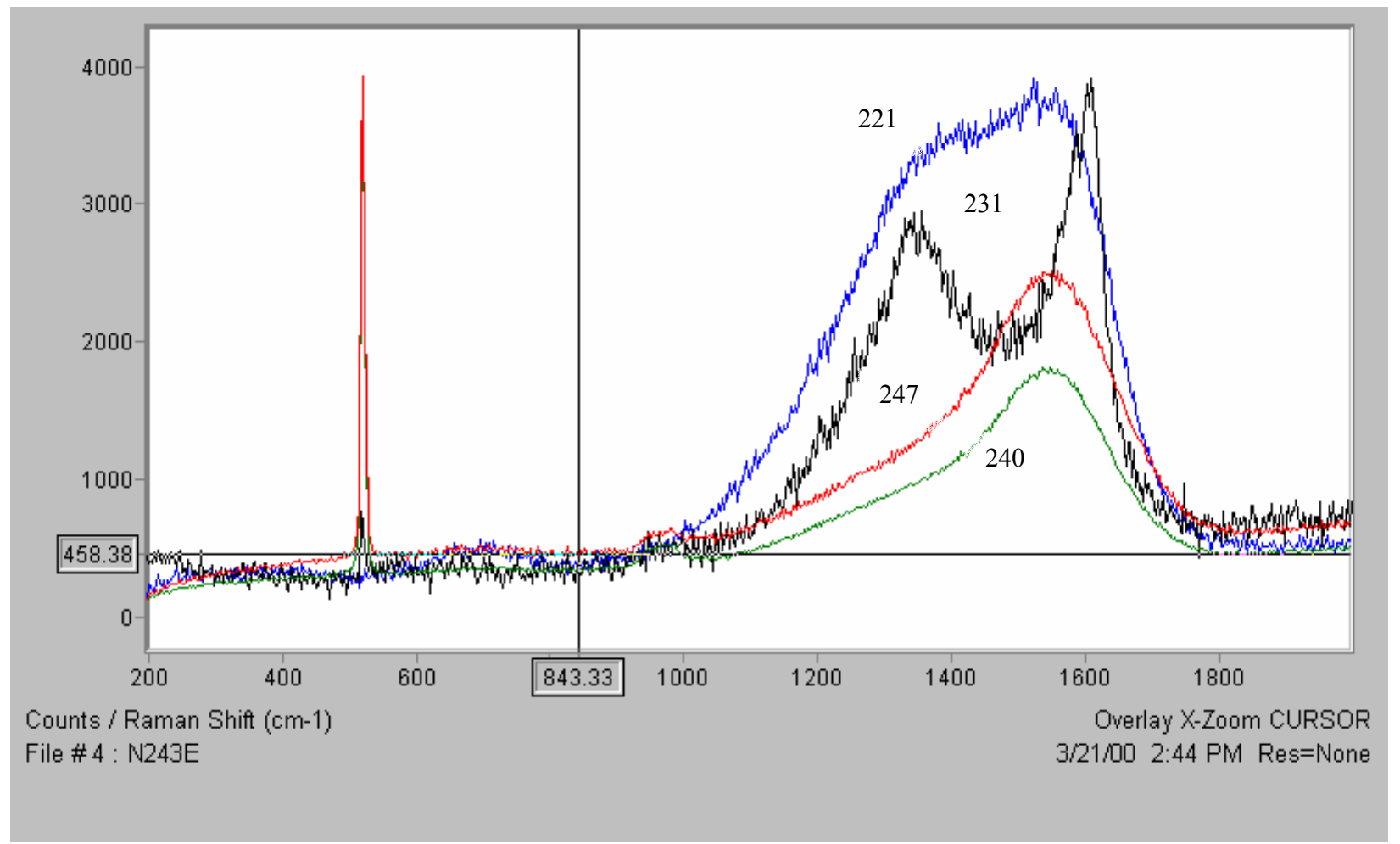

Figure 13. Raman Spectra of Samples \#221, \#231, \#240 and \#247.

The film 231 has interesting Raman characteristics. Unlike the other above mentioned three films, this has well defined two peaks located at $1340 \mathrm{~cm}^{-1}$ and $1600 \mathrm{~cm}^{-1}$. The $1340 \mathrm{~cm}^{-1}$ peak could be assigned to DLC signatures and the $1600 \mathrm{~cm}^{-1}$ peak predominantly depicts graphitic nature. It should be noted here that the carbon incorporation in the film is done through gas phase route by depositing titanium using FA source in $\mathrm{CH}_{4}$ environment. Thus there is a formation of $\mathrm{TiC}$ along with segregated graphitic inclusions. This film has shown very high hardness, greater than $30 \mathrm{GPa}$ and hence, can be termed as hard-soft coating.

\section{Surface Morphology}

Highly smooth surface morphology $(\mathrm{Ra}=0.01 \mu \mathrm{m})$ without any particulates have been observed in all Ti and B-based coatings produced by filtered arc in combination with sputtering. The morphology of carbon containing coatings is shown in Figure 14. The $\mathrm{C}_{\mathrm{x}} \mathrm{N}_{\mathrm{y}}$ coating was very smooth without any pinholes and particulates. The TiC/C composite coating showed a few defects, mostly in the form of pinholes. The DLC coatings, 240 and 247, showed varied concentration of pinholes in different areas of the coatings, probably resulting from high levels of stress. 


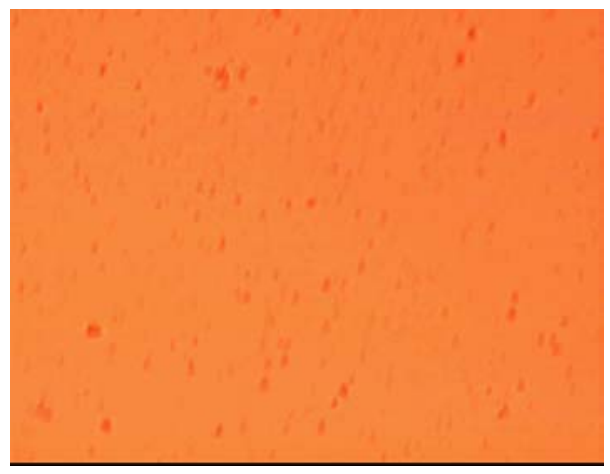

Sample 221

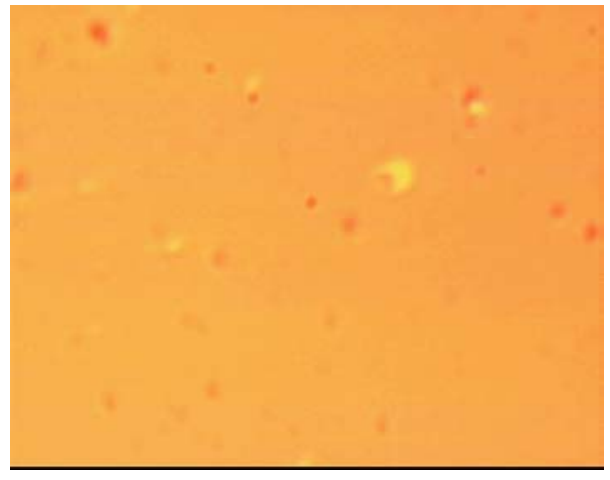

Sample 231

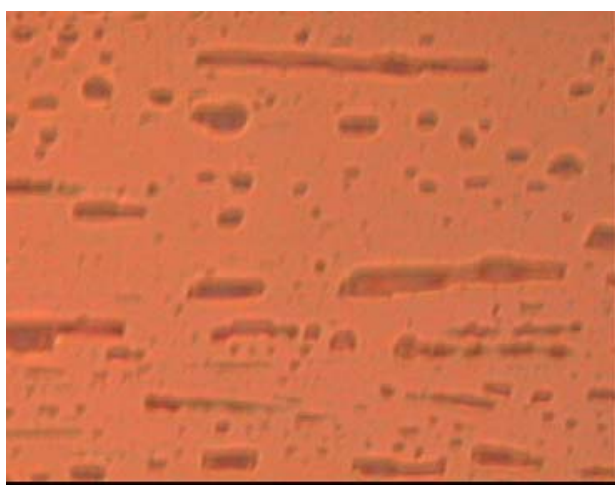

Sample 240

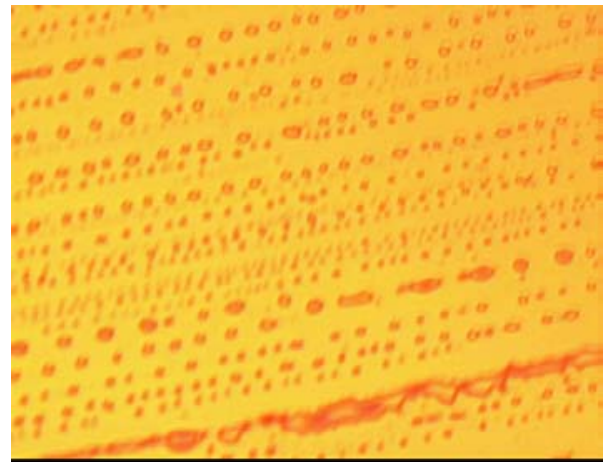

Sample 247

Figure 14. Optical Micrographs of Samples \#221, \#231, \#240 and \#247.

\section{Hardness Measurements}

Hardness and Young's modulus of the as-deposited coatings were measured by using a Nano Indenter at the Microphotonics Inc., Irvine, CA. The indenter used in this work is a Berkovitch diamond tip whose area function was calibrated with a standard quartz sample. In the nano-indentation study, the following indentation parameters were used (Table 2).

Table 2. Indentation Parameters

\begin{tabular}{|l|c|c|}
\hline & Setting 1 & Setting 2 \\
\hline Maximum force $(\mathrm{mN})$ & 1.5 & 5.0 \\
\hline Maximum depth $(\mathrm{nm})$ & Not used & Not used \\
\hline Loading rate $(\mathrm{mN} / \mathrm{min})$ & 3 & 10 \\
\hline Unloading rate $(\mathrm{mN} / \mathrm{min})$ & 3 & 10 \\
\hline Pause(s) & 0 & 0 \\
\hline Indenter type & $\begin{array}{c}\text { Berkovich } \\
\text { Diamond No 21 }\end{array}$ & $\begin{array}{c}\text { Berkovich } \\
\text { Diamond No 21 }\end{array}$ \\
\hline
\end{tabular}


Two distinct loads were used in these measurements: $1.5 \mathrm{mN}$ and $5 \mathrm{mN}$. Five indents were made for each sample. Figures 15 and 16 illustrate typical load-displacement behavior for films 216 and 217. Figures 15 and 16 indicate that $\mathrm{TiB}_{2}$ and $\mathrm{N}$ containing $\mathrm{TiB}_{2}$ coatings are almost fully elastic in their nano-indentation responses. Even when the penetration depth reached $80 \mathrm{~nm}$ the deformation of both coatings was still almost completely recovered. The measured values of hardness and Young's modulus for each sample as well as the depth of penetration $(\Delta \mathrm{d})$ are tabulated below together with their averages and standard deviations. The summary of the results is presented in Table 3. It is clear that the hardness of $\mathrm{TiB}_{2}$ coating is on the order of $50 \mathrm{GPa}$ and the Young's Modulus is over $400 \mathrm{GPa}$. Introduction of nitrogen in the film resulted in the reduction of hardness and modulus. TiC with excess $\mathrm{C}$ (231) also showed a very high hardness and modulus. $\mathrm{C}_{\mathrm{x}} \mathrm{N}_{\mathrm{y}}$ coating showed a lower hardness, $18 \mathrm{GPa}$, while DLC coating showed a very high hardness, $65 \mathrm{GPa}$.

Table 3. Hardness And Young's Modulus

\begin{tabular}{|c|c|c|c|c|c|c|}
\hline \multicolumn{7}{|c|}{ LOAD 5 MN } \\
\hline Sample & $\begin{array}{c}\text { Coating } \\
\text { Type } \\
\text { Chickness } \\
{[\mu \mathrm{m}]}\end{array}$ & $\begin{array}{c}\text { Coating } \\
{[\text { Vickers }]}\end{array}$ & $\begin{array}{c}\mathrm{H} \\
{[\mathrm{MPa}]}\end{array}$ & $\begin{array}{c}\mathrm{E} \\
{[\mathrm{GPa}]}\end{array}$ & $\begin{array}{c}\Delta \mathrm{d} \\
{[\mathrm{nm}]}\end{array}$ \\
\hline 216 & $\mathrm{TiB}_{2}$ & 0.7 & 4625 & 49912 & 406 & 78.75 \\
\hline 217 & $\mathrm{TiB}_{2}+\mathrm{N}$ & 3.27 & 4392 & 47391 & 416 & 78.43 \\
\hline 218 & $\mathrm{TiB}_{2}+\mathrm{N}$ & 1.3 & 3729 & 40238 & 270 & 92.45 \\
\hline 226 & $\mathrm{TiB}_{2}+\mathrm{C}$ & 0.99 & 3189 & 34409 & 299 & 90.97 \\
\hline 231 & $\mathrm{TiC}^{\mathrm{C}} \mathrm{C}$ & 1.00 & 4270 & 46079 & 417 & 78.16 \\
\hline 247 & $\mathrm{DLC}^{2}$ & 0.7 & 6068 & 65484 & 509 & 69.96 \\
\hline \multicolumn{7}{|c|}{ LOAD 1.5 MN } \\
\hline Sample & $\begin{array}{c}\text { Coating } \\
\text { Type }\end{array}$ & $\begin{array}{c}\text { Coating } \\
\text { Thickness } \\
{[\mu \mathrm{m}]}\end{array}$ & $\begin{array}{c}\mathrm{Hv} \\
{[\mathrm{Vickers}]}\end{array}$ & $\begin{array}{c}\mathrm{H} \\
{[\mathrm{MPa}]}\end{array}$ & $\begin{array}{c}\mathrm{E} \\
{[\mathrm{GPa}]}\end{array}$ & $\begin{array}{c}\Delta \mathrm{d} \\
{[\mathrm{nm}]}\end{array}$ \\
\hline 221 & $\mathrm{C}_{\mathrm{x}} \mathrm{N}_{\mathrm{y}}$ & 0.2 & 1749 & 18878 & 142 & 62.58 \\
\hline
\end{tabular}



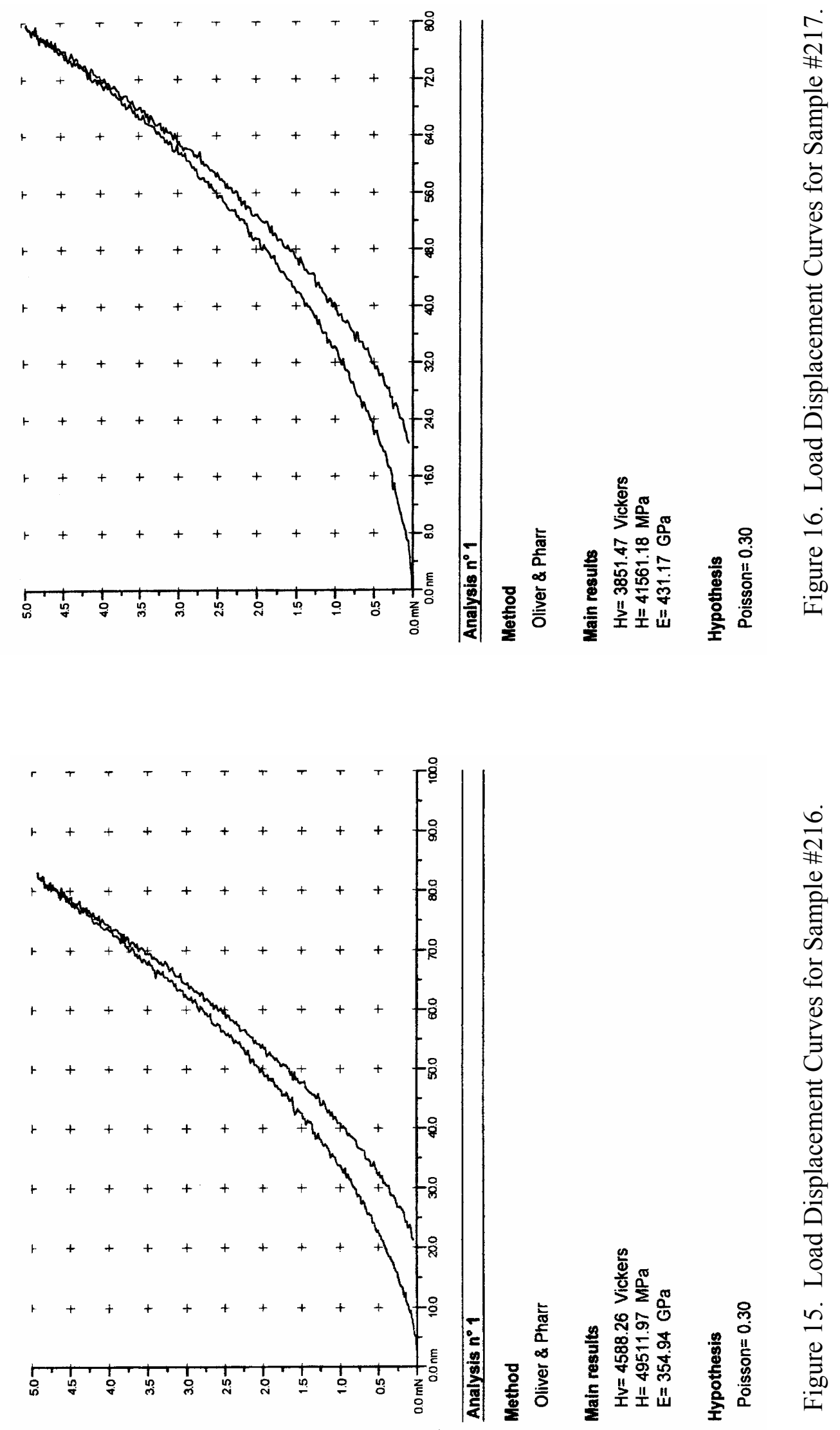


\section{Wear Resistance}

The relative wear resistance of various coatings was measured by using Calotest equipment. A steel ball, $20 \mathrm{~mm}$ diameter, was rotated against the coating at a fixed speed for a predetermined length of time. The diameter of the crater produced on the coating after each test was measured under a calibrated optical microscope. This diameter is a direct measure of the wear of the coating. Figure 17 shows the plots of diameter as a function of time for various coatings. Measurement on a filtered arc TiN coating is also included in this plot. The hardness of filtered arc TiN was $\sim 30 \mathrm{GPa}$. It is clear that the harder coatings developed in this project are more wear resistant than the TiN coating. Hard DLC coatings did not show a measurable wear against this steel ball under these conditions of the wear test.

Wear Resistance Test Results

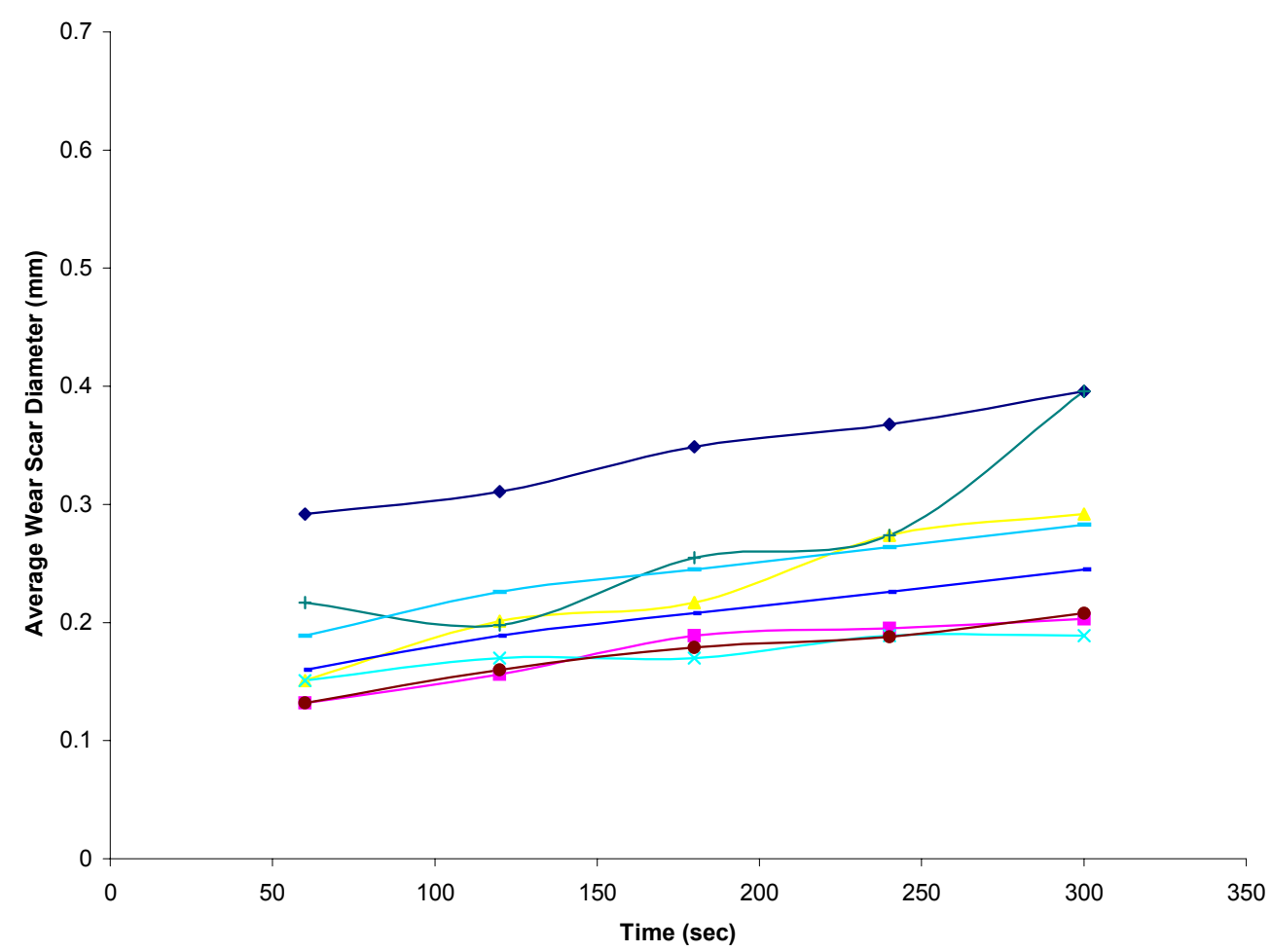

$\rightarrow-\mathrm{H}-13$ steel Baseline

$\rightarrow-$ Run \#216

TiN Run \#67

$x$ Run \#218

$\rightarrow$ Run \#217

- Run \#226

- Run \#221

- Run \#231

Figure 17. Wear Test Results: Crater Diameter as a Function of Time for Various Coatings.

\subsection{RESEARCH CARRIED OUT IN PHASE II}

\subsection{TECHNICAL OBJECTIVES}

The objectives of the proposed program were to:

1. Establish optimum deposition parameters for $\mathrm{TiC} / \mathrm{C}, \mathrm{TiB}_{2}, \mathrm{TiBN}$, and $\mathrm{DLC}$ coatings on tool and die steel, and carbide substrates. 
2. Test the coatings for their performance in selected high performance machining applications, each application selected to represent a different dominant wear mode and coating property. The following machining test situations have been identified based on their technological and commercial potential (applications shown in brackets):

- $\quad$ High speed face milling of hardened tool steels (dies for die casting and forging)

- $\quad$ High speed face milling of hypereutectic Al-Si alloys (die casting transmission housing, lost foam cylinder blocks)

- $\quad$ Milling of Ti-6Al-4V (aeroengine blades, aircraft structures)

3. Identify best coating candidates for each machining application and evaluate their performance by varying the following:

- $\quad$ The coating parameters to obtain coatings with different hardnesses, elastic modulus, intrinsic stresses, substrate adhesion, diffusion barrier, thickness, morphology etc.

- The machining parameters such as cutting speeds, feeds, depths of cut, length of cut, lubrication conditions, cutting tool types (inserts, drills, milling cutters etc.).

4. Establish the best coatings candidates and the machining parameter ranges for each machining situation (configuration). Carry out replications on the chosen cases so that viable confidence intervals can be established.

\subsection{RESULTS OF PHASE II RESEARCH AND DEVELOPMENT}

\subsubsection{Selection of Coating Materials and Coating Design}

We have shown in Phase I that $\mathrm{TiB}_{2}, \mathrm{TiBN}, \mathrm{TiC}+\mathrm{C}$ and DLC coatings have high hardness exceeding $30 \mathrm{GPa}$. Thus, in Phase II, we have selected these coatings for further optimization. It is known that, TiCN coating with about 20 at $\% \mathrm{C}$ performs well in severe cutting operations and against molten $\mathrm{Al}$ in case of die casting application. Thus, we have included TiCN also for further improvement in corrosion resistance. Besides these, we have judiciously introduced the rare earth oxides in multilayer configuration with the hard nitride and carbide layers to produce some niche coatings. These coatings called as ' $T$ itanCoat ${ }^{\mathrm{TM}}$ ', enable countering the problems related to both thermal fatigue as well as soldering in aluminum die casting, and machining of titanium.

\section{Coating Design}

Once the coating materials are selected from the consideration of requirements of metal cutting the design of a coating system is of primary importance because severe constraints are placed on the coating/substrate interface. The thermal expansion mismatch between the substrate and the coating and stress discontinuity at the interface will cause delamination of the coating. Thus, the coating adhesion must be very high to counteract these problems. The adhesion can be improved by forming a graded interfacial zone by ion bombardment and then depositing a metal rich layer that gradually transitions to a ceramic composition. This should result in low interface energy and thus promotes high adhesion. Adhesion strength for Ti/TiCN 
coatings, as determined by scratch tests, up to $60 \mathrm{~N}$ was measured. This value represents the critical load required for complete delamination of the coating. For CVD TiN coating on carbide tools, typical values for excellent adhesion are in the range of 70-90 $\mathrm{N}$ [8,9]. It should be noted that the CVD process operates at much higher temperatures $\left(\sim 1000^{\circ} \mathrm{C}\right)$ and, therefore, a diffusion interface is easily created between the coating and the substrate. Such an interface leads to high adhesion of the coating. In PVD processes, which operate below $500^{\circ} \mathrm{C}$, the adhesion depends more on surface cleanliness and mechanical anchoring of the coating. Therefore, a critical load value of up to $60 \mathrm{~N}$ for a PVD coating is remarkable.

Not only does the coating adhesion have to be high but also the mechanical strength and ductility of the coating itself should be as high as possible. Cracks generated in the coating under thermal cycling will initiate attack by the molten aluminum. A multilayer design of coating with thin metal-rich layers separating the ceramic layers can provide increased toughness. The individual thickness of the layers in a multilayer coating is a critical parameter. It has been shown in the case of a TiCN/TiN multilayer coating [9], and for a TiC/bonding layer $/ \mathrm{Al}_{2} \mathrm{O}_{3}$ coating [10] deposited by CVD on cemented carbide cutting tools, that transition interfaces are effective in promoting fine-grained, non-columnar microstructure and improved fracture toughness in the coating under thermo-mechanical loading conditions typically encountered in metal-cutting. Recently, similar approaches have also been investigated for PVD hard coatings on cutting tools, resulting in the deposition of non-columnar coatings with improved hardness and resistance to microcracking [11].

Based on the results in Phase I, we proposed to deposit multilayers of Ti/TiCN, Ti/TiB 2 $\mathrm{Ti} / \mathrm{TiCN} / \mathrm{TiBN}, \mathrm{Ti} / \mathrm{TiCN} / \mathrm{TiAlN}$ and $\mathrm{Ti} / \mathrm{TiBN} / \mathrm{TiAlN}$ and special coatings called as 'TitanCoat ${ }^{\mathrm{TM}}$ ' in Phase II.

\subsubsection{Tool Wear and Tool Life}

Since the objective of the proposed testing program is to evaluate the wear and failure behavior of cutting tools it is important to clarify what constitute tool failure and tool life. Cutting tools have three possible modes of tool failure in machining: (a) fracture of cutting edges due to stress overload, (b) plastic deformation of the cutting edges due to thermal overload, and (c) gradual wear of cutting tool edges eventually leading to loss of cutting efficiency and tool breakage. A schematic of the wear modes is included in Figure 18.

Gradual or progressive wear occurs at two principal locations of the cutting tool: the top rake face (crater wear) and the flank (notch wear and nose radius wear). Crater wear occurs due to gradual eroding of the rake face of the cutting tool due to frictional heating developed as the cutting chip flows over the rake surface. At high cutting speeds, the temperature at the chip tool interface is of the order of $1000^{\circ} \mathrm{C}\left(1832^{\circ} \mathrm{F}\right)$. Crater wear occurs due to high temperature solid state diffusion. In cemented carbide cutting tools the tool life is determined by the critical amount of crater wear. Maximum depth of the crater is often the limiting criteria, with the depth being measured either optically or by contact methods. 


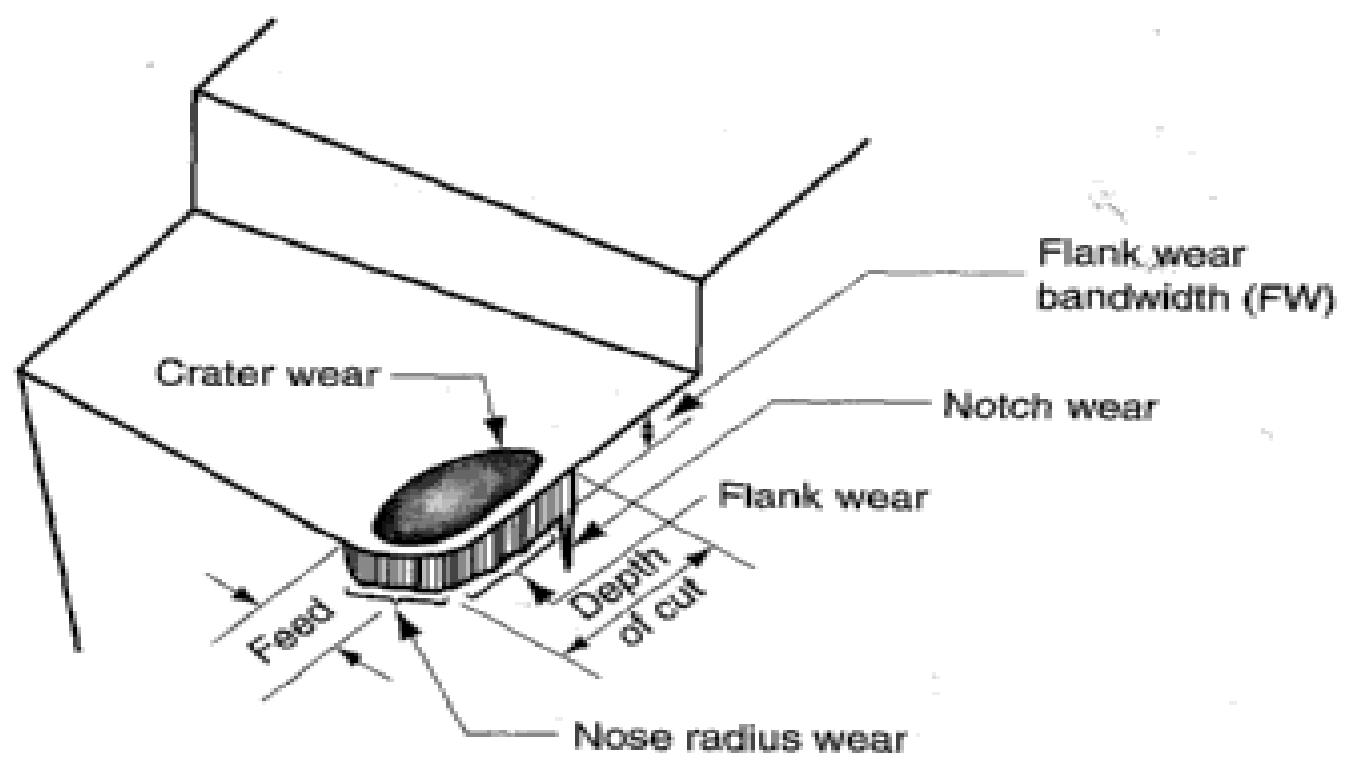

Figure 18. A schematic of the gradual wear modes in cutting tools (shown for a single point turning tool).

The wear of the flank surface is non-uniform with several peaks. It often contains a wear notch or groove formed as a result of contact between the cutting tool and the work hardened layer of the work material formed during preceding operation.

The wear of the flank land is often denoted as VB and the criteria for tool failure taken as $\mathrm{VB}_{\max }$. Abrasion and adhesion are the primary wear mechanisms that contribute to flank wear. Often flank wear is more dominant at lower cutting speeds and crater wear at higher cutting speeds. ISO standards for tool life testing describe the important features of tool wear in single point turning. These are included in Figure 19.

The "tool life" is defined as the length of cutting time that the tool can be used. It is determined by first determining the maximum value of tool wear (crater depth or flank wear $\mathrm{VB}_{\max }$ ) that can be tolerated before rejecting the tool. Once this is fixed (for example $\mathrm{VB}_{\max }$ of .02 in) a horizontal line is drawn on the tool wear vs. time of cutting curve, as shown in

Figure 20, and tool life (time of cutting for given $\mathrm{VB}_{\max }$ ) read from the curve for different cutting speeds. Then these values are plotted on a cutting speed vs. tool life plot, as shown in Figure 21, which gives the tool life relationship [12]. 


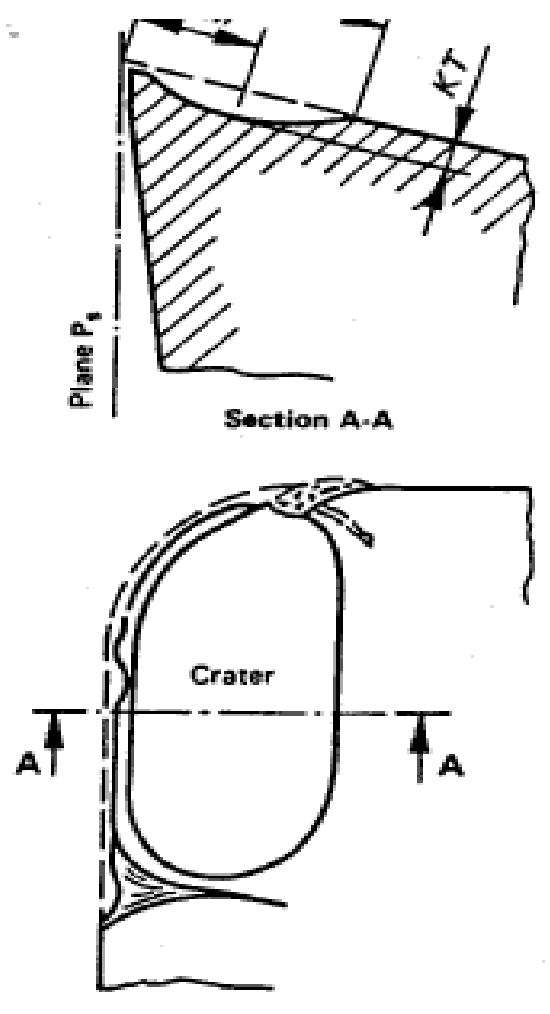

$$
\begin{aligned}
& K B=\text { crater width } \\
& K M=\text { crater centre distance } \\
& K T=\text { crater depth }
\end{aligned}
$$

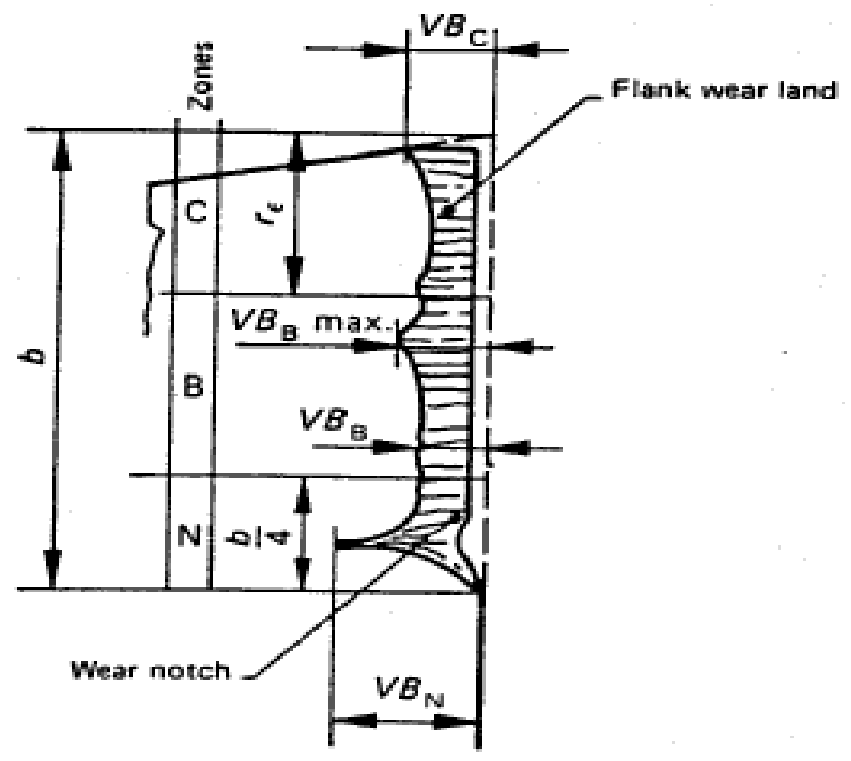

Figure 19. Features of a single point tool wear in turning (ISO Standard).

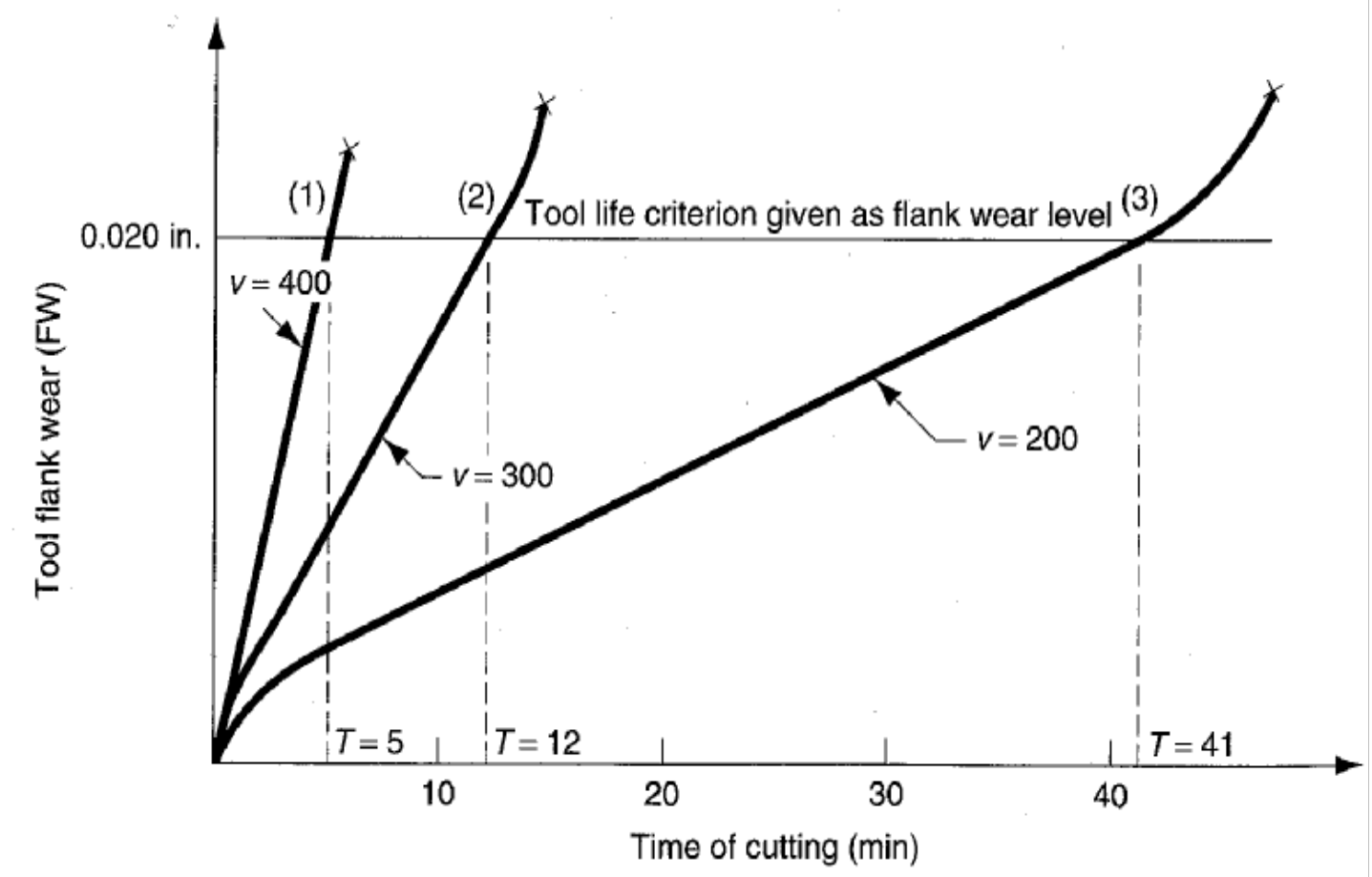

Figure 20. Curves of tool flank wear and time of cutting for different cutting speeds [12]. 


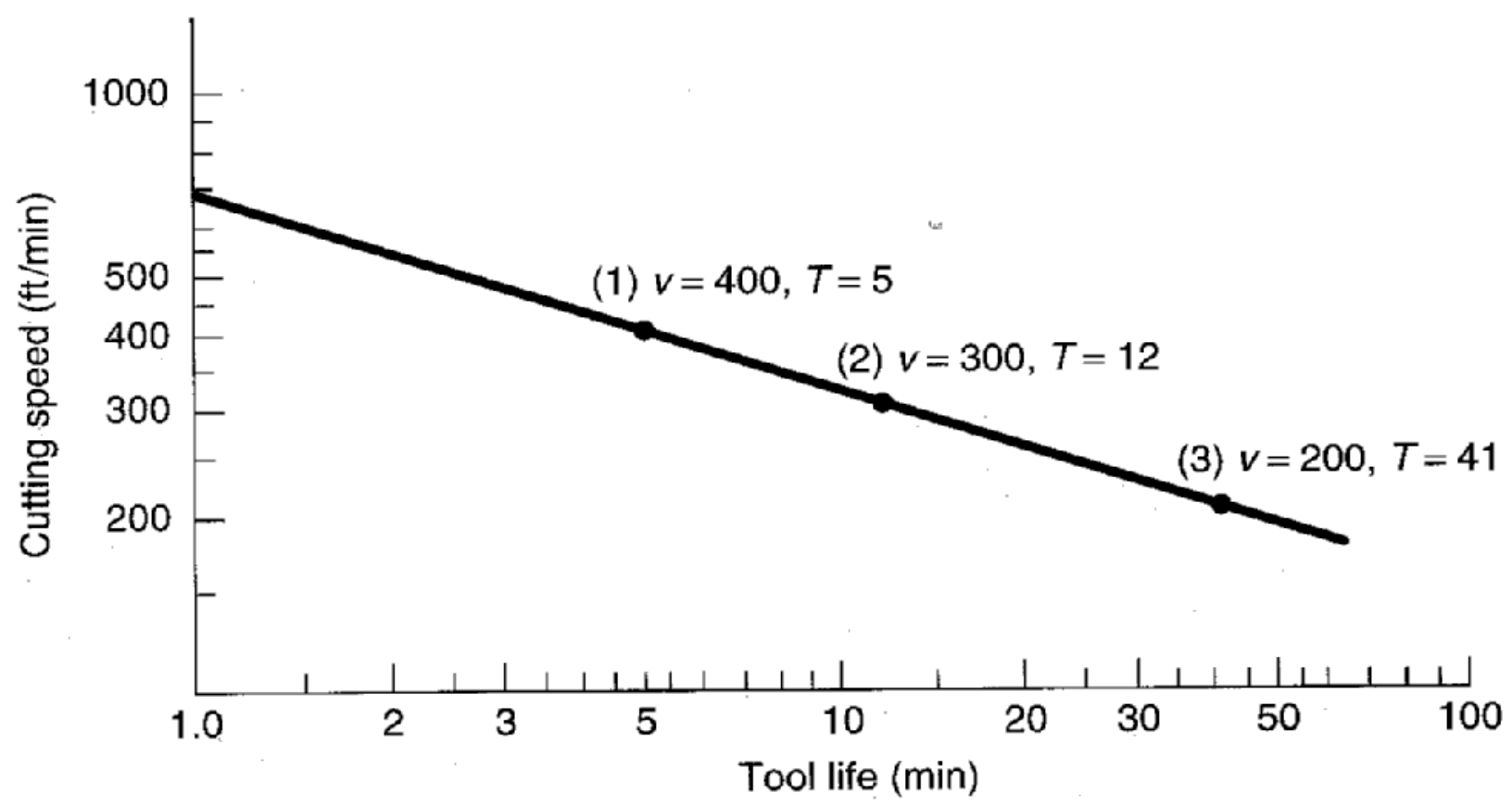

Figure 21. Tool lives from Figure 20 plotted against cutting speed on a log-log graph [12].

\subsubsection{Selection of Substrate Materials and Heat Treatment}

Cutting tools and die casting dies are made of several grades of steel, selected according to the mechanical and thermal stresses that will be encountered. Most of the cutting tools are also made out of the cemented tungsten carbide materials manufactured via powder metallurgy route. Generally cutting tools are also made out of high speed steels and are hardened using the traditional heat treatment processes. The HSS tool hardness is in the range of 62-65 Rc and its composition varies from manufacturer to manufacturer, but is typically $0.85-1.00 \% \mathrm{C}, 4 \% \mathrm{Cr}$, $6 \% \mathrm{~W}, 5 \% \mathrm{Mo}$, and $2 \% \mathrm{~V}$. The method of construction of cutting tools \& dies and choice of steel varies according to the preferences of the manufacturing company and the life expectation of the die. In case of the die casting dies the metal being cast also determines selection of the die steels that satisfy some of the above criteria and production quantities expected from the die. The composition most favored by the die casting companies is that with $5 \% \mathrm{Cr}, 1.5 \% \mathrm{Mo}$, and $1.0 \%$ $\mathrm{V}$ commonly known as H-13. H-13 is very popular grade of die steel in United States whereas, H11 is most favored in Europe.

\section{Heat Treatment}

A typical heat treatment cycle for the standard M2 HSS tool steel is: preheat at $1500^{\circ} \mathrm{F}$, harden at $2200^{\circ} \mathrm{F}$ and finally temper at $1000^{\circ} \mathrm{F}$ to get a hardness of about $65 \mathrm{Rc}$. Similarly the die material H-13 steel is heat treated as follows: stress relieved for 0.5 hours at $1000^{\circ} \mathrm{F}$, vacuum hardened for 90 minutes at $1875^{\circ} \mathrm{F}$, quenched, tempered for 3 hours at $1000^{\circ} \mathrm{F}$, tempered again for $3 \mathrm{hrs}$ at $1100^{\circ} \mathrm{F}$ and tempered again for $2 \mathrm{hrs}$ at $1000^{\circ} \mathrm{F}$. The final hardness was measured as 46-48 HRc. 


\section{Polishing Details}

An important aspect of the coating deposition and achievement of superior adhesion relates to the original surface finish of the substrate. Even an as-ground surface of the core pins (which are centerless ground) is sufficiently uneven at the nano-scale of the coating/substrate interface to offer sites for stress concentration. This can then lead to relatively easy failure of the coating, sometimes merely due to thermal mismatch and internal stresses generated during deposition. When subjected to the harsh erosive/corrosive environment, such stress concentration sites become the preferred locations for the coating failure. Therefore, surface finish of the part being coated must be carefully considered. In the present work, it was observed that polishing the substrate to remove surface irregularities was an important aspect of improved coating adhesion and performance. However, round tools made of high speed tool steel and inserts made of carbide were coated on as-received tools after cleaning.

\subsubsection{Substrate Surface Preparation and Deposition of Coatings}

To improve the adhesion of the coatings to the substrate and prevent contamination of the chamber due to dissociation of hydrocarbons and such other contaminants, it is very important to thoroughly clean the surface before admission into the coating chamber.

Residual oils and other contaminants can be removed by scrubbing the components with detergent solutions and heavy chemical contamination can be removed by the use of acid etches. Ultrasonic cleaning followed by vapor de-greasing improves matters further. A typical cleaning process for metallic components usually consists of the following parts.

- Visual inspection to check damage in the form of grinding marks, nicks, burrs etc.

- Ultrasonic cleaning in solvent for greases.

- Vapor de-grease in same solvents.

- Ultrasonic cleaning in detergent.

- $\quad$ Rinse in de-ionized water.

- Ultrasonic cleaning in a dehydrant solution.

- $\quad$ Final air blow-off and drying.

It is also very important to avoid particulate contamination from the coating system and therefore, a clean dust-free location for the coating chamber is usually recommended.

In the case of the system at UES Inc., a very good surface finish was one of the primary requirements for good adhesion of the coatings to the substrate. Therefore, the coupons and core pins were lapped prior to deposition of coatings.

\section{Deposition of Coatings}

Coatings were deposited on various substrates at UES Inc., using the Large Area Filtered cathodic-Arc Deposition (LAFAD) system. The unique, patented design of the coating system allows the creation of a "plasma immersed" environment in the coating chamber by manipulating the arc plasma jets using strategically placed scanning magnetic coils and auxiliary anodes [13]. 
This technique allows the plasma flux from different cathodes in a multi-cathode chamber to be uniformly mixed and enveloped around the part.

The large-area filtered arc cathodic arc deposition system at UES is shown schematically in Figure 22. It consists of three key components: direct arc sources, large area filtered arc sources and the auxiliary anode assembly. It has been shown by Gorokhovsky [14] and by Vetter and Perry [15] that the arc sources can be used to extract highly energetic electrons and used to ionize the gaseous plasma, such that the plasma envelope that completely surround the part can be created in the coating chamber. Using this technique, very high ion currents can be obtained as compared to the other PVD techniques such as EBPVD and sputtering. The high degree of ionization of the gaseous plasma permits ion saturation levels suitable for ion nitriding. Moreover, when the substrate is strongly biased, significant ion implantation can be achieved.

The arc plasma is generated by a patented electronic trigger and arc-spot control circuitry that effectively eliminates the tendency for the arc spot to be extinguished unpredictably, and provides a stable and continuous operation of the arc for an extended period. The deposition chamber is evacuated to a pressure of $7 \times 10^{-4} \mathrm{~Pa}$ prior to the introduction of gases such as argon or nitrogen for cleaning of the substrates or for metal deposition, respectively. The substrates are mounted on a variable speed substrate holder with double-planetary rotation capability, which can be biased to a desired voltage using either a bipolar DC pulse or RF power supply.

Some of the advantages of this process are:

- $\quad$ The macroparticle trap generated due to the plasma filter successfully prevents all macroparticles form being deposited on to the substrate thereby improving the quality of the coating (Figure 23).

- $\quad$ The material evaporated from the cathode passes very quickly to the vapor phase from solid phase.

- $\quad$ No heat-up phase is required and the evaporation of cathode material is simultaneous with the initiation of the arc.

- A solid cathode source allows placement of cathodes in any orientation to insure proper plasma density leading to coating uniformity on the substrate.

- Cathodes are independently powered allowing better control and operation according to substrate requirements.

- Arc evaporation imparts ion energies up to $50 \mathrm{eV}$, which are far higher than those observed in other PVD processes such as Magnetron Sputtering $(3 \mathrm{eV})$ and E-Beam Evaporation $(0.3 \mathrm{eV})$. This is very useful in improving the adhesion of the coating to the substrate.

- High ionization levels of $80 \%$ of the (source material) vapor reaching the substrate.

- $\quad$ Alloyed coatings of different materials are easily deposited, since the cathode is manufactured using powder metallurgy techniques. 


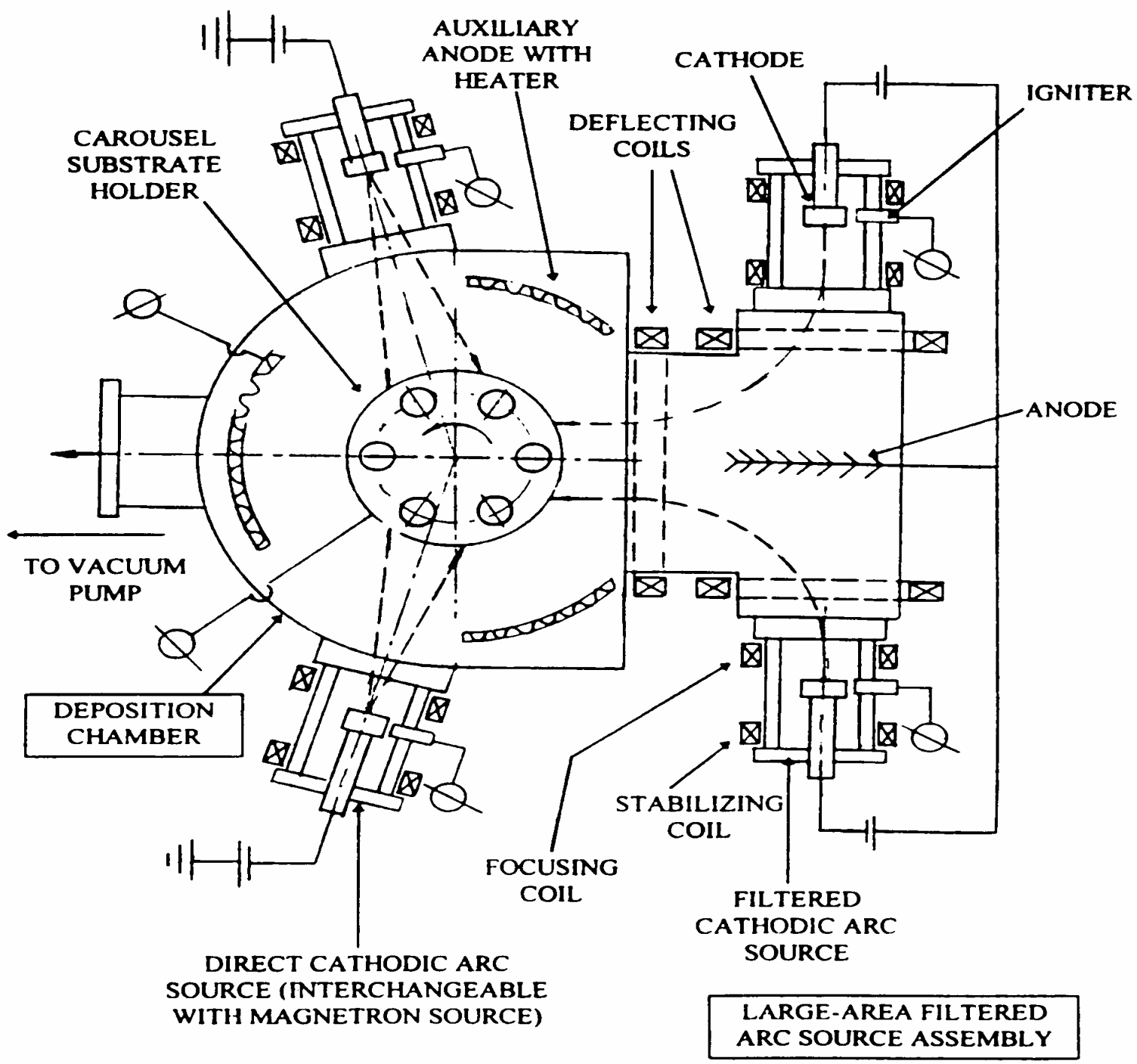

Figure 22. Schematic of the Large Area Dual Filtered Cathodic Arc Deposition System.

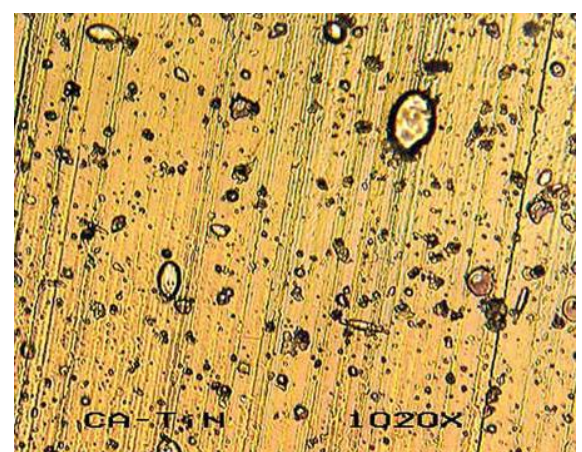

Direct Arc

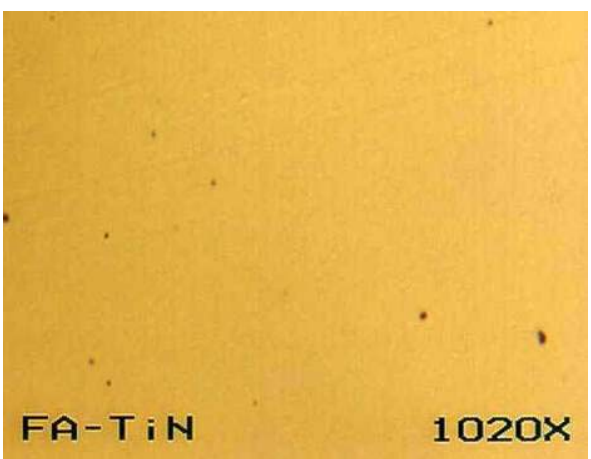

Filtered Arc

Figure 23. Surface morphology of direct arc and filtered arc TiN coating. 


\subsubsection{Boron and Carbon Based Coating Development}

\section{Boron Based Coatings}

For depositing boron based titanium coatings, different approaches were employed. Initially, two cathodes $\mathrm{Ti}$ and $\mathrm{TiB}_{2}$ were used in the filtered arc mode. A thin (nanometers) $\mathrm{Ti}$ interface layer was used prior to depositing coatings. The deposition chambers were evacuated to a pressure of $5 \times 10^{-3} \mathrm{~Pa}$ prior to introducing nitrogen gas. The introduction of nitrogen resulted in a thin (submicron) TiN buffer interlayer which provides better adhesion to the substrate. Similarly various multilayer structures of $\mathrm{TiAlN}$ and $\mathrm{TiB}_{2}$ or $\mathrm{TiBN}$ were deposited on carbide cutting tools. TiAlN was deposited from the TiAl (Ti:Al = 1:1 by at \%) arc source by bleeding in nitrogen during deposition. Finally, trimethyl boron gas was used to create Ti-B-C-N system resulting in $\sim 13 \%$ atomic carbon. The WC substrates were mounted on a variable speed rotary holder that was biased to a desired voltage using either a DC or RF power. Many variants of the boron and carbon containing coatings were produced, and the deposition conditions of the selected few are listed in Table 4.

Table 4. Coating Type: $\mathrm{TiB}_{2} / \mathrm{TiBN}$

\begin{tabular}{|c|c|c|c|c|c|c|c|}
\hline \multirow[b]{2}{*}{ Run } & \multicolumn{6}{|c|}{ PROCESS } & \multirow[b]{2}{*}{ COMMENTS } \\
\hline & Target & Gas & Bias & Temp & $\begin{array}{c}\text { Arc } \\
\text { Current (A) }\end{array}$ & $\begin{array}{l}\text { Aux Anode } \\
\text { Current (A) }\end{array}$ & \\
\hline 386 & $\begin{array}{c}\mathrm{TiB}_{2} \\
(1.6 \mathrm{kw} \\
\text { two targets) }\end{array}$ & $\mathrm{Ar}$ & $-30 \mathrm{~V}$ & $400^{\circ} \mathrm{C}$ & 50 & 18 & $\mathrm{Ti} / \mathrm{TiB}_{2}$ multilayer \\
\hline 410 & $\mathrm{Ti} / \mathrm{TiBN}$ & $\begin{array}{l}\mathrm{Ar} \& \\
\mathrm{Ar} / \mathrm{N}_{2}\end{array}$ & $-20 \mathrm{~V}$ & $400^{\circ} \mathrm{C}$ & 50 & 10 & Ti/TiBN multilayer \\
\hline 460 & $\begin{array}{c}\text { (F.A.) } \\
\text { TiAl \& } \text { TiB }_{2}\end{array}$ & $\begin{array}{l}\mathrm{N}_{2} \\
\mathrm{Ar}\end{array}$ & $-30 \mathrm{~V}$ & $400^{\circ} \mathrm{C}$ & 50 & 20 & $\mathrm{TiAl} / \mathrm{TiB}_{2}$ multilayer \\
\hline 461 & $\mathrm{TiAl} \& \mathrm{TiB}_{2}$ & $\begin{array}{l}\mathrm{N}_{2} \\
\mathrm{Ar}\end{array}$ & $-30 \mathrm{~V}$ & $400^{\circ} \mathrm{C}$ & 50 & 20 & $\mathrm{TiAl} / \mathrm{TiB}_{2}$ multilayer \\
\hline
\end{tabular}

\section{Characterization of Coatings}

The selected coatings were characterized for thickness, hardness and adhesion. The thickness and layer structures were characterized by Calotest equipment. Auger electron microscopy (AES) was used for compositional characterization.

\section{Multilayered Coatings}

Figures 24 shows the AES profile of Ti/TiAlN multilayer that has been used as an underlayer for some of the boron and carbon based coatings for evaluations of machining and die casting. In general, TiAlN composition consisted of about $20 \% \mathrm{Al}, 30 \% \mathrm{~N}$ and $45 \% \mathrm{Ti}$. A small amount of $\mathrm{C}$ was always present. Figures 25-29 show the AES profiles of various boron based multilayered coatings developed in Phase II using the deposition conditions listed in Table.4. Figure 25 shows that the $\mathrm{TiB}_{2}$ film is stoichiometric in composition. In TiBN films (Figure 26), the composition appears to be TiBNO with about equal amounts of nitrogen and oxygen. This is likely to be due to the incorporation of oxygen from the residual gas because of very low rate of deposition of TiBN film. 


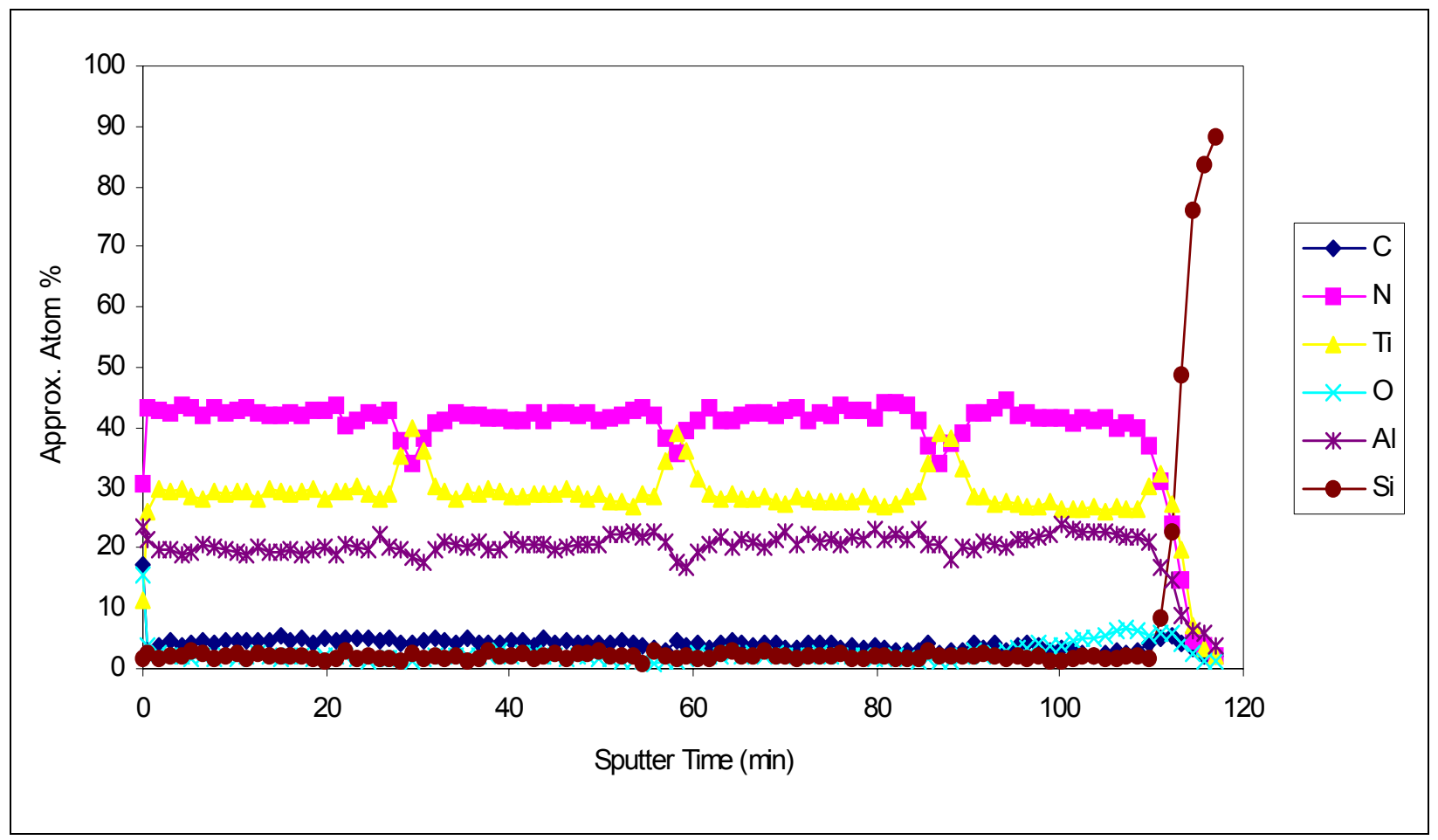

Figure 24. AES Profile of Ti/TiAlN Multilayer.

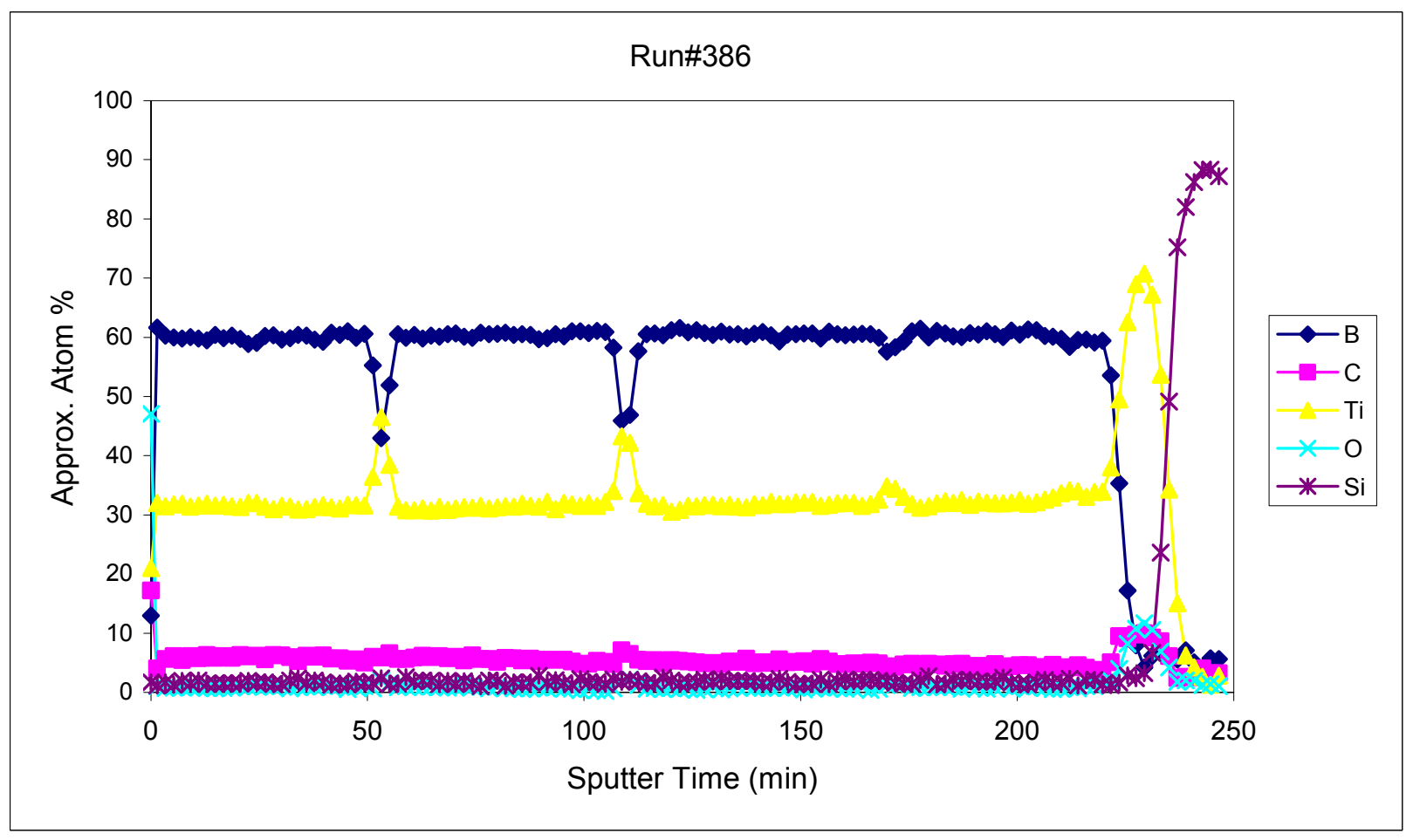

Figure 25. AES Profile of $\mathrm{Ti} / \mathrm{TiB}_{2}$ Multilayer. 


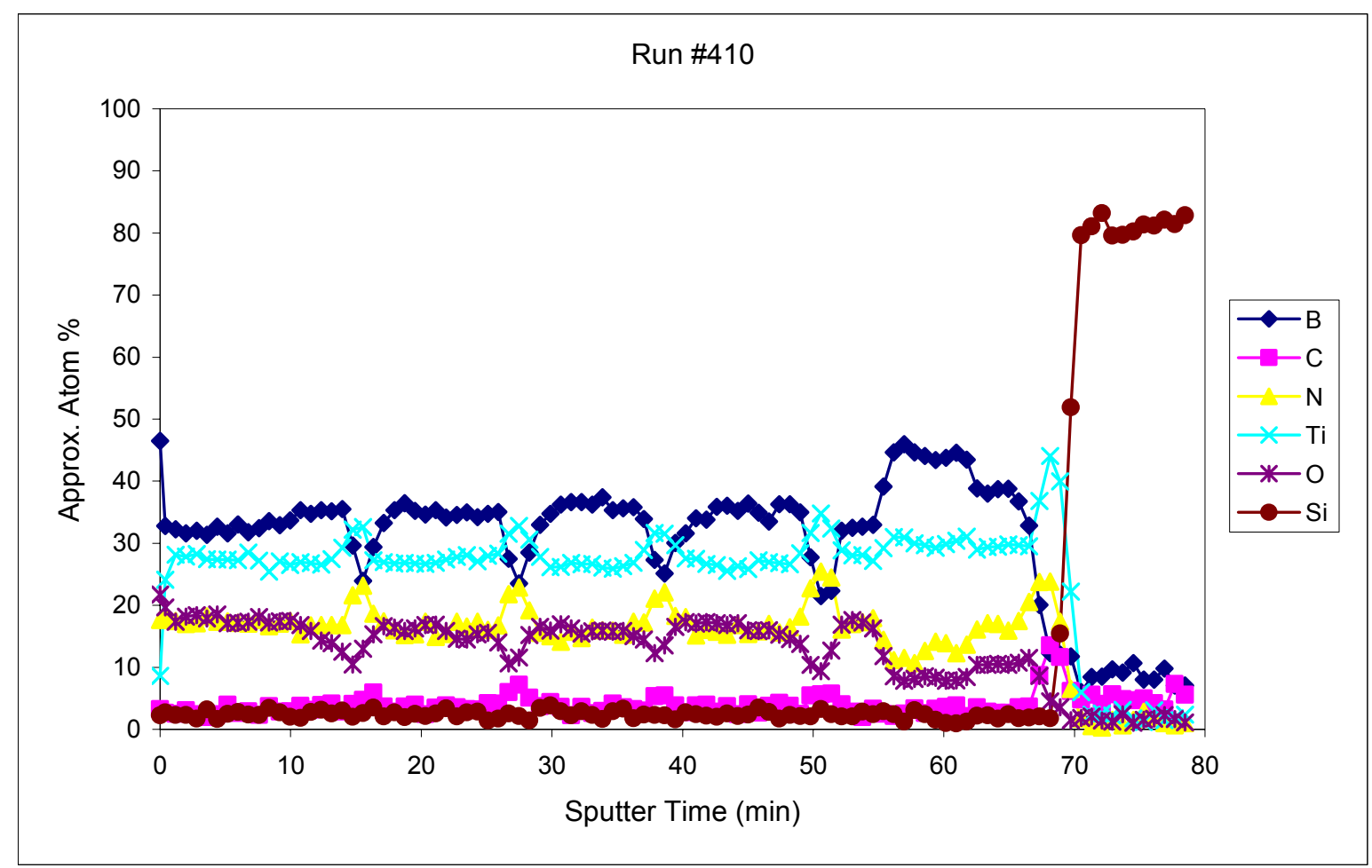

Figure 26. AES Profile of Ti/TiBN Multilayer.

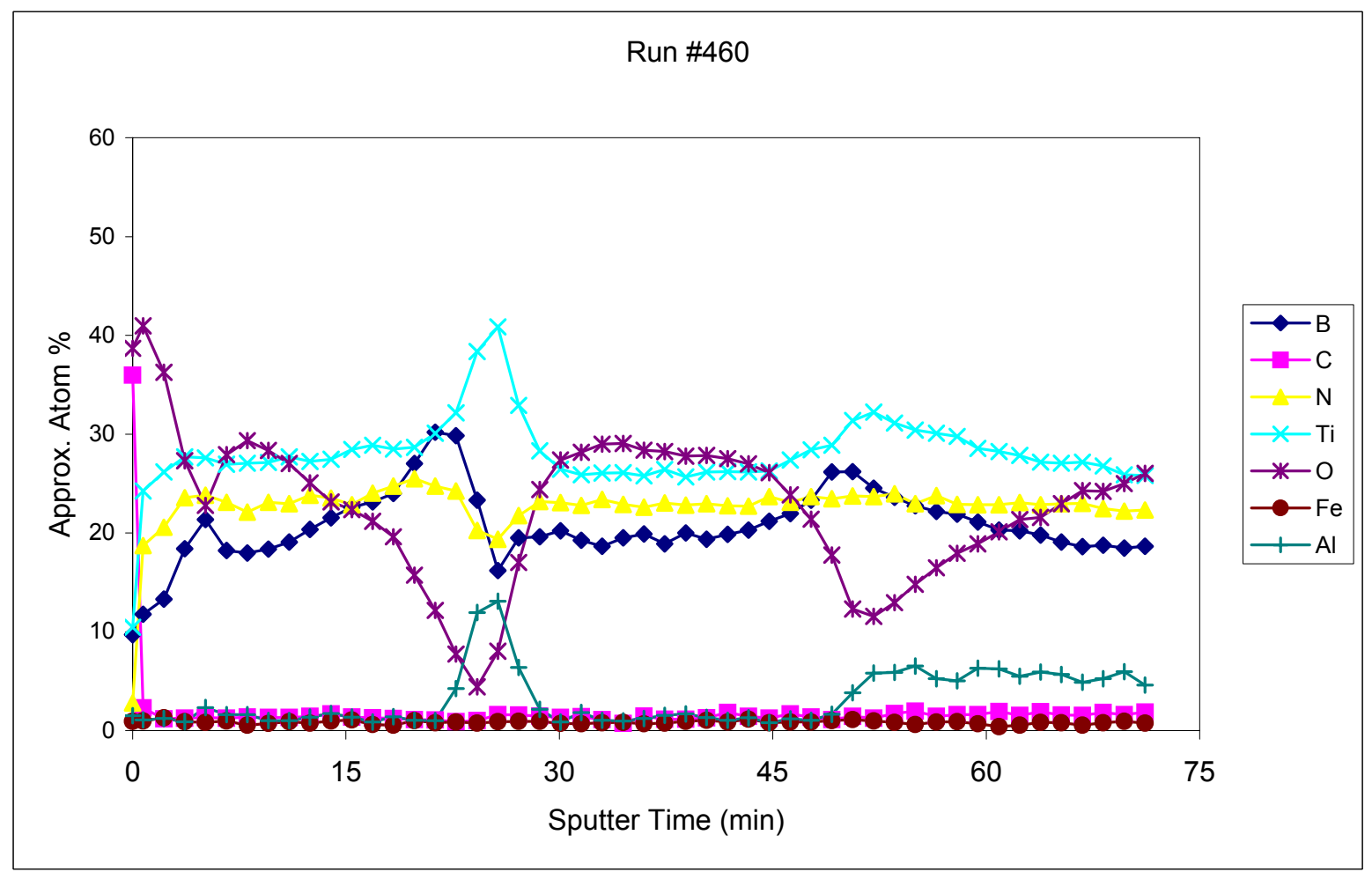

Figure 27. AES Profile of TiBN/Ti Multilayer. 
Run \#461

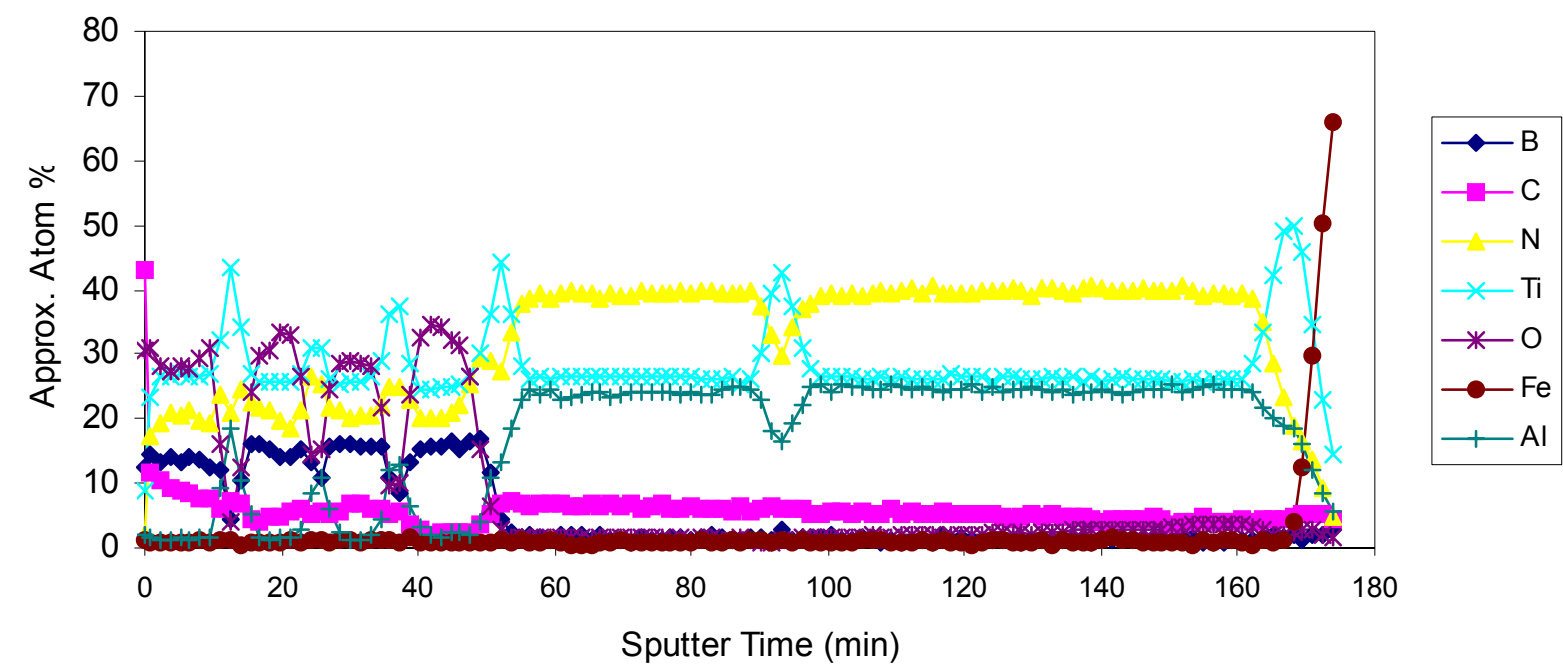

Figure 28. AES Profile of TiAlN/TiBN Multilayer on TiAlN Base Layer.

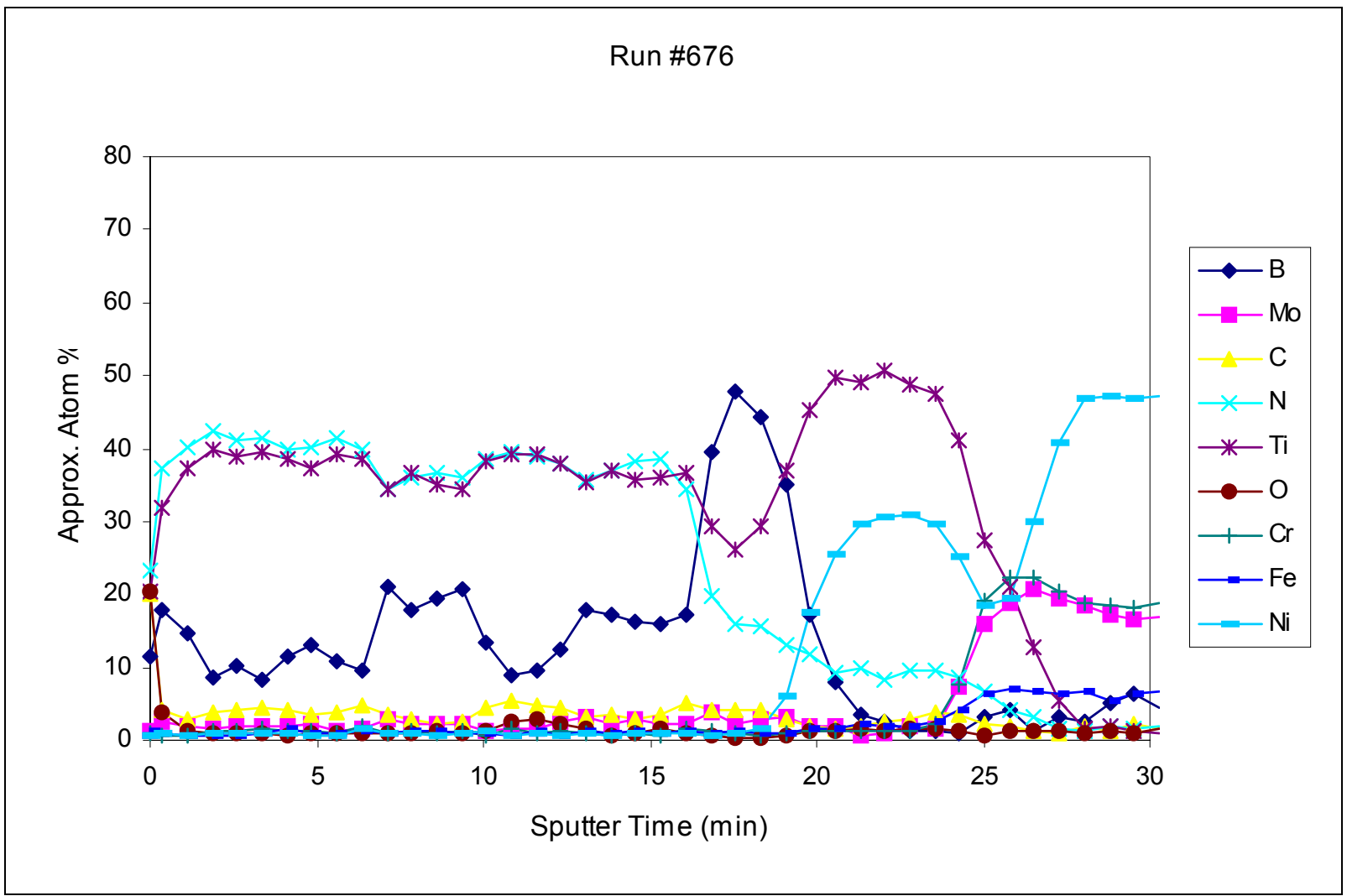

Figure 29. AES Profile of TiBN. 


\section{Carbon Based Coatings}

AES profiles of various carbon based coatings are shown in Figures 30-35. The deposition conditions for these coatings are listed in the Table 5. According to AES analysis, TiC films appear to be slightly carbon deficient (Figure 30). The concentrations of carbon and nitrogen in TiCN layer are about $30 \%$ and $20 \%$ respectively, (Figure 31 ).

The composition of $\mathrm{TiC}+\mathrm{C}$ layers could be varied greatly by varying the deposition conditions. The primary parameters are arc current and $\mathrm{C}_{2} \mathrm{H}_{2}$ or $\mathrm{CH}_{4}$ gas pressure.

Table 5. Coating Type: $\mathrm{TiC}+\mathrm{C}$

\begin{tabular}{|c|c|c|c|c|c|c|c|c|}
\hline \multirow{3}{*}{ Run } & \multicolumn{7}{|c|}{ PROCESS } & \multirow{3}{*}{ COMMENTS } \\
\hline & \multicolumn{2}{|c|}{$\begin{array}{c}\text { Target } \\
\text { TI }\end{array}$} & \multirow{2}{*}{$\begin{array}{c}\text { Gas } \\
\text { Pressure } \\
\text { (Pa) }\end{array}$} & \multirow[t]{2}{*}{ Bias } & \multirow[t]{2}{*}{ Temp } & \multirow{2}{*}{$\begin{array}{c}\text { Arc } \\
\text { Current (A) }\end{array}$} & \multirow{2}{*}{$\begin{array}{l}\text { Aux Anode } \\
\text { Current (A) }\end{array}$} & \\
\hline & \#1 & & & & & & & \\
\hline 300 & $\mathrm{On}$ & On & $\mathrm{CH}_{4} 6 \times 10^{-2}$ & $-40 \mathrm{~V}$ & $400^{\circ} \mathrm{C}$ & 70 & 12 & Ti/TiC Multilayers \\
\hline 301 & On & On & $\begin{array}{l}\mathrm{N}_{2}+\mathrm{CH}_{4} \\
6 \times 10^{-2}\end{array}$ & $-40 \mathrm{~V}$ & $400^{\circ} \mathrm{C}$ & 70 & 14 & Ti/TiCN Multilayers \\
\hline 425 & $\mathrm{Ti}$ & & $\mathrm{C}_{2} \mathrm{H}_{2} 3 \times 10^{-1}$ & $-60 \mathrm{~V}$ & $400^{\circ} \mathrm{C}$ & 70 & 10 & $\begin{array}{l}\text { Nearly stiochromatic TiC } \\
\text { Flowrate } \mathrm{CH}_{4}=230 \mathrm{sccm}\end{array}$ \\
\hline 426 & & $\mathrm{Ti}$ & $\mathrm{C}_{2} \mathrm{H}_{2} 3 \times 10^{-1}$ & $-60 \mathrm{~V}$ & $400^{\circ} \mathrm{C}$ & 50 & 10 & Moderately high matches with run $\# 500$ \\
\hline 427 & & $\mathrm{Ti}$ & $\mathrm{C}_{2} \mathrm{H}_{2} 3 \times 10^{-1}$ & $-60 \mathrm{~V}$ & $400^{\circ} \mathrm{C}$ & 50 & 10 & Very high $\mathrm{C}$ \\
\hline 447 & & On & $\mathrm{CH}_{4} 3 \times 10^{-1}$ & $-60 \mathrm{~V}$ & $400^{\circ} \mathrm{C}$ & 70 & 18 & $\begin{array}{l}\text { Good adhesion. Plasma cleaning done } \\
\text { with anx.anode }=30 \mathrm{~A}\end{array}$ \\
\hline 458 & & On & $\mathrm{CH}_{4} 3 \times 10^{-1}$ & $-60 \mathrm{~V}$ & $400^{\circ} \mathrm{C}$ & 70 & 30 & Check composition \\
\hline 676 & $\mathrm{Ti}$ & & $\underset{6 \times 10^{-2}}{\left(\mathrm{CH}_{3}\right) \mathrm{B} \& \mathrm{~N}_{2}}$ & $-30 \mathrm{~V}$ & $400^{\circ} \mathrm{C}$ & 70 & 8 & TiN/TiBCN Multilayers \\
\hline
\end{tabular}

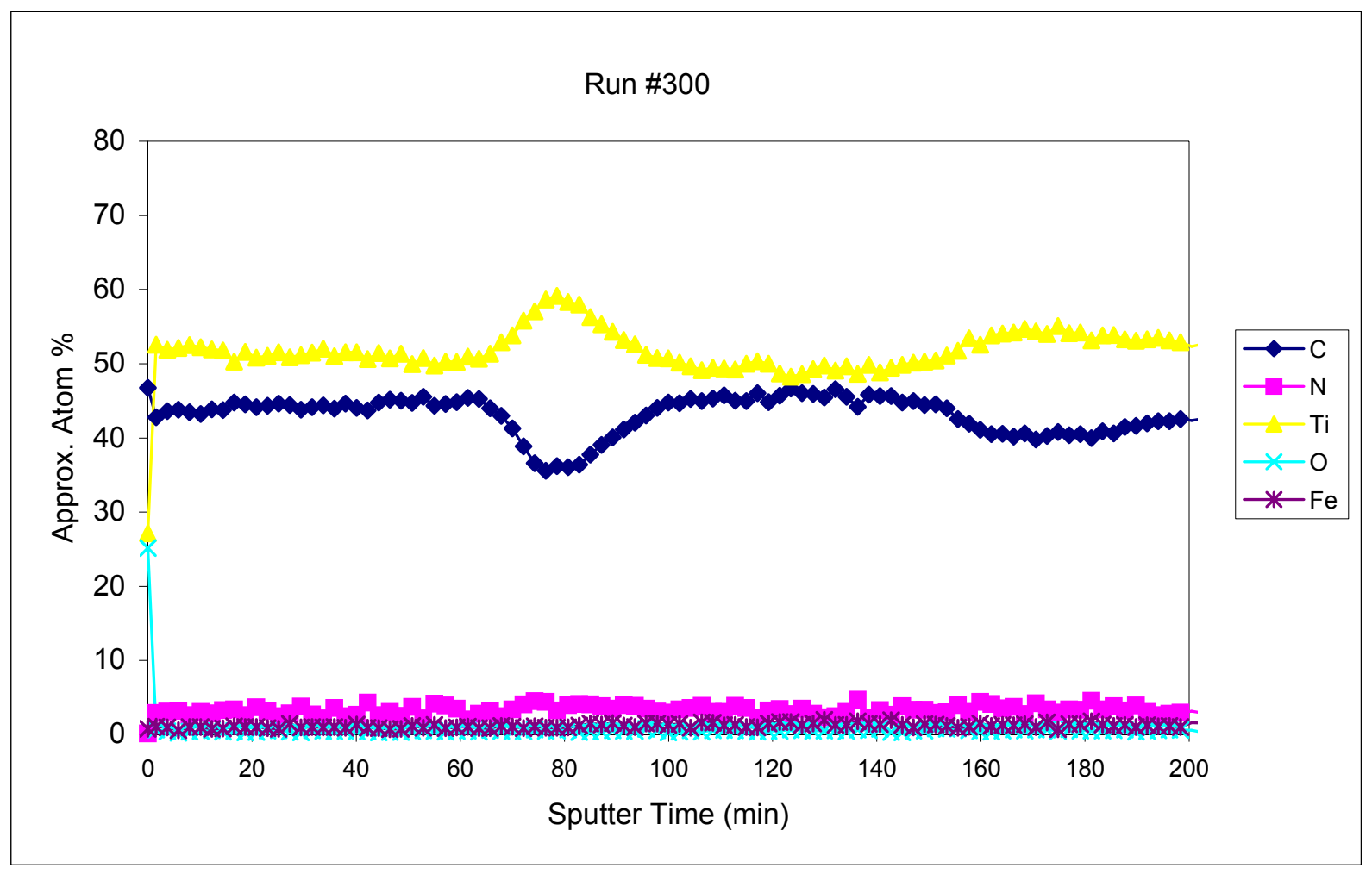

Figure 30. AES Profile of Ti/TiC Multilayer. 


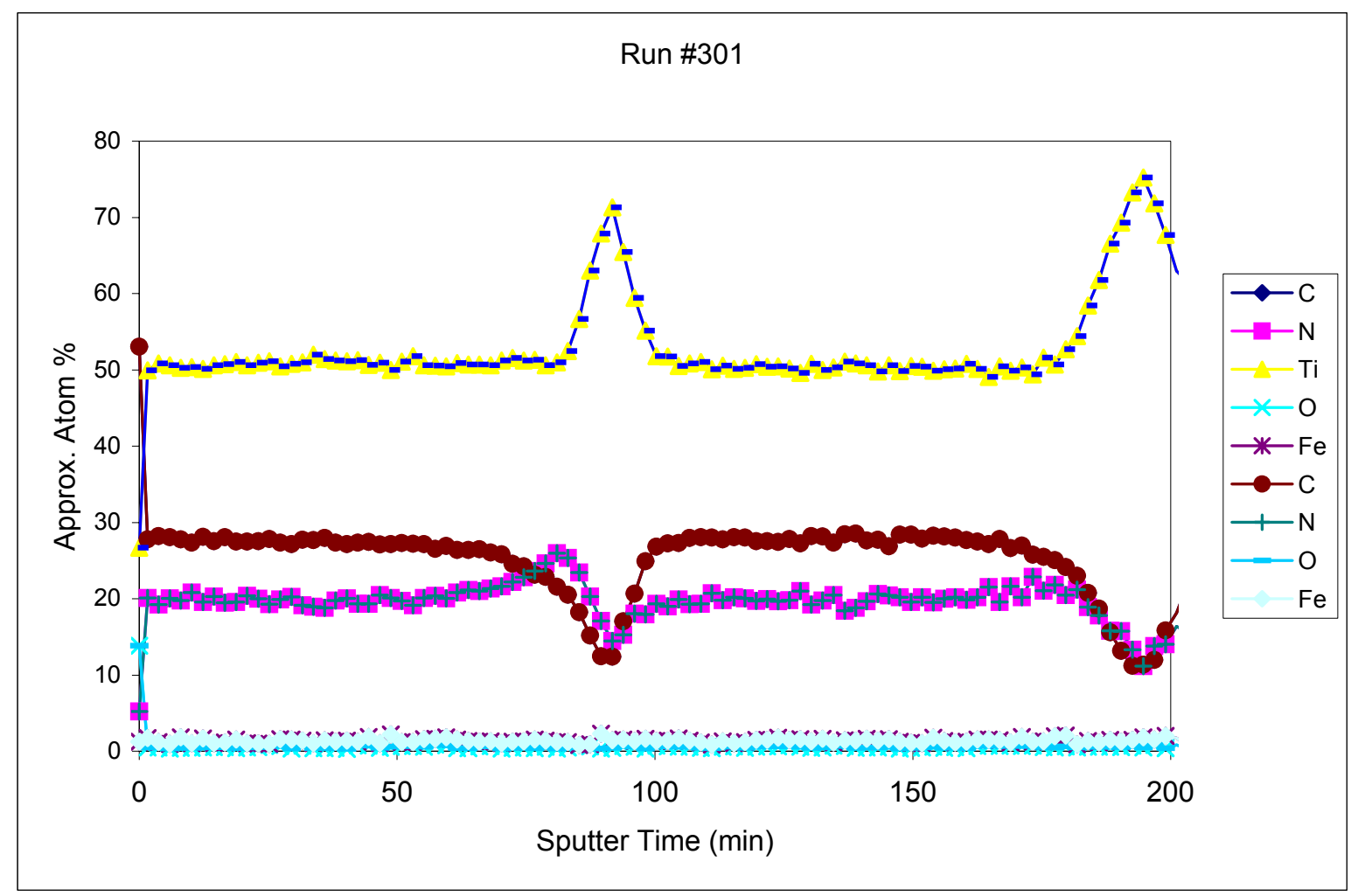

Figure 31. AES Profile of Ti/TiCN Multilayer.

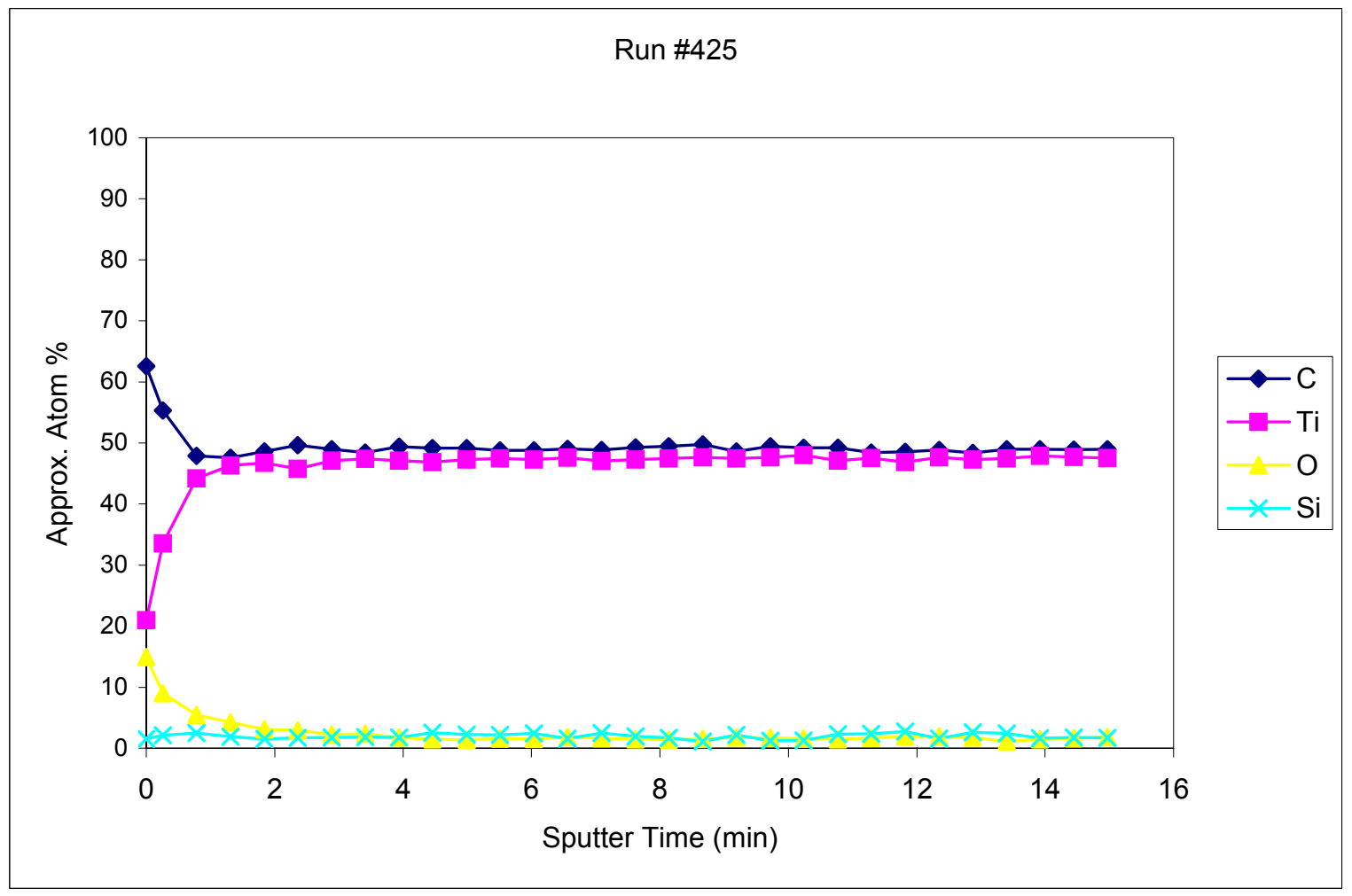

Figure 32. AES Profile of TiC $+\mathrm{C}$ Layer of Run \#425. 


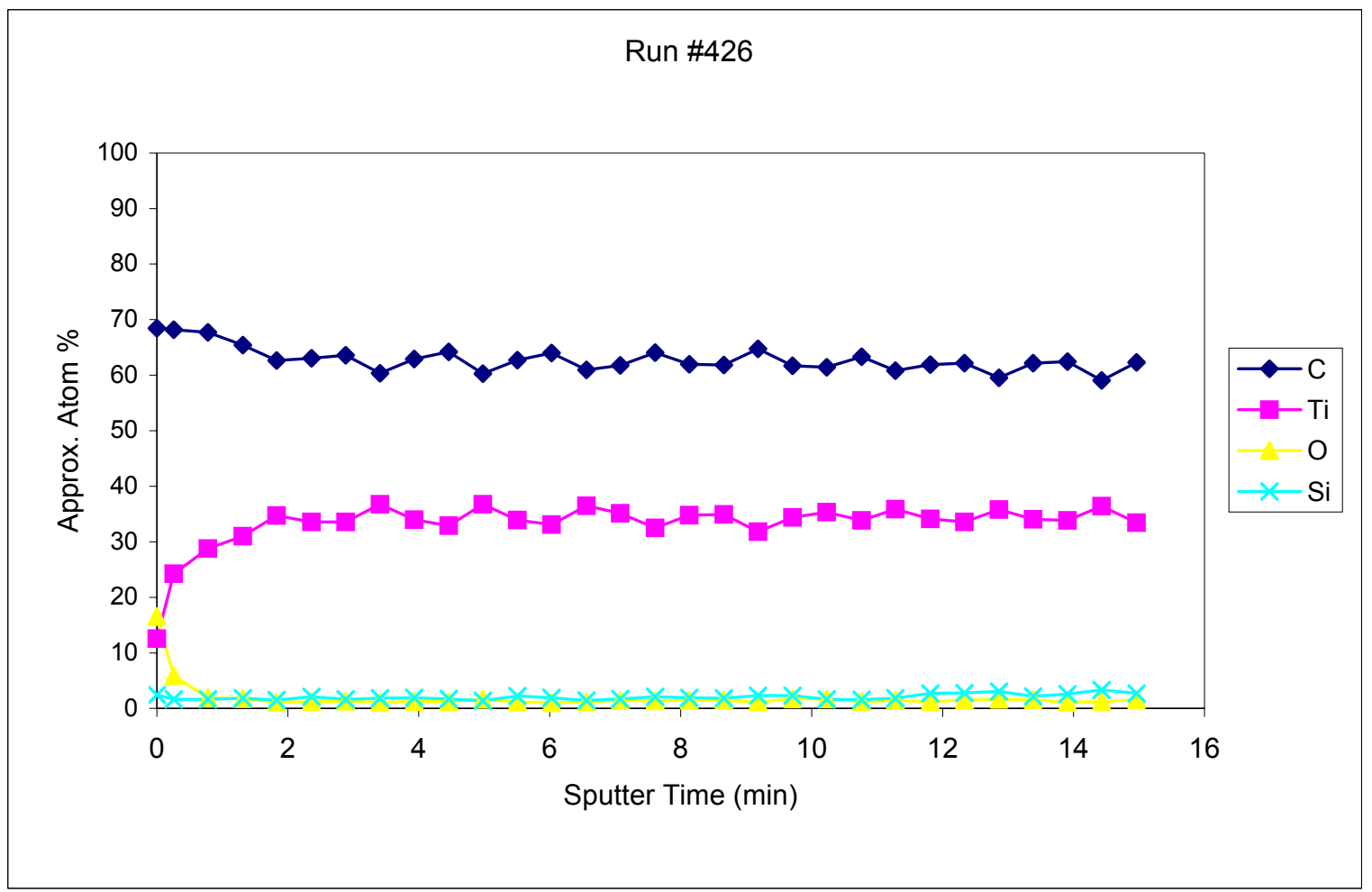

Figure 33. AES Profile of TiC $+\mathrm{C}$ Layer of Run \# 426.

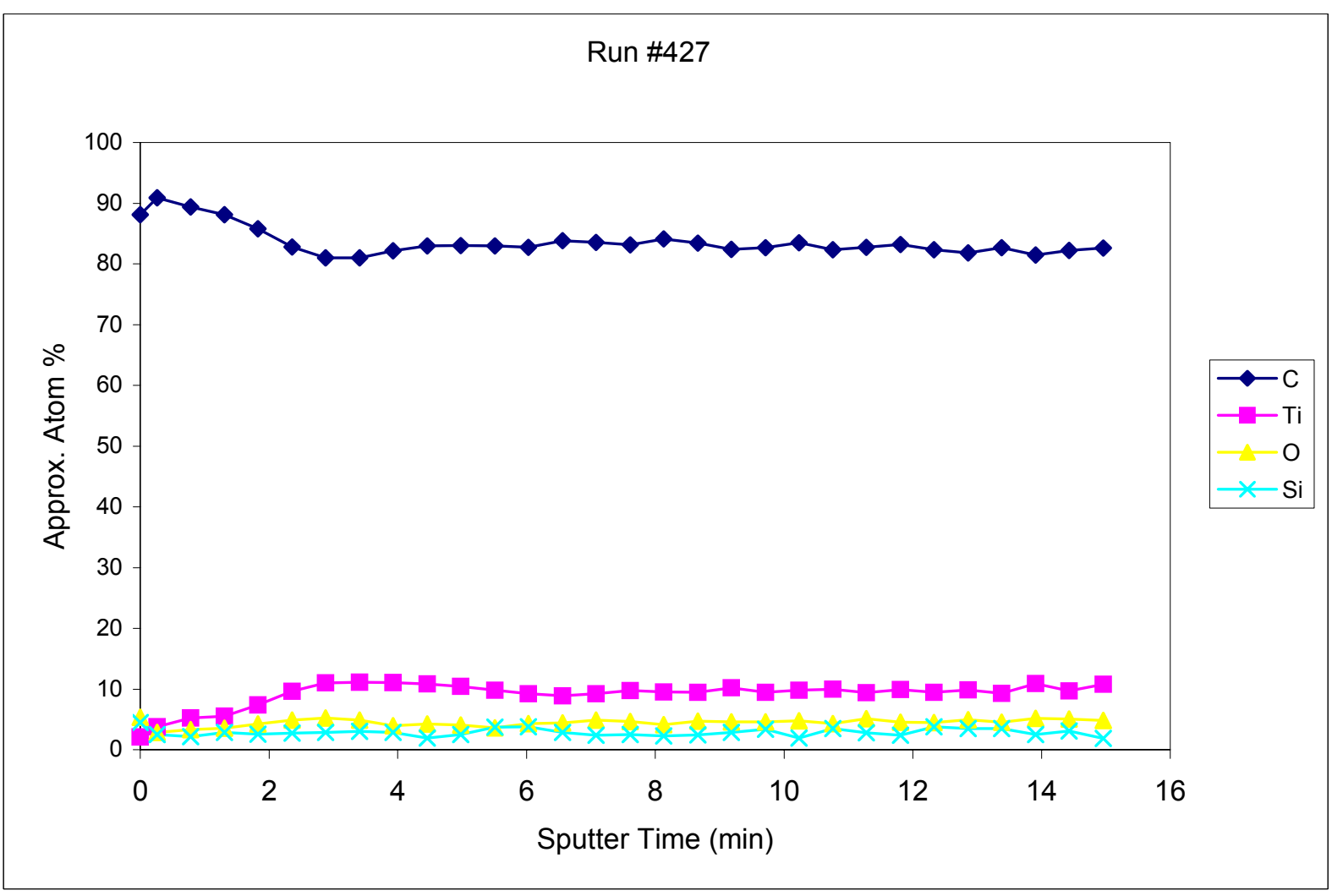

Figure 34. AES Profile of TiC $+\mathrm{C}$ Layer of Run $\# 427$. 


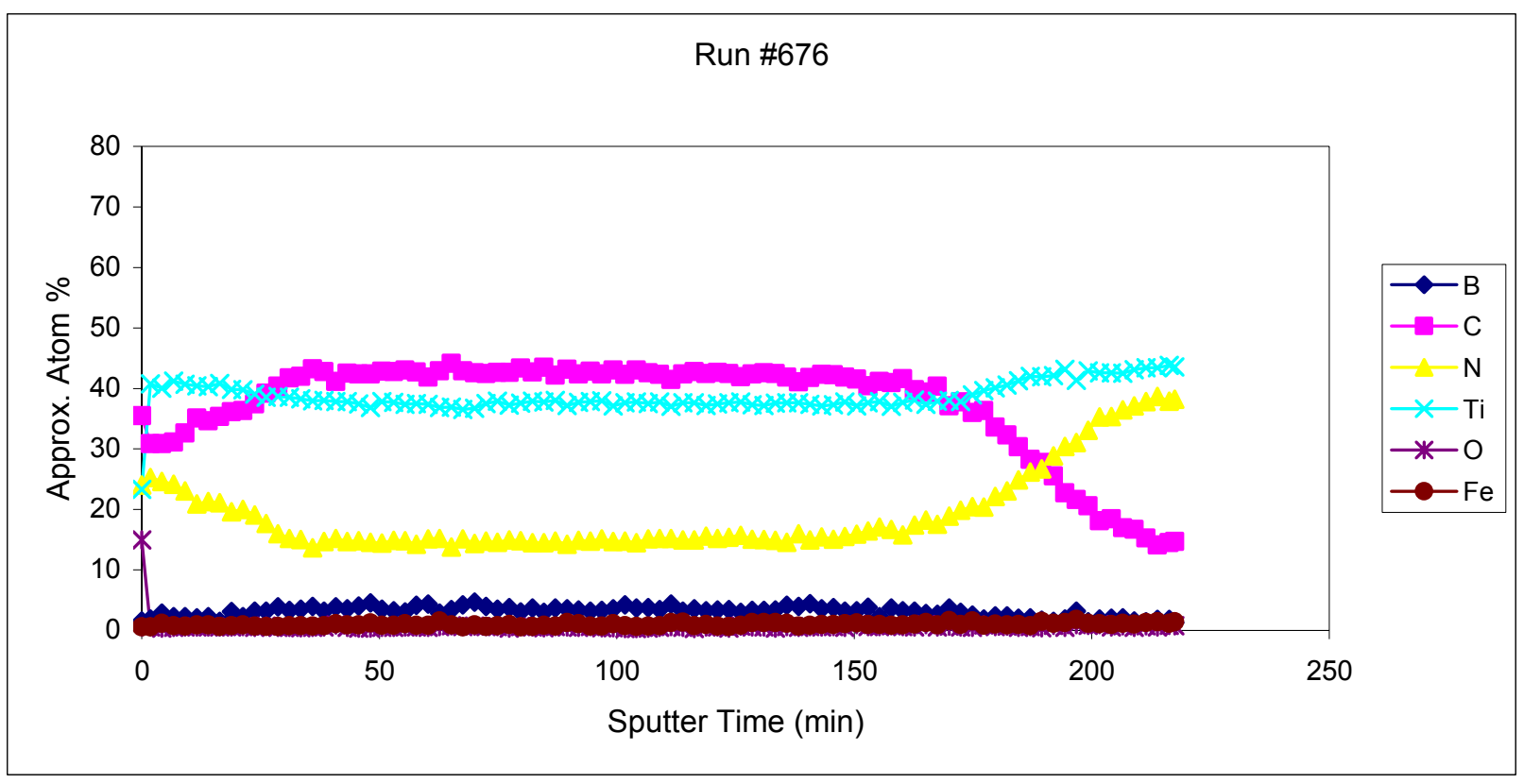

Figure 35. AES Profile of B Doped TiC+C Layer on Run \#676.

\section{Coating Thickness and Adhesion Measurement (Mercedez Test)}

Coating thickness was measured by a standard Calo Test method that involves uniform wear of the coated surface with the help of a rotating carbide ball and quantification of the coating thickness by measuring the diameters of the crater formed. The adhesion is measured by Mercedez test. This is a standard ASTM test, in which a diamond indentation is made on the coated substrate [16]. The indentation is made on the Rockwell C scale (150 Kg. normal load) and the surface of the coating is examined under an optical microscope. The coating adhesion is qualitatively estimated by visual observation. The various adhesion standards are depicted in the Figure 36. The first two stages indicating minimum radial cracks are representative of coatings having good adhesion whereas the ones from stage 3 to 6 represent progressive poor adhesion of the coating with the substrate.

Figures 37 a,b,c show the Mercedez test results for a few B based coatings. Run \#386 produced better adhesion then Run \#460 and Run \#461. The difference was primarily due to thinner $\mathrm{TiB}_{2}$ layers in Run \#386, as compared to that in Run \#460 and Run \#461. Carbon containing layers, being relatively softer than B containing coatings, possess good adhesion strength showing radial cracks in the Mercedez test. 
Method

Hardness of Substrate

Layer Thickness

Judgement

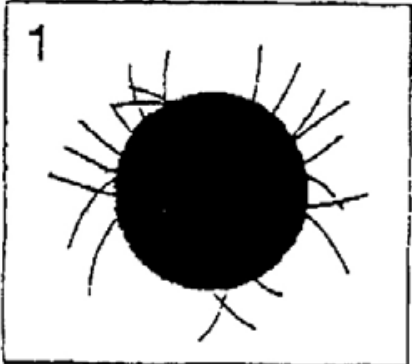

3

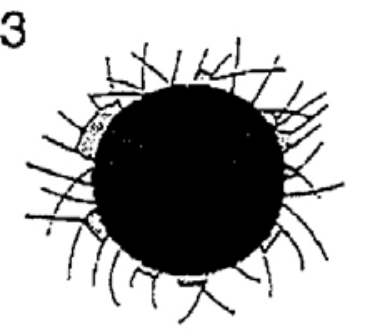

5

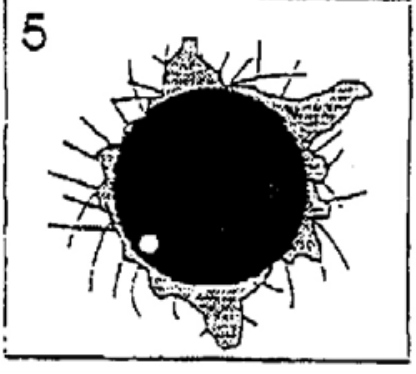

: HAc Hardness Measurement

At Least 54 HRc.

:Max. $5 \mu \mathrm{m}$.

: Observe the HRc indentation with

a Magnification of 100 Times.

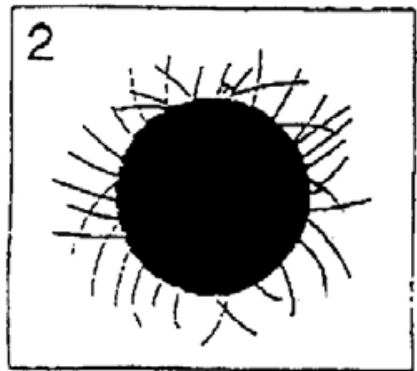

4

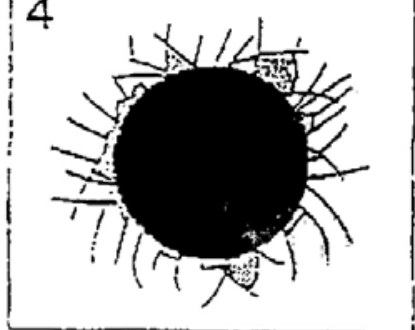

$\frac{0}{\frac{0}{0}}$
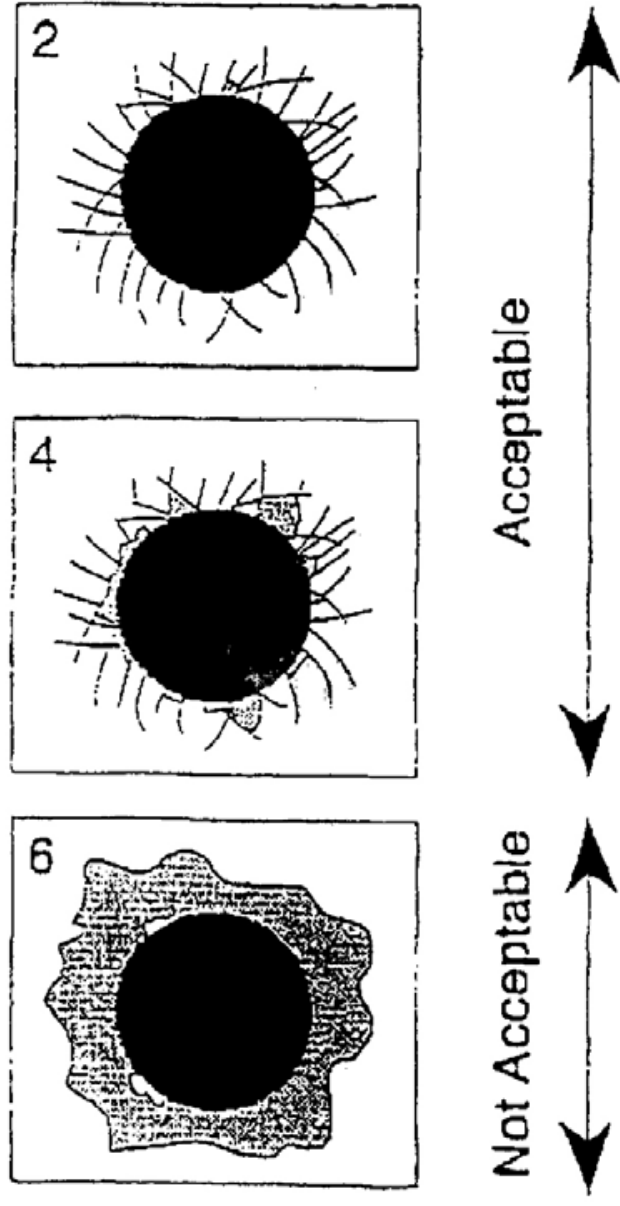

$\$$ Cracks

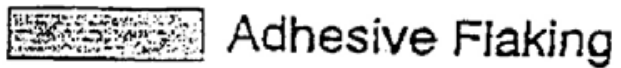

(The substrate is visible.

Figure 36. Adhesion Judgment of PVD-Layers using Mercedez Test. 


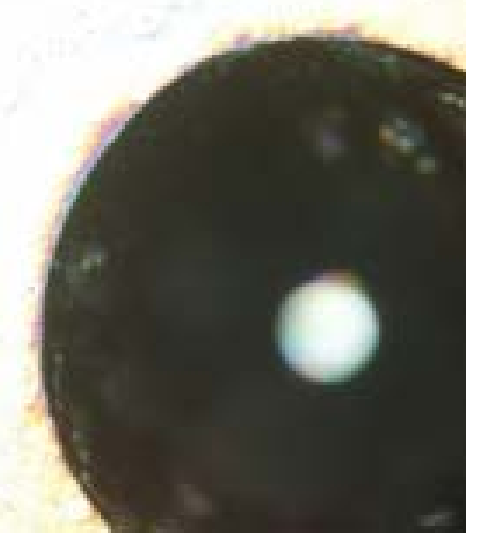

(a) Run \#386 Ti/TiB 2

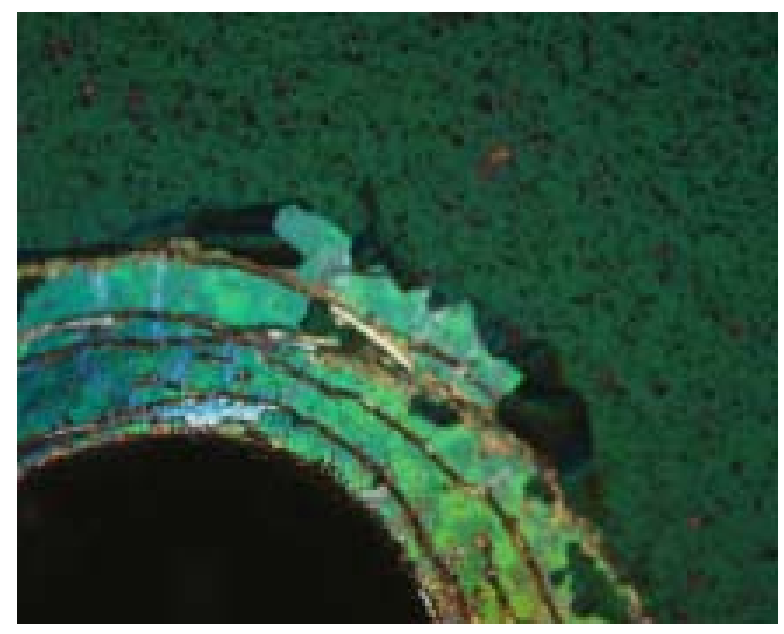

(b) Run \#460 Ti/TiB 2 Multilayer

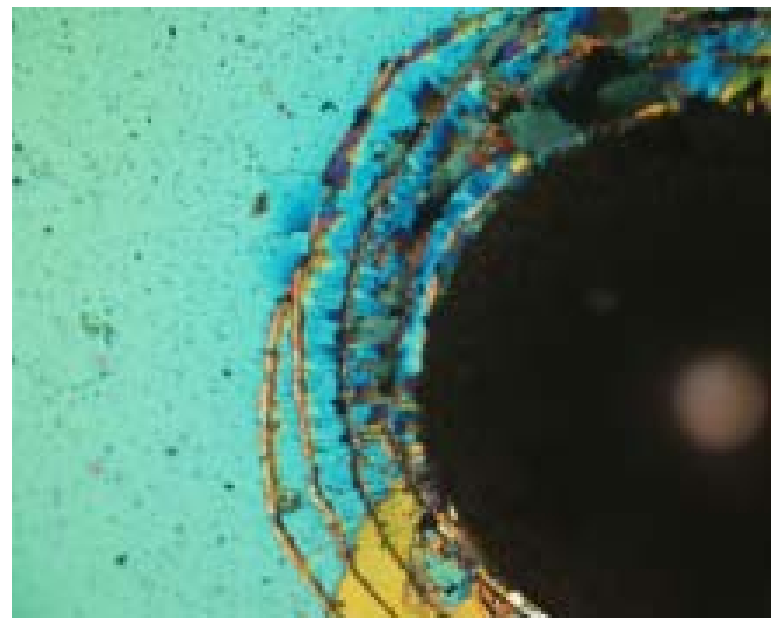

(c) Run \#461 Ti/TiBN Multilayer

Figure 37. Mercedez Test Results for Boron Based Coatings: (a) Run \#386 Ti/TiB 2 , (b) Run \#460 Ti/TiB 2 Multilayer and (c) Run \#461 Ti/TiBN Multilayer. 


\section{Nano Hardness Testing}

The Nano-Hardness tester uses an already established method where an indenter tip with a known geometry is driven into a specific site of the material to be tested, by applying an increasing normal load. When reaching a pre-set maximum value, the normal load is reduced until partial or complete relaxation occurs. This procedure is performed repetitively; at each stage of the experiment the position of the indenter relative to the sample surface is precisely monitored with a differential capacitive sensor.

A nano indenter at Microphotonics, Inc., Irvine, CA was used for hardness and Young's Modulus measurements of the coatings. For each loading/unloading cycle, the applied load value is plotted with respect to the corresponding position of the indenter. The resulting load/displacement curves provide data specific to the mechanical nature of the material under examination. Established models are used to calculate quantitative hardness and modulus values for such data. The indentation parameters used for these tests are shown in Table 6.

Table 6. Test Conditions and Procedure

\begin{tabular}{|l|l|}
\hline Maximum force $(\mathrm{mN})$ & 5 \\
Maximum depth $(\mathrm{nm})$ & Not used \\
Loading rate $(\mathrm{mN} / \mathrm{min})$ & 10 \\
Unloading rate $(\mathrm{mN} / \mathrm{min})$ & 10 \\
Pause $(\mathrm{s})$ & 0 \\
Adjust Depth Offset & $1000 / 100 \%$ \\
Computation Method & Oliver \& Pharr \\
Poisson coefficient & 0.30 \\
Indenter type & Berkovich diamond B-C43 \\
\hline
\end{tabular}

The measured values of Hardness and Young's modulus for the sample as well as the penetration depth $(\Delta \mathrm{d})$ are tabulated below together with their averages and standard deviations. Table 7 presents a summary of the results. Hardness in $\mathrm{TiC}+\mathrm{C}$ coatings has been found to be inversely correlated with $\mathrm{C}$ content, i.e., higher the $\mathrm{C}$ content, the lower the hardness. In general, harder films are obtained for $\mathrm{C}$ concentrations slightly higher than that of TiC films. Doping of $\mathrm{B}$ using $\left(\mathrm{CH}_{3}\right) \mathrm{B}$ gas in the discharge makes the film harder (Run \#676).

Table 7. Nano Indentation Results

\begin{tabular}{|l|c|c|c|}
\hline $\begin{array}{c}\text { TiC+C } \\
\text { Coatings }\end{array}$ & $\begin{array}{c}\text { Hv } \\
\text { [ Vickers ] }\end{array}$ & $\begin{array}{c}\mathrm{H} \\
\text { [ MPa ] }\end{array}$ & $\begin{array}{c}\mathrm{E} \\
\text { [ GPa ] }\end{array}$ \\
\hline Run \# 425 & 2446 & 26397 & 278.20 \\
Run \# 426 & 1408 & 15188 & 151.95 \\
Run \# 427 & 511 & 5519 & 40.23 \\
Run \# 447 & 2401 & 25910 & 215 \\
Run \# 458 & 2436 & 26291 & 267 \\
Run \#676 & 2988 & 32254 & 484 \\
\hline
\end{tabular}




\subsubsection{Machining Tests}

The Machining experiments were all conducted at TechSolve Inc. based in Cincinnati, Ohio and at Stellram, at Nashville, Tennessee. TechSolve, formerly the Institute of Advanced Manufacturing Sciences (IAMS), was founded on December 29, 1982 as part of a regional effort to improve the competitiveness of manufacturing and related businesses in Ohio. Those credited with this initiative include the City of Cincinnati, the Greater Cincinnati Chamber of Commerce, The University of Cincinnati and large local industry. Stellaram is a leading carbide cutting tool manufacturer in North America.

\section{Experimental Evaluation}

Coatings were tested in face milling experiments at the Eugene Machining Laboratory of TechSolve Inc. The workpiece materials selected for the purpose were H13 die steel, Ti-6Al-4V titanium alloy, and A390 hypereutectic Al-Si alloy. A 3-axis vertical milling center, Tongil TNV-80 having a maximum speed of 8000 RPM, was used. The forces during the milling experiments were measured using a Kistler type piezo-electric dynamometer. The flank wear on the insert was periodically measured using an optical microscope. The selected tool life criterion was flank wear $0.375 \mathrm{~mm}$ (uniform) or $0.750 \mathrm{~mm}$ (maximum). The insert geometry used was CNMG 433 MR4 883 (IC $12.5 \mathrm{~mm}$, rake angle $6^{\circ}$, nose diameter $1.17 \mathrm{~mm}$ and clearance 00). It is a WC insert with 6\% cobalt. Tool holder used was KL2IR-1.5-CN4-0 with a diameter of 37.5 $\mathrm{mm}$ and a lead angle of zero degrees.

\section{Tongil TNV-80}

Tongil TNV-80 is a vertical machining center suitable for difficult cutting materials. Rigidity and precision is raised by applying $\varnothing 45 \mathrm{~mm}$ large girth ball screws. Some of the parameters for the machine are listed in Table 8.

Table 8. Machining Center Parameters

$\begin{array}{rr}\text { Machining Center: } & \text { Tongil TNV-80 } \\ \text { Type: } & \text { 3-Axis VMC } \\ \text { HPM Max: } & 20 \\ \text { Feed Max. ipm: } & 8,000 \\ \text { Travel XYZ Limit, in.: } & 158 \\ \text { Coolant Tank, gallons: } & 30 \times 20 \times 15 \\ \text { Tooling: } & \text { 40BT 30 Tool (ATC) }\end{array}$

\section{Cutter Body}

The cutter body used was Kennametal KL 21R 15 CN 4-0 (Figure 38). Kennametal has been a leader in the industry in making tooling systems for metal cutting purposes. The particular cutter used is 1.5 inch in diameter with a 2-pocket body. It has a zero degree lead angle, a-11 degree radial rake and -5 degree axial rake. Some of the other critical parameters associated with the cutter body are given in the table below. 


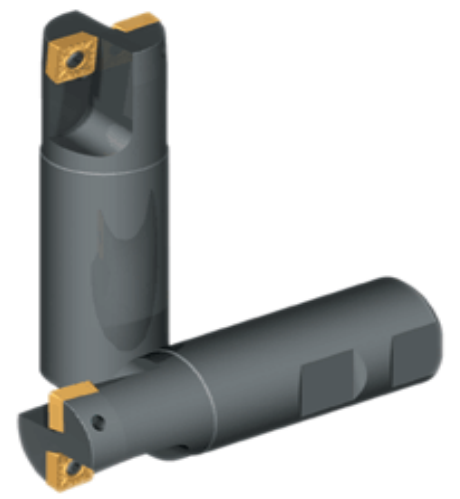

$\begin{array}{ll}\text { D } & 0.7500 \\ \text { 1/MIN } & 6000 \\ \text { Ibs. } & <2.00 \\ \text { insert 1 } & \text { CNM_43 } \\ \text { Ap1 max } & 0.4740 \\ \text { D1 } & 2.0000 \\ \text { L2 } & 1.7500 \\ \text { D2 } & 2.0000 \\ \text { D1 max } & 2.0000 \\ \text { Z U } & 3 \\ \text { Z } & 3 \\ \text { Z ADJ } & 0 \\ \text { L } & 3.7800 \\ \text { LS } & 2.0300\end{array}$

Figure 38. Cutter Body and Cutter Parameters.

The followings are descriptions for the coatings tested (Table 9):

Table 9. Coatings Tested for Machining

\begin{tabular}{|l|l|l|l|}
\hline \multicolumn{1}{|c|}{ Code } & \multicolumn{1}{c|}{ Coating Material } & Thickness (microns) & \multicolumn{1}{c|}{ Description } \\
\hline 461 & TiAlN/TiBN & & $\begin{array}{l}\# 549 \text { is a TiAlN and Yttrium } \\
\text { oxide multilayer coating }\end{array}$ \\
\hline $546 \sim 549$ & $\begin{array}{l}\text { Yttrium based } \\
\text { coatings }\end{array}$ & & \\
\hline 675 & TiBN & $\sim 3$ & TiN $\sim 0.4$, TiBN $\sim 0.6$ \\
\hline 676 & TiBN/TiN & layer stacking \\
\hline $\begin{array}{l}\text { Balzers coatings B1-X, B2-N: the X stands for Xtreme and is a single layer graded TiAlN } \\
\text { coating whereas N stands for nano and is a nanolayered TiN/TiAlN coatings }\end{array}$ \\
\hline
\end{tabular}

\section{Force Measurement}

The force was measured using Kistler type dynamometer (Figure 39). Kistler's stationary dynamometer is the work-horse of multi-component force measurement. Its main applications are the measurement of cutting forces, ground reaction forces (in biomechanics), wheel forces and impact forces. Kistler is a Korean company involved in making pressure and force measurement systems besides a lot of other automotive and aerospace parts. It has separate cutting force measurement system for different cutting processes like turning, milling, grinding and drilling. All the instruments have great rigidity, high natural frequency and a very high resolution. The particular instrument used in this case was 9257-B, a 3-Component Dynamometer. 


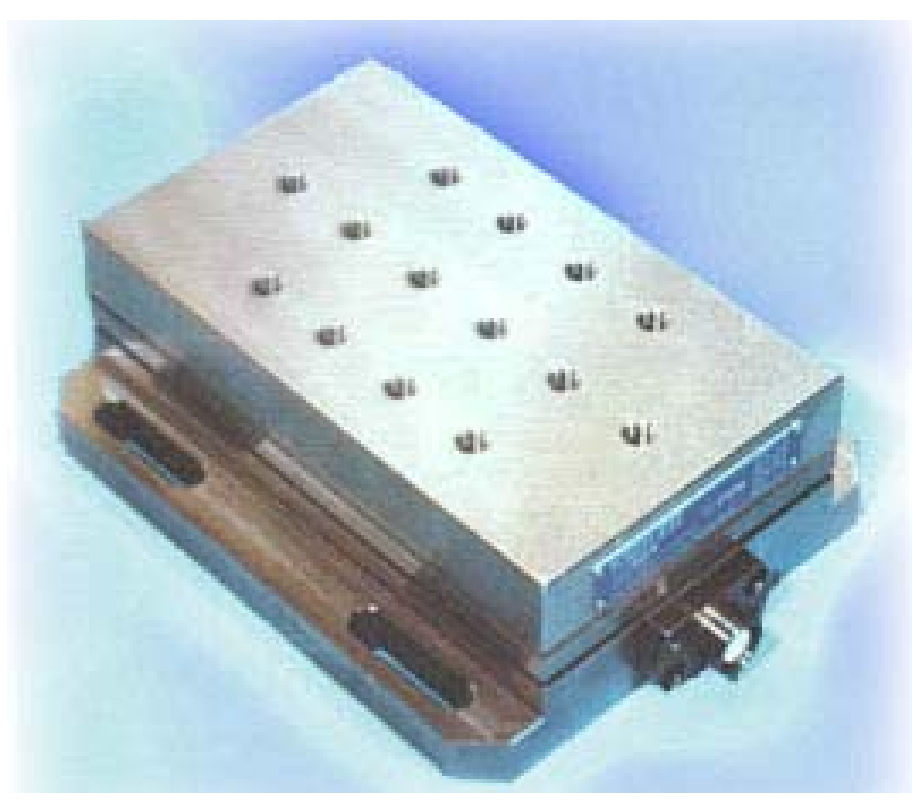

Figure 39. Kistler's Stationary Dynamometer.

\section{Insert Type}

The insert used for applying coatings CNMG 433 MR4 883. It is a cemented carbide insert composed of WC/Co and manufactured by Seco Carboloy. This insert is ideal for roughing hot-strength super alloys. The insert used for applying coatings CNMG 433 MR4 883. It is a cemented carbide insert composed of WC/Co and manufactured by Seco Carboloy. This insert is ideal for roughing hot-strength super alloys. Some of the important parameters related to this insert are listed in Table 10.

Table 10. CNMG 433 MR4 Parameters

\begin{tabular}{|c|c|c|c|c|}
\hline Size & I.C (in) & S (in) & h (in) & $r_{\epsilon}$ \\
\hline 43 & $1 / 2$ & $3 / 16$ & .203 & $1 / 64-1 / 16$ \\
\hline
\end{tabular}

\subsubsection{End Milling Of AISI H13}

The two workpieces selected for the purpose were: 1) block 1 with $257.175 \mathrm{~mm}$ length, $114.3 \mathrm{~mm}$ thickness, and $123.825 \mathrm{~mm}$ width and, 2) block 2 with $257.175 \mathrm{~mm}$ length, 79.375 $\mathrm{mm}$ thickness, and $131.233 \mathrm{~mm}$ width.

Tables 11 to 13 list the measurement from the tested inserts. $7 \%$ cimperial coolant was used during the experiment. Depth of cutter in radial and axial direction are 0.75 in and 0.03 inch respectively. Only 1 insert is on the cutter. There are 3 cutting speed used in the experiment, 250, 350 and 450 SFPM. Uniform wear and maximum were measured for evaluate the coating performance during cutting process. 
Table 11. Wear data for cutting speed of 250 SFPM (RPM=673), feed rate: IPT=0.008; $\mathrm{IPM}=5.092$

\begin{tabular}{|c|c|c|c|}
\hline No of passes & Total time $(\mathrm{sec})$ & Wear Uniform & Max Wear \\
\hline \multicolumn{4}{|l|}{ Insert 883} \\
\hline 1 & 35 & 0.0027 & 0.0037 \\
\hline 5 & 175 & 0.015 & 0.046 \\
\hline & \multicolumn{3}{|c|}{ Insert chipped } \\
\hline \multicolumn{4}{|l|}{ Insert $675(\mathrm{TiBN})$} \\
\hline 1 & 35 & 0.0007 & 0.004 \\
\hline 5 & 175 & 0.0012 & 0.0085 \\
\hline 10 & 350 & 0.0026 & 0.0122 \\
\hline 20 & 700 & 0.0042 & 0.0151 \\
\hline 30 & 1050 & 0.0064 & 0.0171 \\
\hline 35 & 1225 & 0.0072 & 0.0187 \\
\hline 45 & 1575 & 0.0088 & 0.022 \\
\hline 55 & 1925 & 0.0108 & 0.037 \\
\hline 60 & 2100 & 0.012 & 0.046 \\
\hline 65 & 2275 & 0.083 & 0.083 \\
\hline & \multicolumn{3}{|c|}{ Insert chipped } \\
\hline \multicolumn{4}{|l|}{ Insert 676(TiBN/TiN) } \\
\hline 1 & 35 & 0.001 & 0.0021 \\
\hline 5 & 175 & 0.00175 & 0.0035 \\
\hline 10 & 350 & 0.0035 & 0.005 \\
\hline 20 & 700 & 0.007 & 0.01 \\
\hline 30 & 1050 & 0.0112 & 0.0132 \\
\hline 35 & 1225 & 0.015 & 0.02 \\
\hline & \multicolumn{3}{|c|}{ Insert chipped } \\
\hline \multicolumn{4}{|l|}{ Insert B1-X } \\
\hline 1 & 35 & 0.002 & 0.0034 \\
\hline 5 & 175 & 0.0038 & 0.0064 \\
\hline 10 & 350 & 0.0053 & 0.0083 \\
\hline 20 & 700 & 0.011 & 0.0115 \\
\hline 30 & 1050 & 0.015 & 0.0315 \\
\hline & \multicolumn{3}{|c|}{ Insert chipped } \\
\hline \multicolumn{4}{|l|}{ B2-N } \\
\hline 1 & 35 & 0.0025 & 0.0036 \\
\hline 5 & 175 & 0.0062 & 0.0088 \\
\hline 10 & 350 & 0.0084 & 0.0097 \\
\hline 20 & 700 & 0.0095 & 0.0123 \\
\hline 30 & \multirow{2}{*}{\multicolumn{3}{|c|}{ 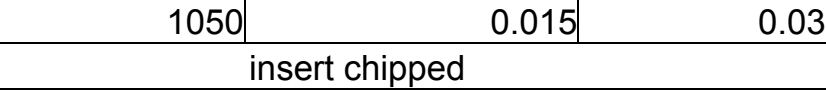 }} \\
\hline & & & \\
\hline
\end{tabular}

Figure 40 represents tool life for different coatings during milling tests for cutting speed of 250 SFPM., while Figure 41 shows the progression of wear at the same cutting speed. 


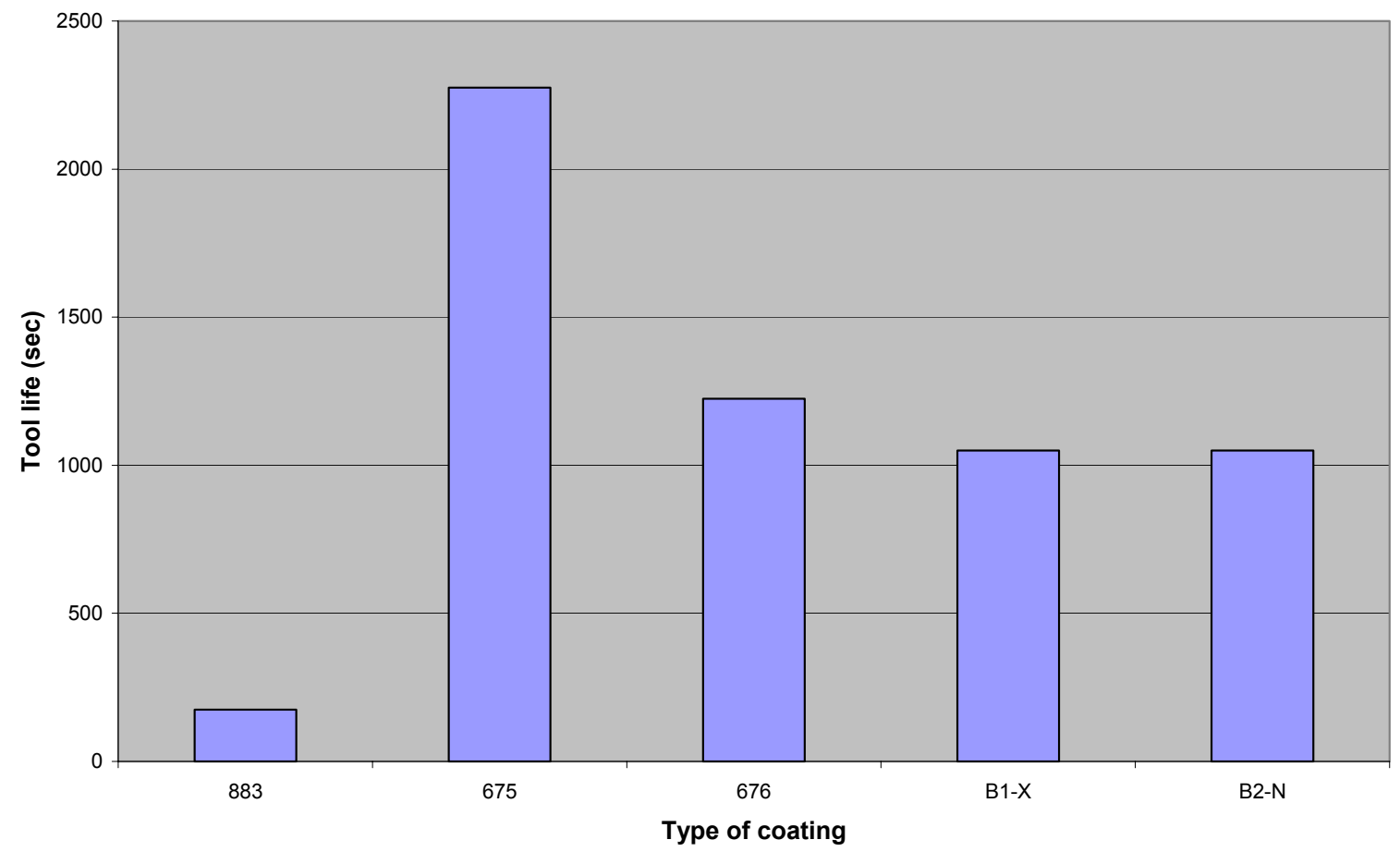

Figure 40. Tool lives of different coatings during experiments (250 SFPM (RPM=673), feed rate: $\mathrm{IPT}=0.008 ; \mathrm{IPM}=5.092$ ).

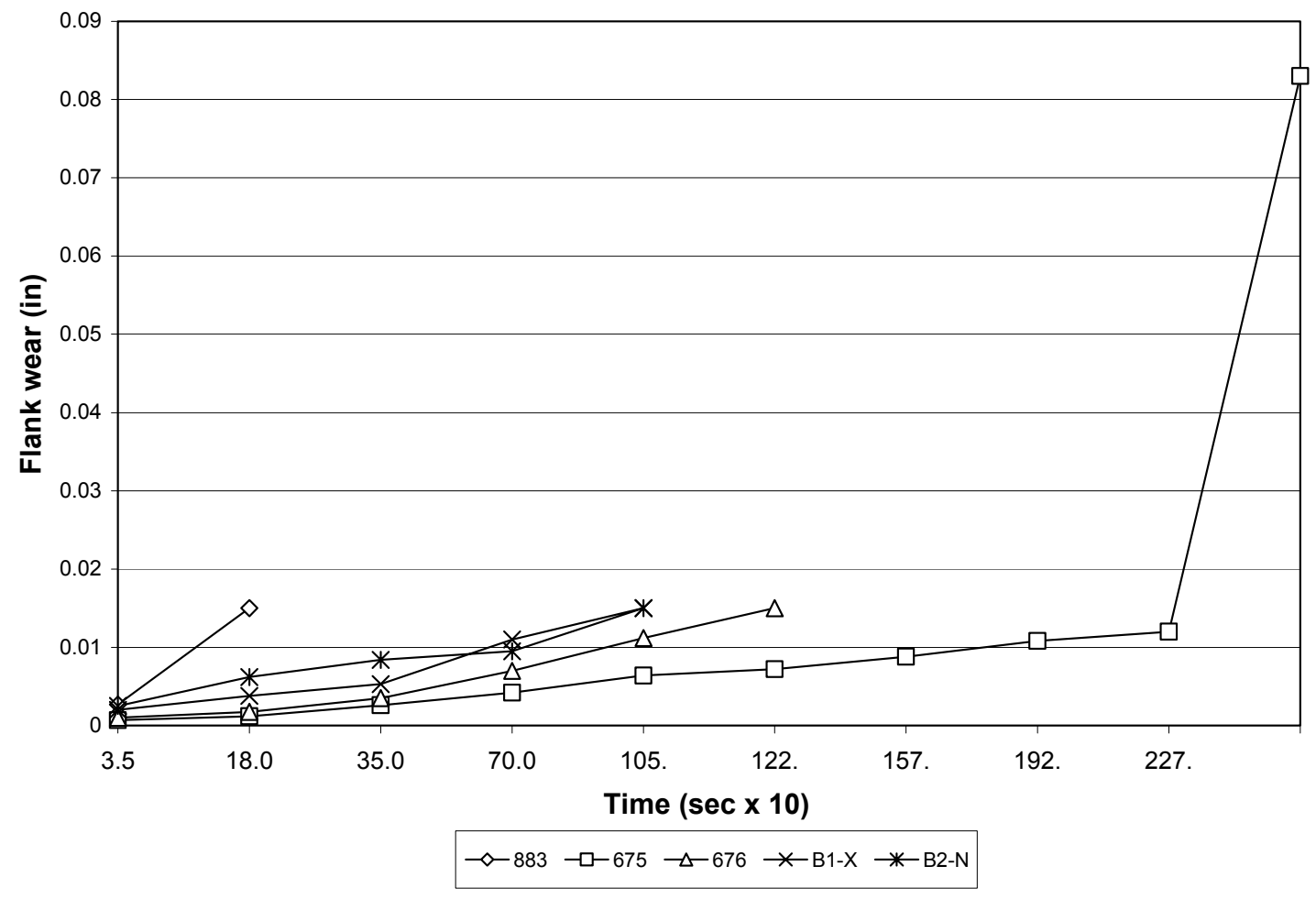

Figure 41. Progression of wear at cutting speed of 250 SFPM (feed rate: IPT $=0.008$; $\mathrm{IPM}=5.092$ ). 
Table 12. Wear data for cutting speed of 350 SFPM $(\mathrm{RPM}=891)$, feed rate: IPT=0.008; IPM=7.13

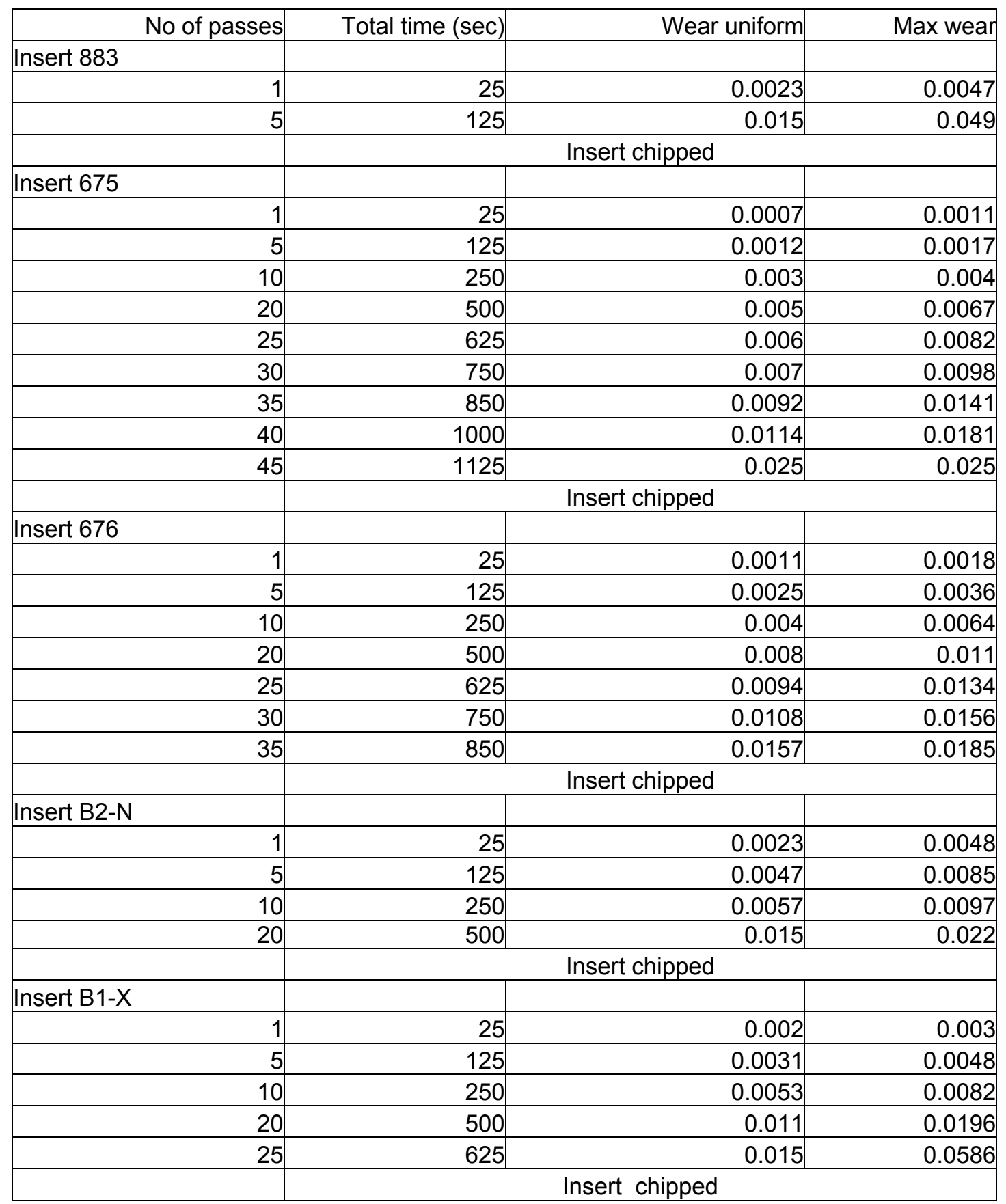

Figure 42 represents tool life for different coatings during milling tests for cutting speed of 350 SFPM., while Figure 43 shows the progression of wear at the same cutting speed. 


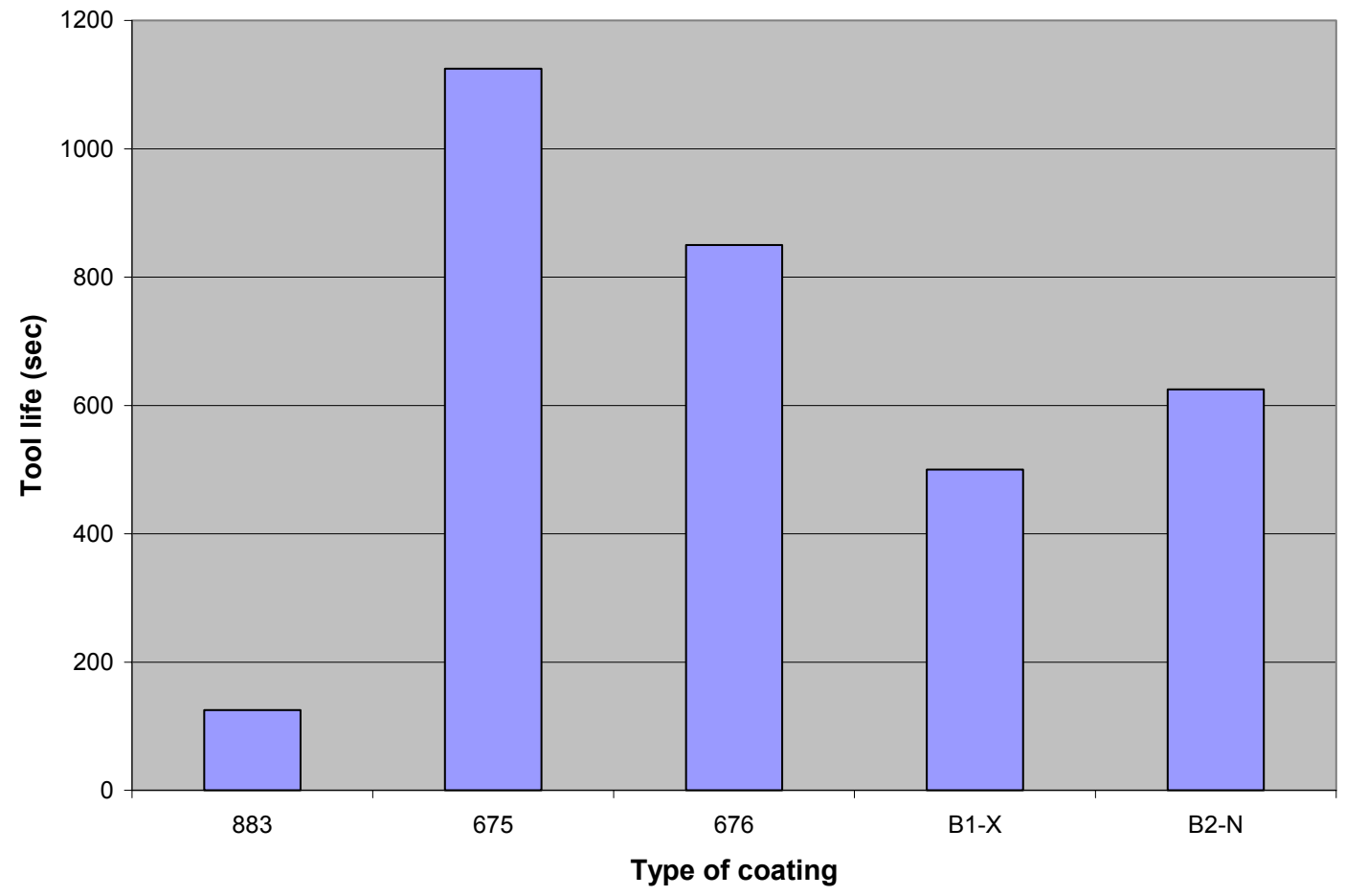

Figure 42. Tool lives of different coatings during experiments (350 SFPM (RPM=891), feed rate: $\mathrm{IPT}=0.008 ; \mathrm{IPM}=7.13$ ).

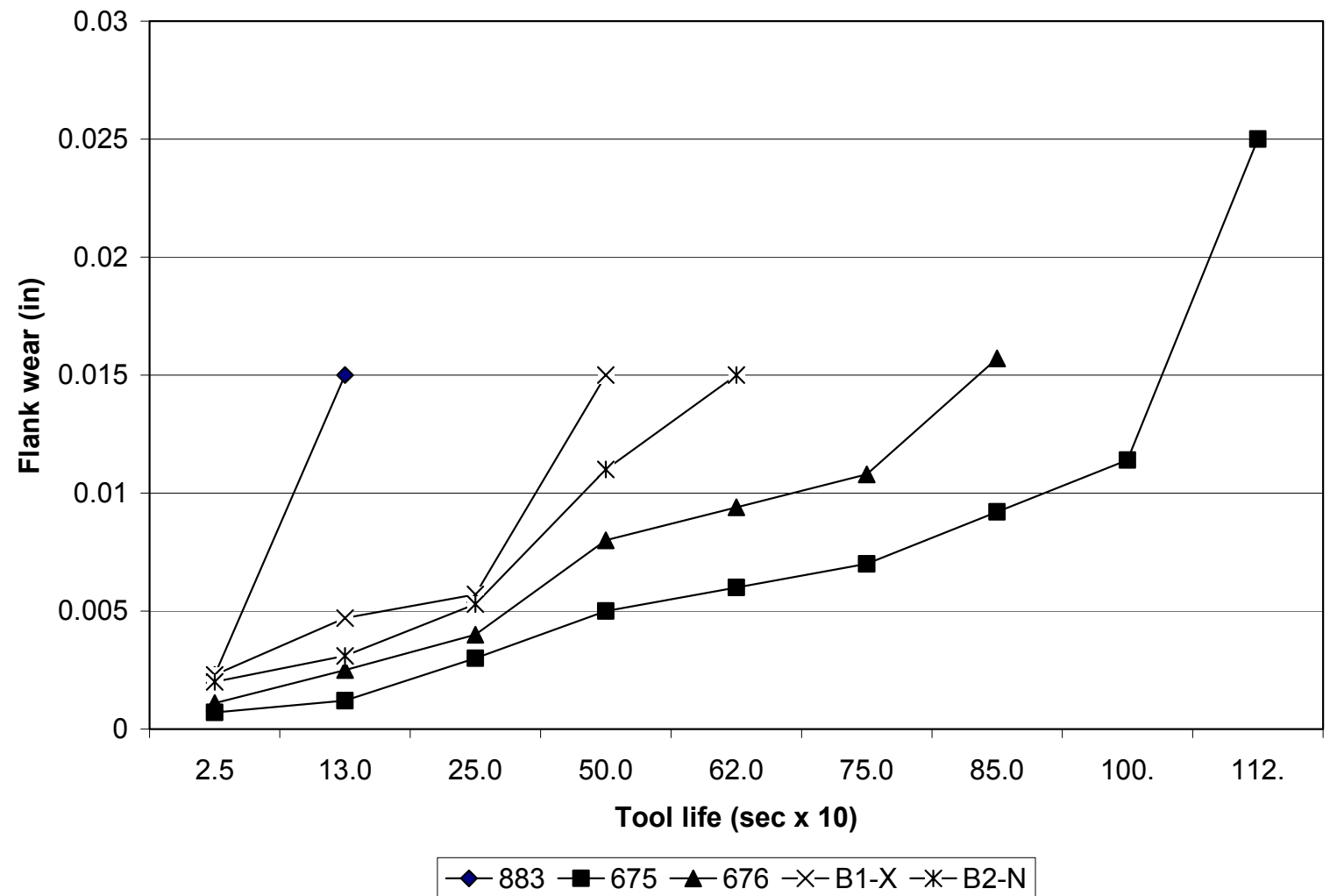

Figure 43. Progression of wear at cutting speed of 350 SFPM (feed rate: IPT=0.008; IPM=7.13). 
Table 13. Wear data for cutting speed of 450 SFPM $(\mathrm{RPM}=891)$, feed rate: IPT=0.008; $\mathrm{IPM}=9.166$

\begin{tabular}{|c|c|c|c|}
\hline No of passes & Total time(sec) & Wear uniform & Max wear \\
\hline \multicolumn{4}{|l|}{ Insert 883} \\
\hline 1 & & 00037 & 00065 \\
\hline 5 & 95 & 0.013 & 0.017 \\
\hline 7 & 133 & 0.02 & 0.023 \\
\hline & \multicolumn{3}{|c|}{ Insert chipped } \\
\hline \multicolumn{4}{|l|}{ Insert 675} \\
\hline 1 & 19 & 0.0008 & 0.0015 \\
\hline 5 & 95 & 0.0018 & 0.0025 \\
\hline 7 & 133 & 0.0022 & 0.0031 \\
\hline 10 & 190 & 0.0029 & 0.0044 \\
\hline 15 & 285 & 0.0041 & 0.0059 \\
\hline 20 & 380 & 0.0053 & 0.0075 \\
\hline 25 & 475 & 0.012 & 0.018 \\
\hline 30 & 570 & 0.094 & 0.094 \\
\hline & \multicolumn{3}{|c|}{ Insert chipped } \\
\hline \multicolumn{4}{|l|}{ Insert 676} \\
\hline 1 & 19 & 0.0007 & 0.0015 \\
\hline 5 & 95 & 0.0038 & 0.0066 \\
\hline 7 & 133 & 0.0049 & 0.0074 \\
\hline 10 & 190 & 0.006 & 0.008 \\
\hline 15 & 285 & 0.008 & 0.0103 \\
\hline 20 & 380 & 0.01 & 0.0127 \\
\hline 25 & 475 & 0.05 & 0.086 \\
\hline & \multicolumn{3}{|c|}{ Insert chipped } \\
\hline \multicolumn{4}{|l|}{ Insert B1-X } \\
\hline 1 & 19 & 0.0011 & 0.0021 \\
\hline 5 & 95 & 0.0027 & 0.0035 \\
\hline 7 & 133 & 0.004 & 0.0059 \\
\hline 10 & 190 & 0.0053 & 0.0082 \\
\hline 15 & 285 & 0.011 & 0.012 \\
\hline 20 & 380 & 0.0131 & 0.05 \\
\hline & \multicolumn{3}{|c|}{ Insert chipped } \\
\hline \multicolumn{4}{|l|}{ Insert B2-N } \\
\hline 1 & 19 & 0.0025 & 0.0037 \\
\hline 5 & 95 & 0.0035 & 0.0052 \\
\hline 7 & 133 & 0.0056 & 0.0085 \\
\hline 10 & 190 & 0.0078 & 0.0118 \\
\hline 15 & 285 & 0.0149 & 0.022 \\
\hline & \multicolumn{3}{|c|}{ Insert chipped } \\
\hline
\end{tabular}

Figure 44 represents tool life for different coatings during milling tests for cutting speed of 350 SFPM, while Figure 45 shows the progression of wear at the same cutting speed. 


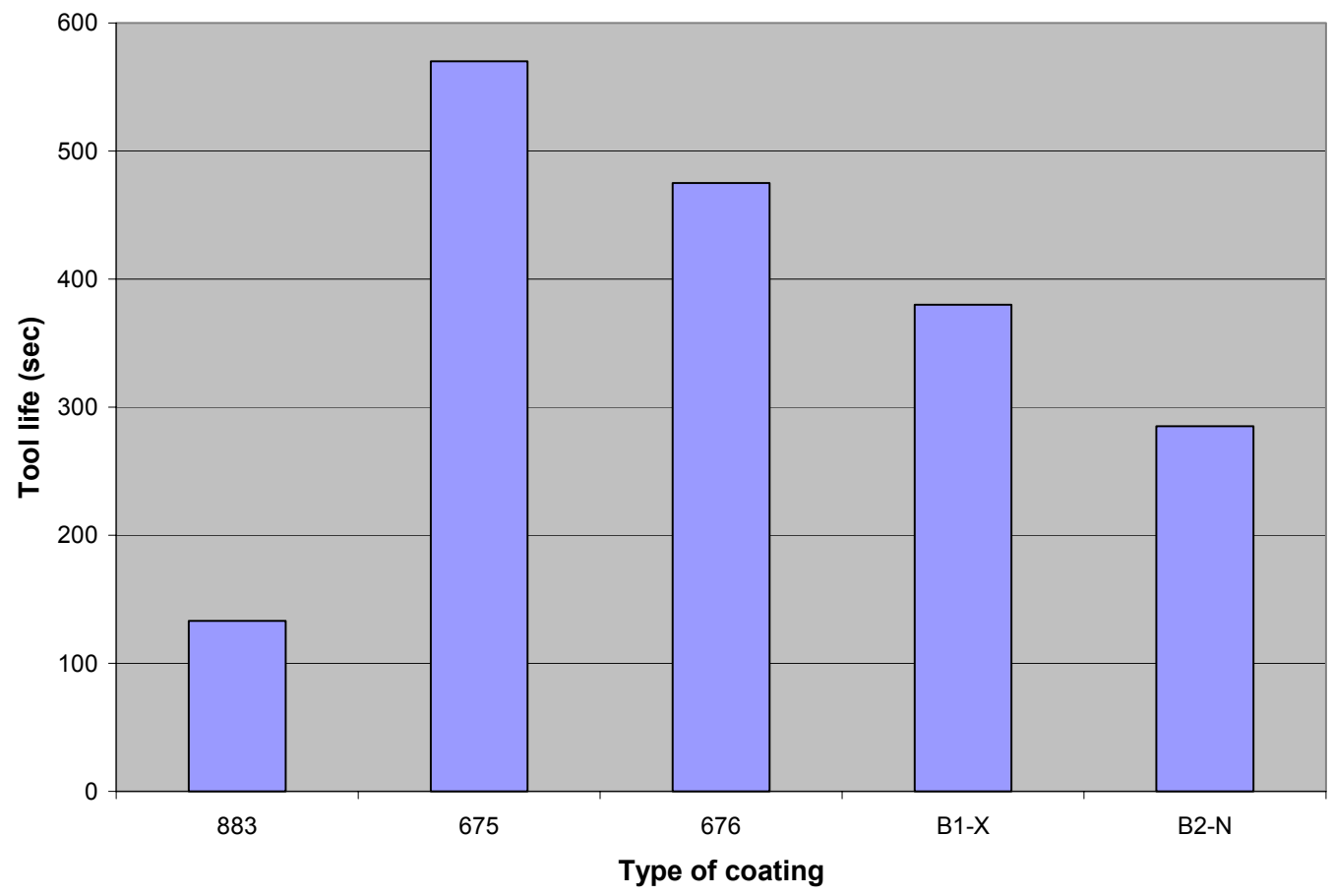

Figure 44. Tool lives of different coatings during experiments (450 SFPM (RPM=891), feed rate: $\mathrm{IPT}=0.008 ; \mathrm{IPM}=9.166$ ).

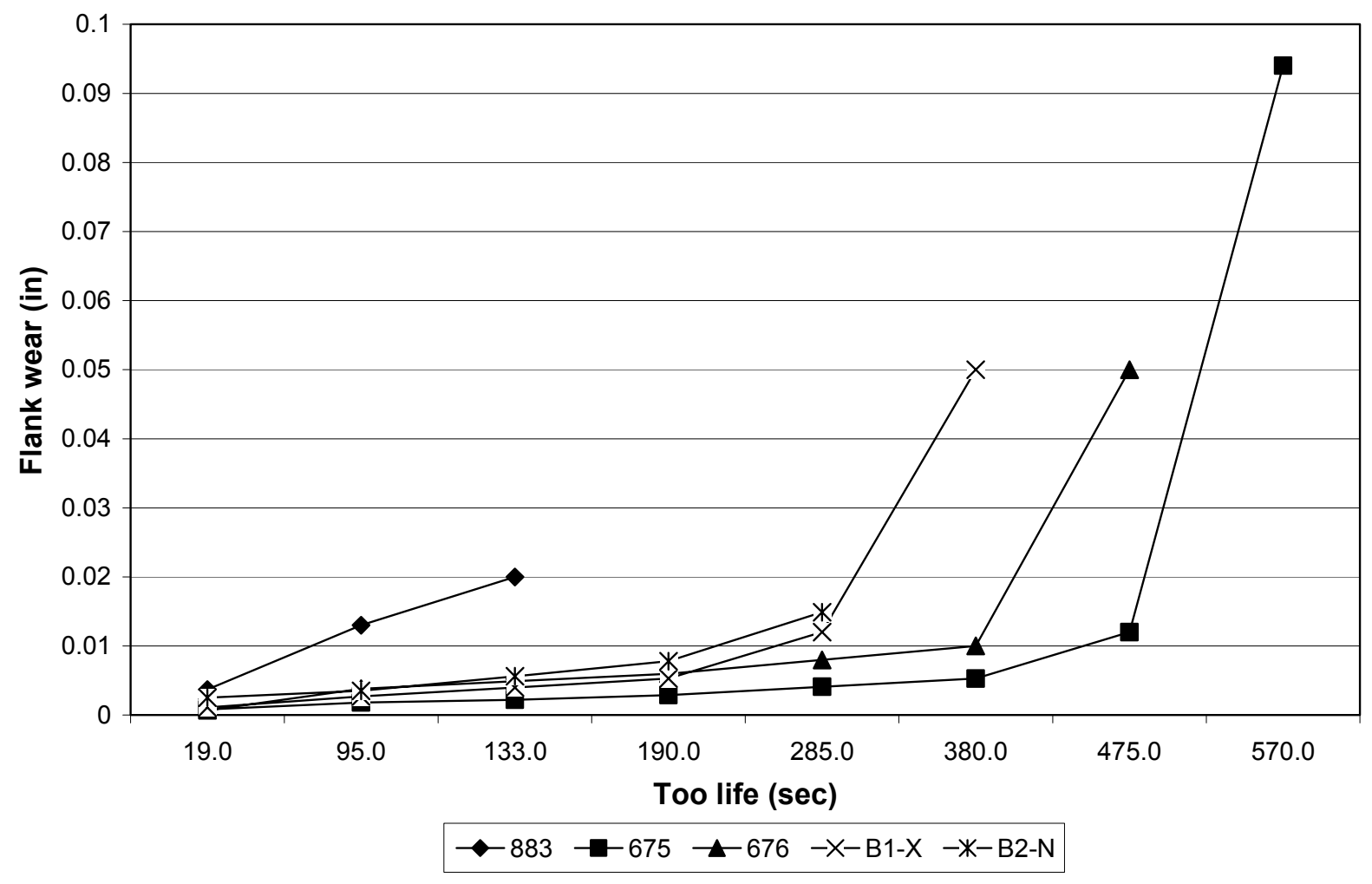

Figure 45. Progression of wear at cutting speed of 450 SFPM (feed rate: IPT=0.008; IPM=9.166). 
Based on the analysis of above experimental data, it is seen that in machining of AISI H13 the single-layer TiBN coating insert (\#675) provides the best performance to resist flank wear. Double-layer TiBN/TiN coating possesses good tool life next to the single-layer TiBN coating. Uncoated tool (\#833) provides the worst performance among all inserts tested. The possible reason may be that during machining of AISI H13, the flank wear in the cutting tool is of abrasive nature. This kind of wear is mainly dependant on the strength of the tool material. In other words, the flank wear of the cutting tool is mainly determined by the load capacity of the coating. Single layer of TiBN is thicker than TiBN in the double layer TiBN/TiN coating, i.e. the single layer TiBN is stronger than that in double layer TiBN/TiN coating. Therefore, the single layer TiBN coating possesses longer tool life. Once the coating is consumed, the tool substrate exposes to the workpiece material and wears out very quickly.

\subsubsection{End Milling of Ti-6Al-4V}

The material used was Ti-6Al-4V in the form of a rectangular bar of dimensions, 5 inch $\times$ 14 inch $\times 4$ inch. The insert used was CNMG 433 MR4 883, an uncoated tungsten carbide that uses cobalt as a binder. The cutter body used was KL2IR-1.5-CN4-0, with a lead angle of $0^{\circ}$. The coolant used for the face milling was $7 \%$ Cimperial.

Tables 14 to 17 list the measurement from the tested inserts. 7\% Cimperial coolant was used during the experiment. Depth of cutter in radial and axial direction are 0.75 in and 0.03 inch respectively. Only 1 insert is on the cutter. There are 3 cutting speeds used in the experiment: 120, 180, 240 and 300 SFPM. Uniform wear and Maximum wear were measured to evaluate the coating performance during cutting process. Figures 46 to 51 illustrate tool lives for different coatings and progression of wear of different coatings during the cutting processes. It can be seen from these figures that performance of coatings varies with cutting speeds. In other words, some coatings that present good resistance to flank wear at low cutting speed are not good at high cutting speeds. 
Table 14. Wear data for cutting speed of 120 SFPM $(\mathrm{RPM}=305)$, feed rate: IPT=0.008; IPM=2.44

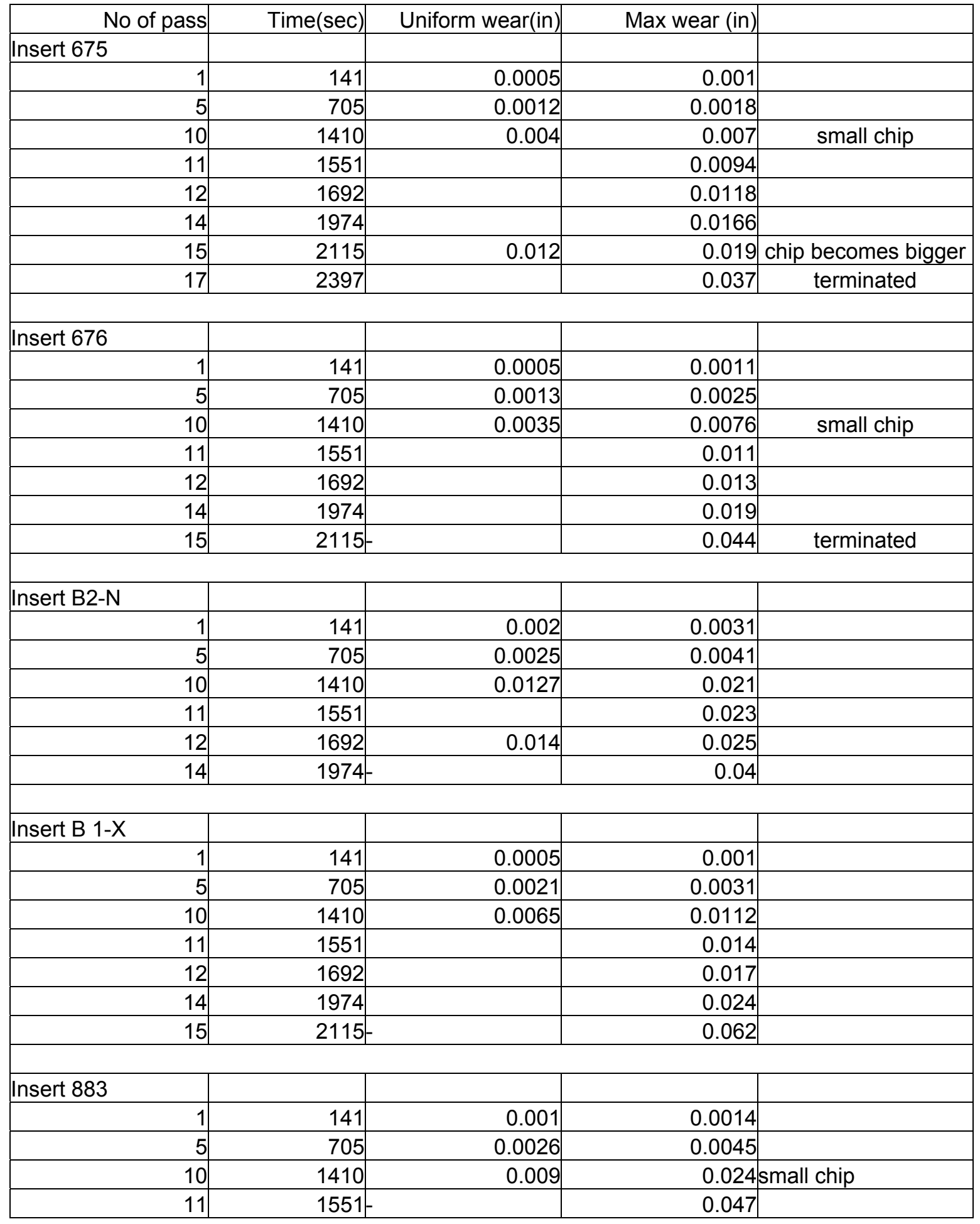




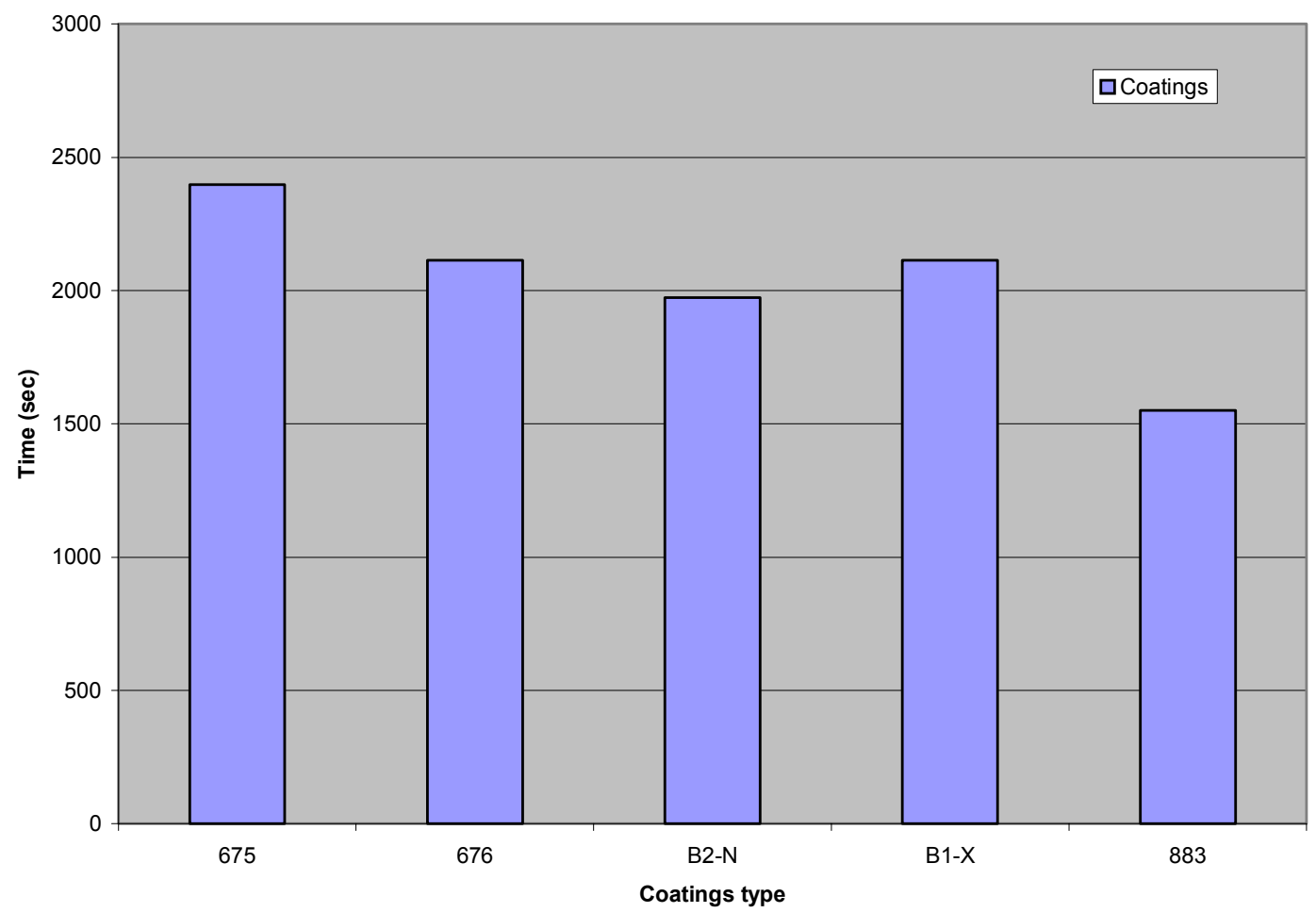

Figure 46. Tool lives of different coatings during experiments (120 SFPM (RPM=305), feed rate: $\mathrm{IPT}=0.008 ; \mathrm{IPM}=2.44$ ).

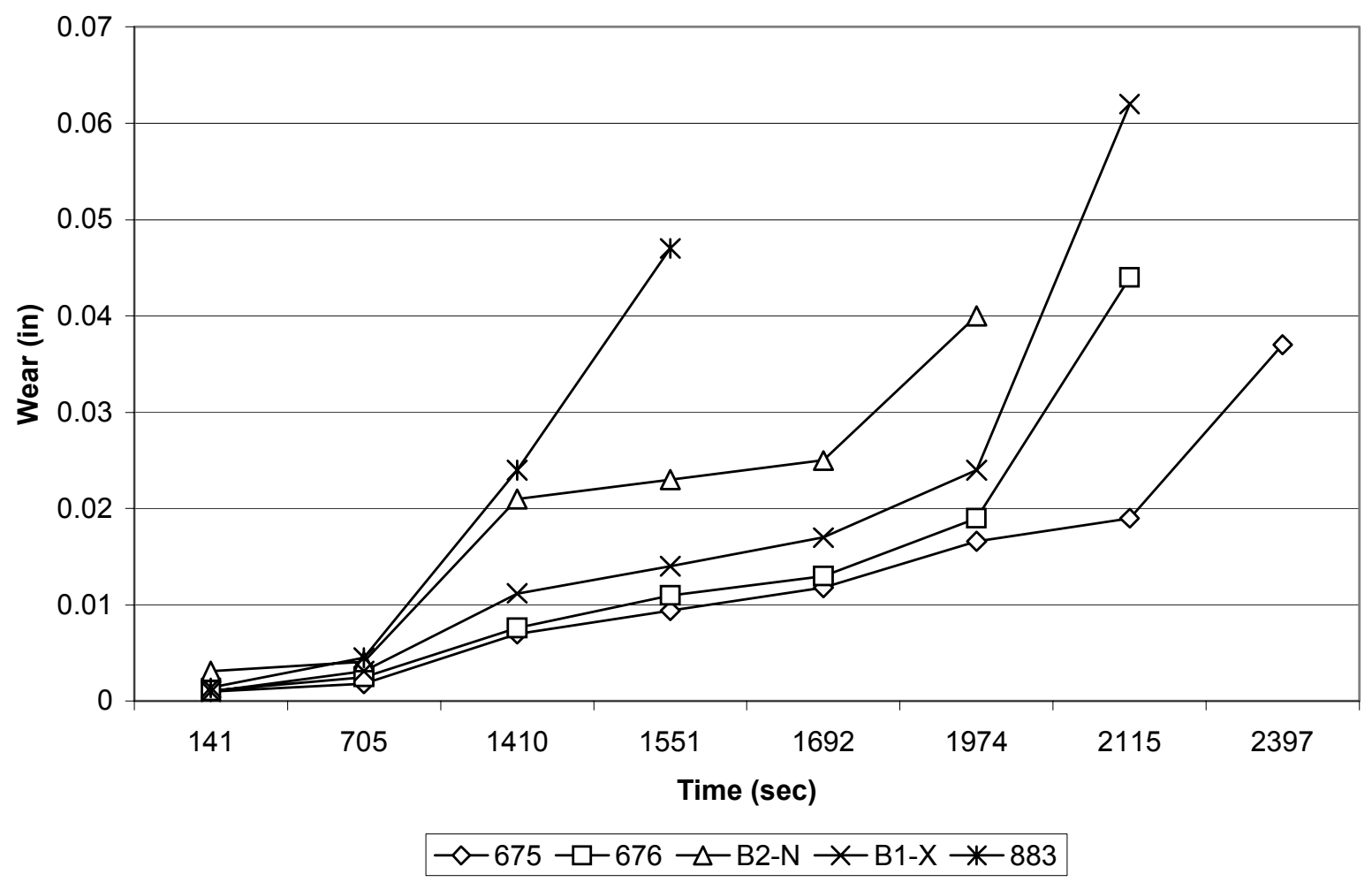

Figure 47. Progression of wear at cutting speed of 120 SFPM (feed rate: IPT=0.008; IPM=2.44). 
Table 15. Wear data for cutting speed of 180 SFPM (RPM=458), feed rate: IPT=0.008; IPM=3.664

\begin{tabular}{|c|c|c|c|}
\hline No of Passes & Time total (sec) & Uniform wear(in) & Max Wear(in) \\
\hline \multicolumn{4}{|l|}{ Insert 675} \\
\hline 1 & 94 & 0.001 & 0.0015 \\
\hline 5 & 470 & 0.0014 & 0.0023 \\
\hline 9 & & & 0.015 \\
\hline \multirow[t]{2}{*}{10} & $940-$ & & 0.041 \\
\hline & \multicolumn{3}{|c|}{ Insert chipped } \\
\hline \multicolumn{4}{|l|}{ Insert 676} \\
\hline & & & \\
\hline 1 & 94 & 0.0005 & 0.0011 \\
\hline 5 & 470 & 0.0021 & 0.0035 \\
\hline 9 & 846 & & 0.015 \\
\hline \multirow[t]{2}{*}{10} & 940 & & 0.051 \\
\hline & \multicolumn{3}{|c|}{ Insert Chipped } \\
\hline \multicolumn{4}{|l|}{ Insert B2-N } \\
\hline & & & \\
\hline 1 & 94 & 0.0026 & 0.0048 \\
\hline 5 & 470 & 0.0044 & 0.0101 \\
\hline 9 & 846 & & 0.025 \\
\hline \multirow[t]{2}{*}{10} & $940-$ & & 0.068 \\
\hline & \multicolumn{3}{|c|}{ Insert Chipped } \\
\hline \multicolumn{4}{|l|}{ Insert B1-X } \\
\hline & & & \\
\hline 1 & 94 & 0.0013 & 0.0017 \\
\hline 5 & 470 & 0.0096 & 0.0146 \\
\hline 9 & $846-$ & & 0.062 \\
\hline & \multicolumn{3}{|c|}{ Insert Chipped } \\
\hline \multicolumn{4}{|l|}{ Insert 883} \\
\hline & & & \\
\hline 1 & 94 & 0.001 & 0.0013 \\
\hline 5 & 470 & 0.006 & 0.008 \\
\hline 9 & 846 & & 0.023 \\
\hline \multirow[t]{2}{*}{10} & 940 & & 0.07 \\
\hline & \multicolumn{3}{|c|}{ Insert Chipped } \\
\hline
\end{tabular}




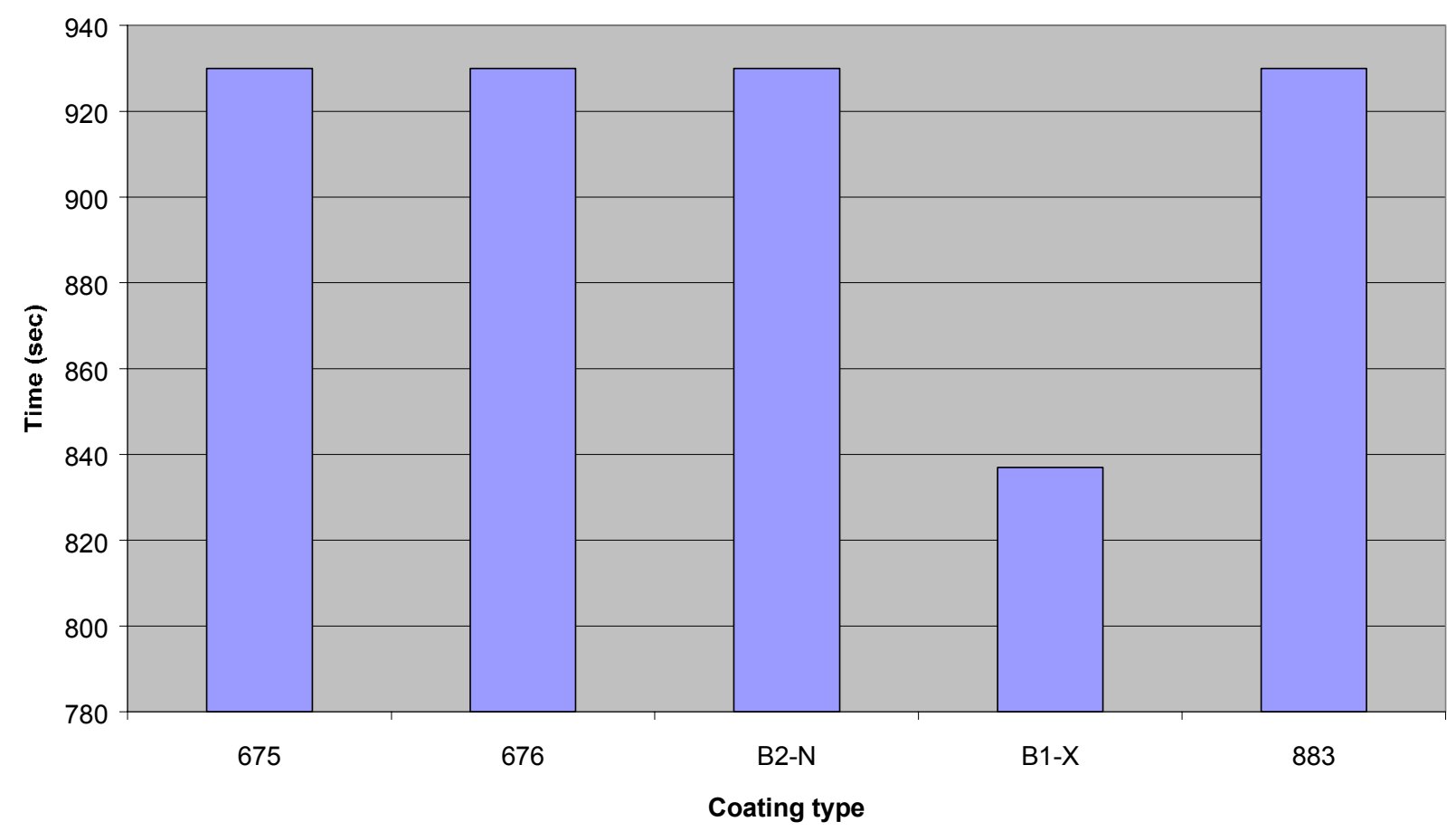

Figure 48. Tool lives of different coatings during experiments (180 SFPM (RPM=458), feed rate: $\mathrm{IPT}=0.008 ; \mathrm{IPM}=3.664$ ).

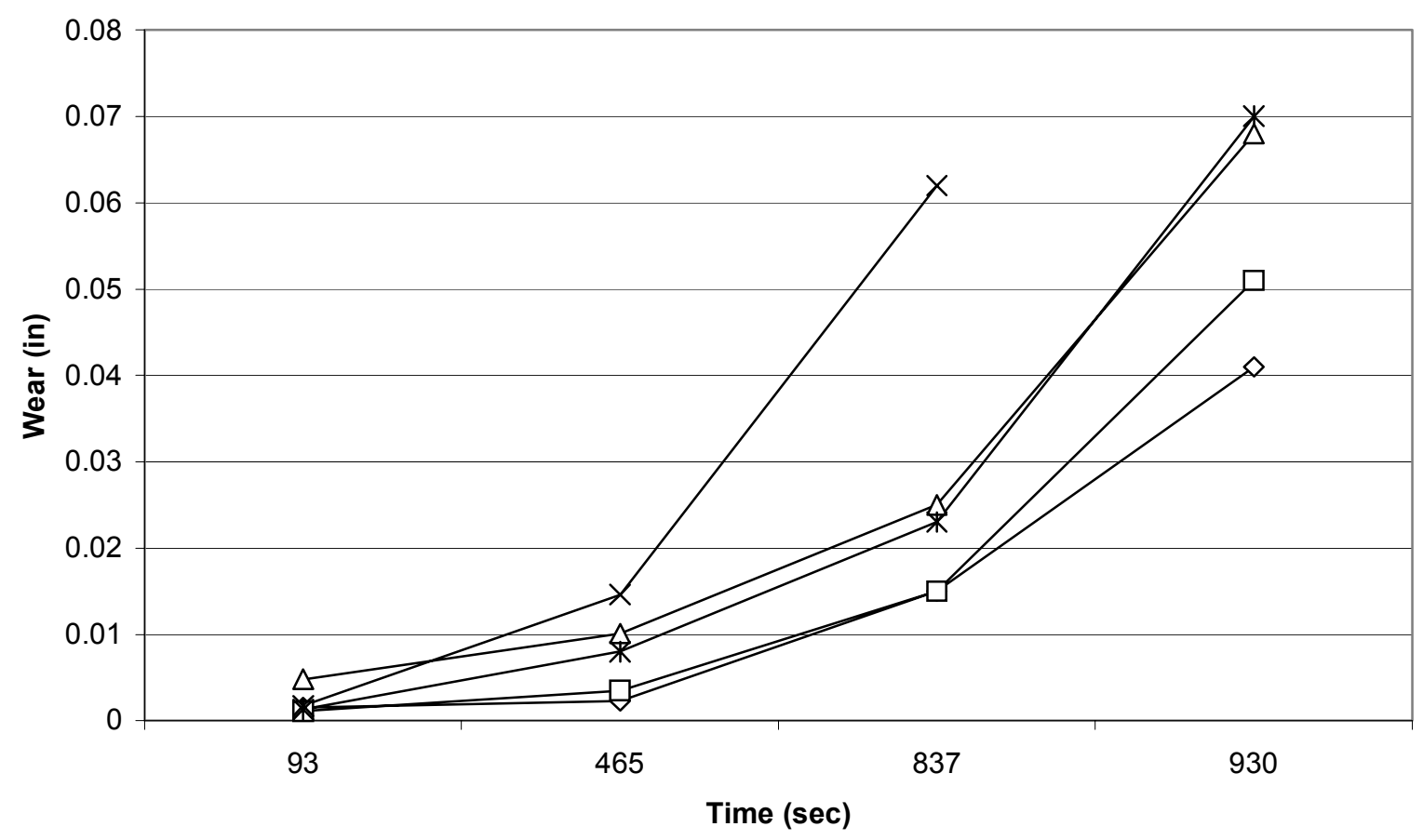

$\checkmark-675-\square-676-\triangle \mathrm{B} 2-\mathrm{N} \rightarrow \mathrm{B} 1-\mathrm{X} \rightarrow-883$

Figure 49. Progression of wear at cutting speed of 180 SFPM (feed rate: IPT $=0.008$; IPM=3.664). 
Table 16. Wear data for cutting speed of 240 SFPM (RPM=611), feed rate: IPT=0.008; $\mathrm{IPM}=4.884$

\begin{tabular}{|c|c|c|c|}
\hline No of passes & & \multirow[b]{2}{*}{ Uniform wear(in) } & \multirow[b]{2}{*}{ Max Wear(in) } \\
\hline Insert 675 & Total time(sec) & & \\
\hline 1 & 71 & 0.0012 & 0.0023 \\
\hline 5 & 355 & 0.009 & 0.015 \\
\hline 7 & 497- & & 0.071 \\
\hline & \multicolumn{3}{|c|}{ Insert Chipped } \\
\hline \multicolumn{4}{|l|}{ Insert 676} \\
\hline 1 & 71 & 0.0014 & 0.002 \\
\hline 5 & 355 & & 0.056 \\
\hline & \multicolumn{3}{|c|}{ Insert chipped } \\
\hline \multicolumn{4}{|l|}{ Insert B2-N } \\
\hline 1 & 71 & 0.0024 & 0.0033 \\
\hline 5 & 355 & 0.0062 & 0.0098 \\
\hline 7 & 497 & & 0.015 \\
\hline 8 & 568 & & 0.064 \\
\hline & \multicolumn{3}{|c|}{ Insert Chipped } \\
\hline \multicolumn{4}{|l|}{ Insert B1-X } \\
\hline 1 & 71 & 0.0014 & 0.0023 \\
\hline 5 & 355 & 0.016 & 0.019 \\
\hline 7 & 497 & & 0.025 \\
\hline 8 & 568 - & & 0.062 \\
\hline & \multicolumn{3}{|c|}{ Insert Chipped } \\
\hline \multicolumn{4}{|l|}{ Insert 883} \\
\hline & & & \\
\hline 1 & 71 & 0.002 & 0.0052 \\
\hline 3 & 213 & & 0.072 \\
\hline & & isert Chipped & \\
\hline
\end{tabular}

It can be observed from Figures 46 and 47 that at cutting speed of 120 SFPM single layer of TiBN coating provides the best resistance to flank wear. When cutting speed is increased to 180 SFPM, the single layer coating of TiBN, B2-N and double layer coating of TiBN/TiN as well as uncoated tungsten present the same resistance to flank wear. (Figures 48 and 49) 


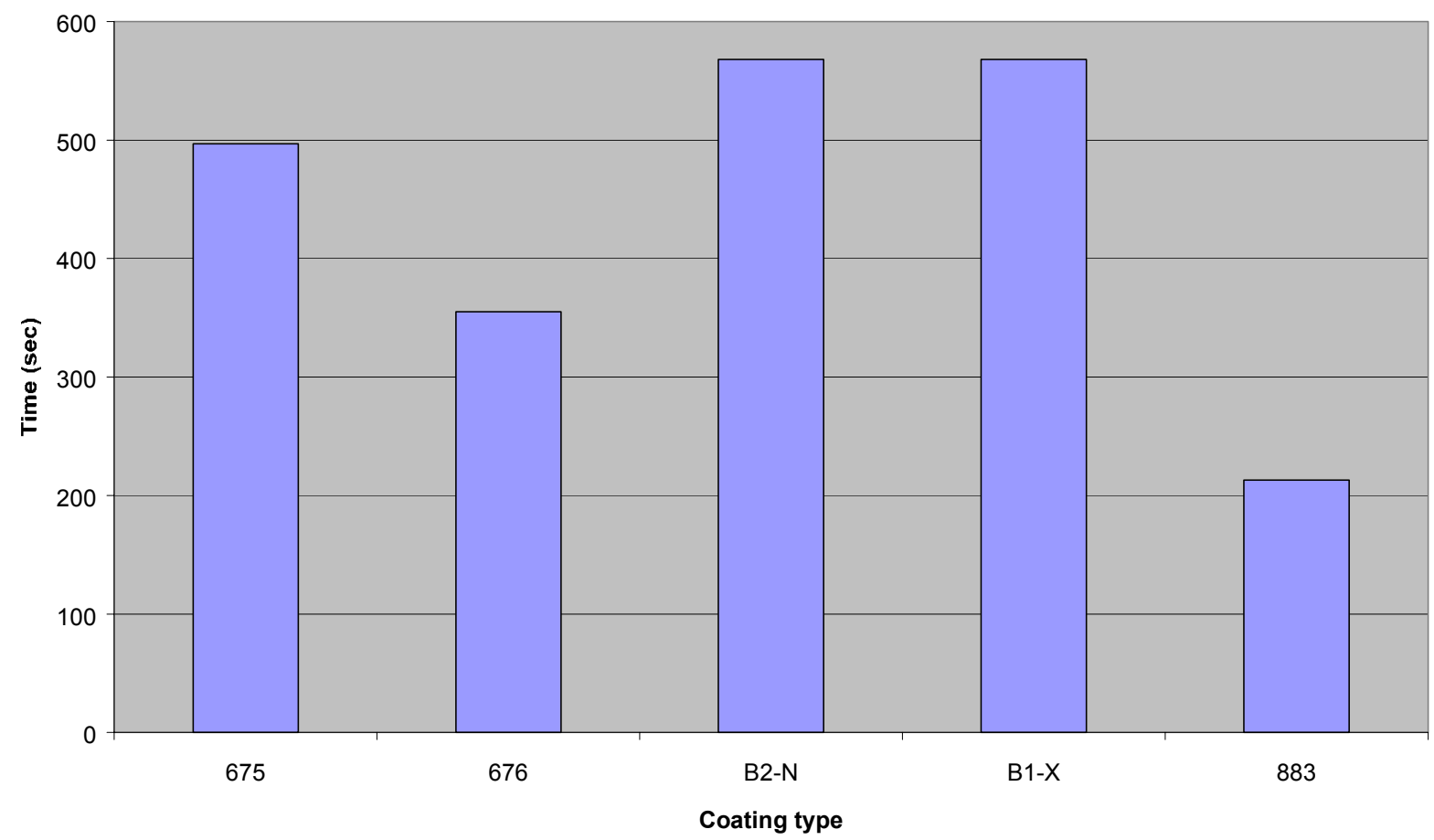

Figure 50. Tool lives of different coatings during experiments (240 SFPM (RPM=611), feed rate: $\mathrm{IPT}=0.008 ; \mathrm{IPM}=4.884$ ).

Progression of wear (Ti milling, $240 \mathrm{sfpm}$ )

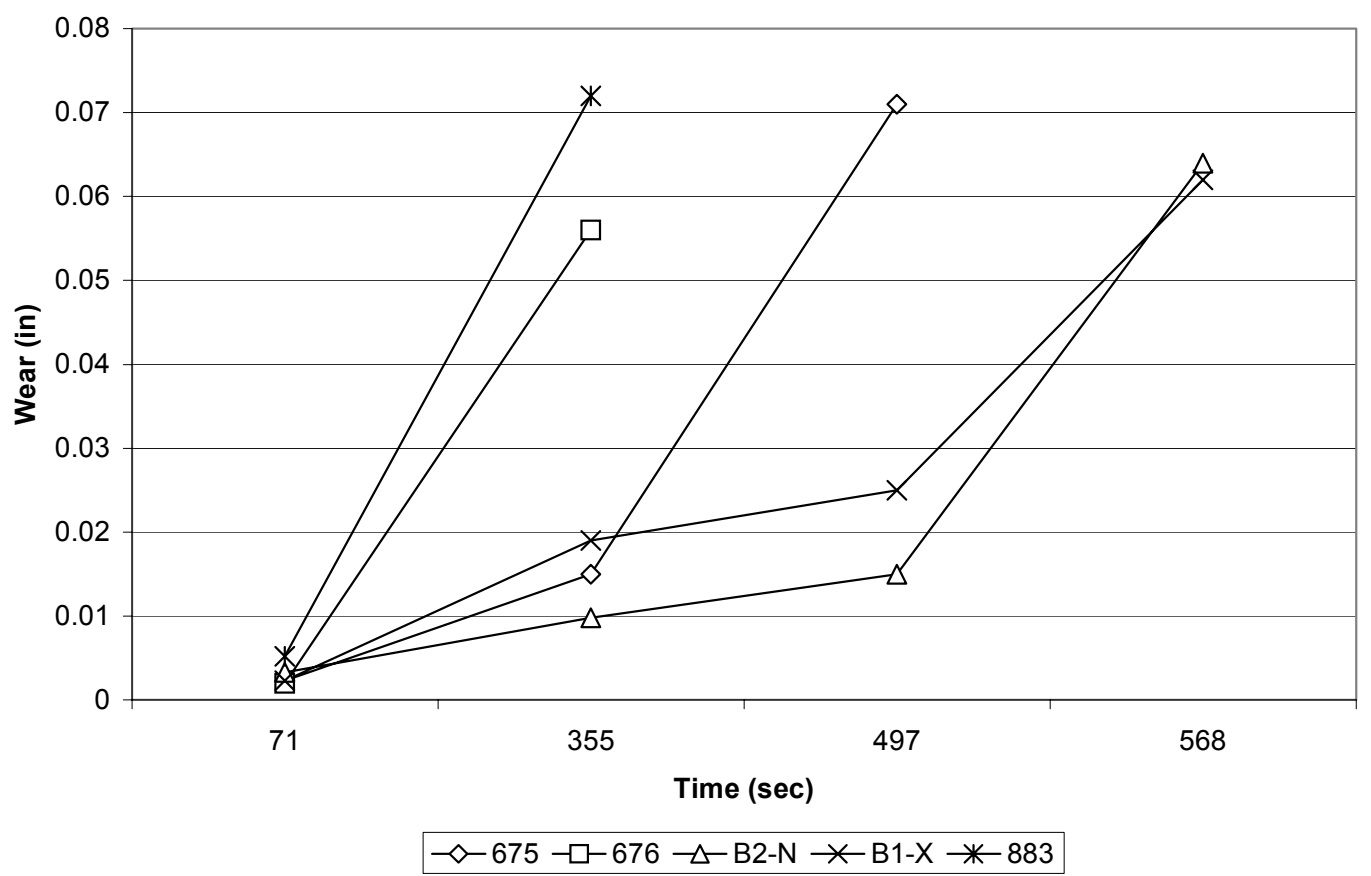

Figure 51. Progression of wear at cutting speed of 240 SFPM (feed rate: IPT=0.008; IPM=4.884). 
Table 17. Wear data for cutting speed of 300 SFPM $(\mathrm{RPM}=764)$, feed rate: IPT=0.008; $\mathrm{IPM}=6.11$

\begin{tabular}{|c|c|c|c|}
\hline No of pass & Time total(sec) & Wear uniform (in) & Max Wear(in) \\
\hline \multicolumn{4}{|l|}{ Insert 883} \\
\hline 1 & 57 & 0.005 & 0.0074 \\
\hline 2 & 114 & 0.01 & 0.0095 \\
\hline 3 & 171 & & 0.117 \\
\hline & \multicolumn{3}{|c|}{ Insert Chipped } \\
\hline \multicolumn{4}{|l|}{ Insert 675} \\
\hline 1 & 57 & 0.0029 & 0.0093 \\
\hline 2 & 114 & & 0.018 \\
\hline 3 & 171 & & 0.037 \\
\hline & \multicolumn{3}{|c|}{ Insert Chipped } \\
\hline \multicolumn{4}{|l|}{\begin{tabular}{|l|} 
Insert 676 \\
\end{tabular}} \\
\hline & & & \\
\hline 1 & 57 & 0.0056 & 0.013 \\
\hline 2 & 114 & & 0.041 \\
\hline & \multicolumn{3}{|c|}{ Insert Chipped } \\
\hline \multicolumn{4}{|l|}{ Insert B2-N } \\
\hline 1 & $57-$ & & 0.0186 \\
\hline 2 & $114-$ & & 0.062 \\
\hline & \multicolumn{3}{|c|}{ Insert Chipped } \\
\hline \multicolumn{4}{|l|}{ Insert B1-X } \\
\hline 1 & 57 & 0.0043 & 0.0071 \\
\hline 3 & $171-$ & & 0.127 \\
\hline & \multicolumn{3}{|c|}{ Insert Chipped } \\
\hline
\end{tabular}

Figures 52 and 53 show the tool life for different coatings and progression of wear of different coatings during the cutting processes. It is seen from these figures that uncoated tungsten carbides and single layer coating of TiBN exhibits good resistance to the flank wear during high speed machining of Ti-6Al-4V. The behavior of uncoated tungsten carbide in this observation is in good agreement with the published experimental results $[17,18]$. 


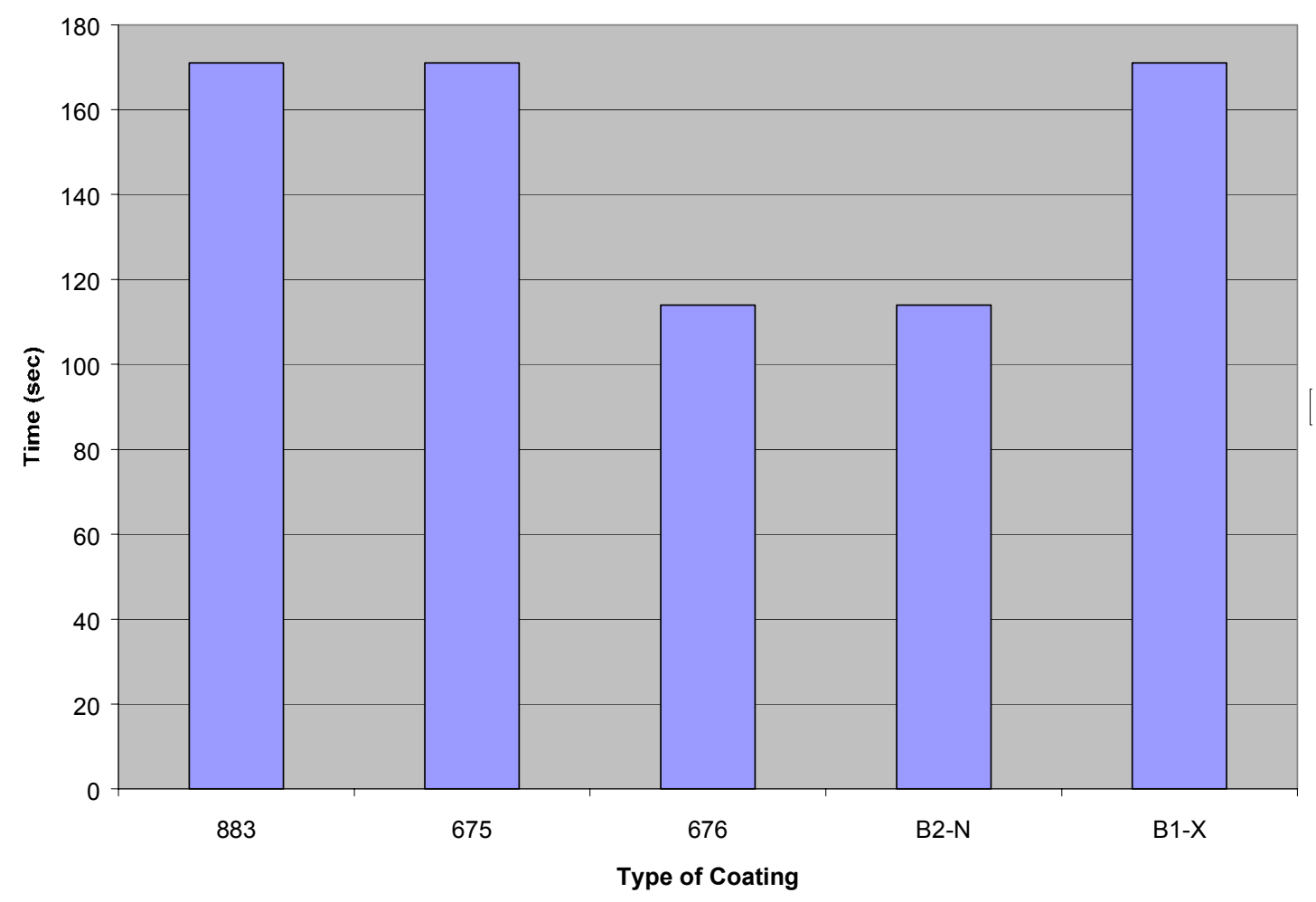

Figure 52. Tool lives of different coatings during experiments (300 SFPM (RPM=764), feed rate: $\mathrm{IPT}=0.008$; IPM=6.11).

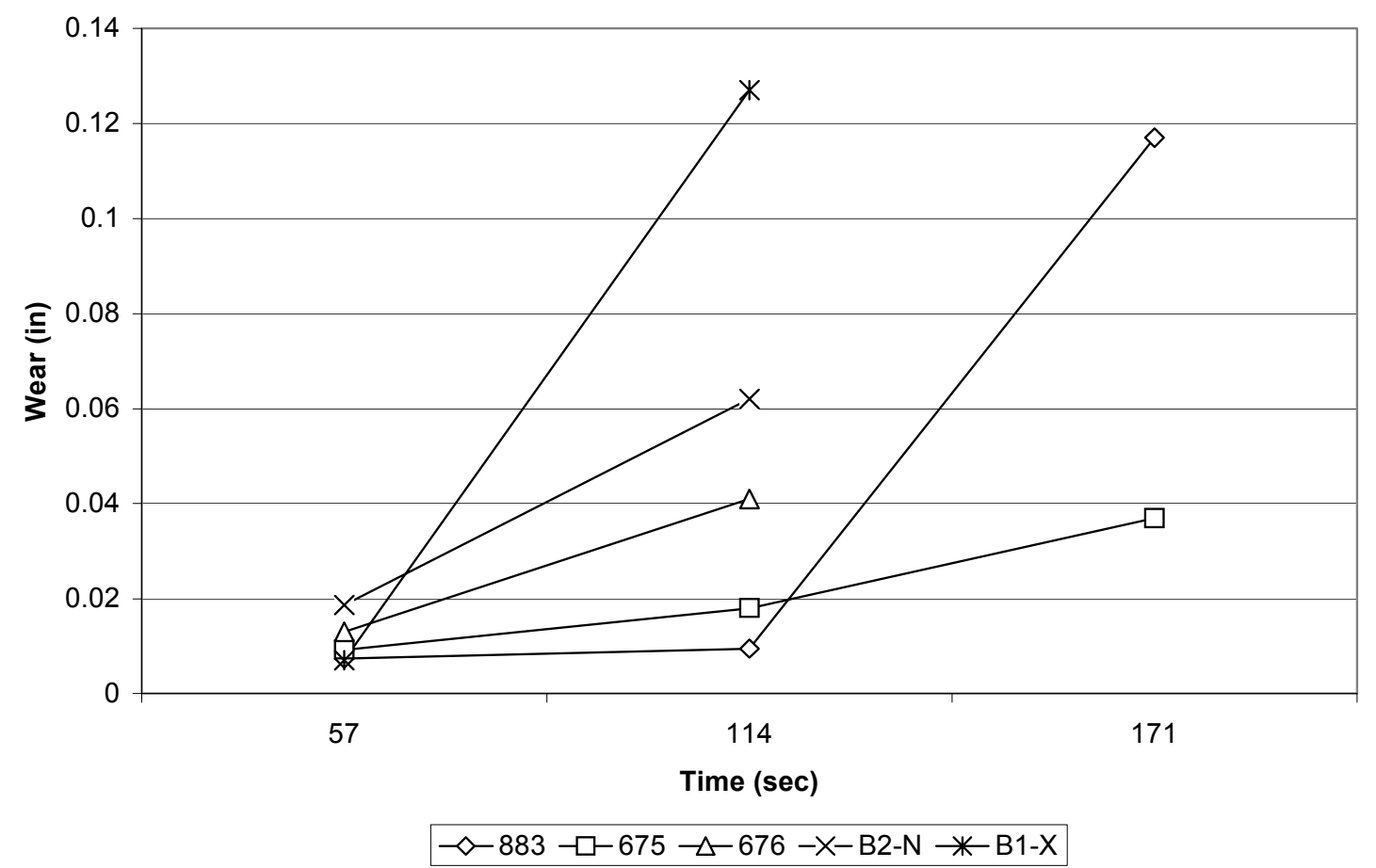

Figure 53. Progression of wear at cutting speed of 300 SFPM (feed rate: IPT=0.008; IPM=6.11). 


\subsubsection{End Milling of Al-Si Alloy}

The workpiece selected for the purpose was a rectangular bar $(25 \mathrm{~cm} \times 25 \mathrm{~cm} \times 20 \mathrm{~cm})$ of hypereutectic Al-Si alloy, A390 with 18\% silicon content. Figure 54 shows the optical images for the worn tool edges for the three coatings candidates. The optical images for the worn tool edges for the three coatings candidates were examined and found to be consistent with abrasive and adhesive modes of failure. However, at the higher cutting speed of 2600 SFPM, Figure 54, adhesion of aluminum at the tool surface was observed for the TiAlN coating, Figure 54c.

It was observed that both the coatings developed in this research performed better than the benchmark TiAlN coating. The relative performance of the coatings developed varied at two different speeds with multi-layer TiBCN performing better at $660 \mathrm{~m} / \mathrm{min}$ and $\mathrm{TiB}_{2}$ at $780 \mathrm{~m} / \mathrm{min}$.

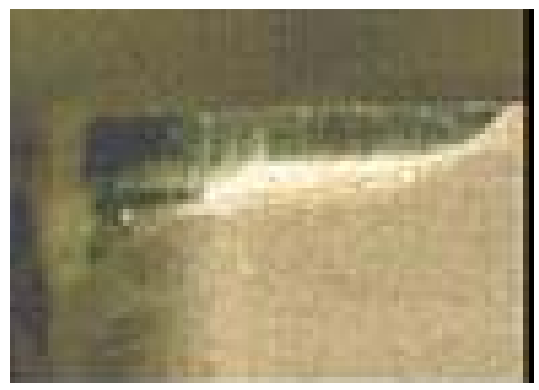

(a)

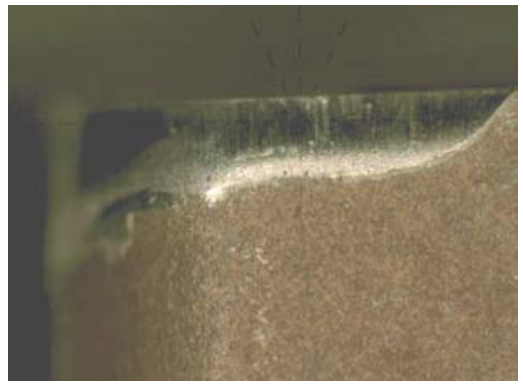

(b)

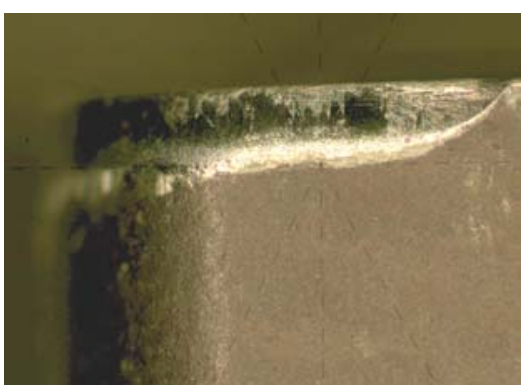

(c)

Figure 54. Worn out edges at 2600 SFPM: (a) $\mathrm{TiB}_{2}$, (b) TiBCN, and (c) TiAlN.

Tables 18 to 19 list the measurement from the tested inserts. $7 \%$ cimperial coolant was used during the experiment. Depth of cut 0.1 inch with 2 inserts on the cutter. There are 2 cutting speeds used in the experiment, 2200 and 2600 SFPM. Uniform wear and Maximum wear were measured to evaluate the coating performance during cutting process.

Figures 55 to 58 show the tool life and progression of wear of different coatings during end milling of Al-Si alloy at 2200 and 2600 SFPM. 
Table 18. Wear data for cutting speed of 2200 SFPM (RPM=5600), feed rate: IPT=0.01; IPM=112, 2 inserts on cutter

\begin{tabular}{|c|c|c|c|}
\hline No of passes & Total time (sec) & Uniform wear(in) & Max wear(in) \\
\hline \multicolumn{4}{|l|}{ Insert 549} \\
\hline 1 & 6 & 0.0018 & 0.0034 \\
\hline 5 & 30 & 0.0042 & 0.0054 \\
\hline 10 & 60 & 0.0066 & 0.0078 \\
\hline 20 & 120 & 0.01 & 0.0125 \\
\hline 30 & 180 & 0.0125 & 0.0157 \\
\hline \multicolumn{4}{|l|}{ Insert 460} \\
\hline 1 & 6 & 0.0024 & 0.0032 \\
\hline 5 & 30 & 0.0045 & 0.0056 \\
\hline 10 & 60 & 0.0075 & 0.009 \\
\hline 20 & 120 & 0.011 & 0.015 \\
\hline 30 & 180 & 0.0153 & 0.0188 \\
\hline \multicolumn{4}{|l|}{ Insert 675} \\
\hline 1 & 6 & 0.0012 & 0.002 \\
\hline 5 & 30 & 0.003 & 0.0044 \\
\hline 10 & 60 & 0.0054 & 0.0073 \\
\hline 20 & 120 & 0.0094 & 0.0116 \\
\hline 30 & 180 & 0.0126 & 0.0153 \\
\hline \multicolumn{4}{|l|}{ Insert 676} \\
\hline 1 & 6 & 0.0015 & 0.0035 \\
\hline 5 & 30 & 0.0045 & 0.0055 \\
\hline 10 & 60 & 0.0056 & 0.0074 \\
\hline 20 & 120 & 0.0092 & 0.0116 \\
\hline 30 & 180 & 0.0122 & 0.0142 \\
\hline \multicolumn{4}{|l|}{ Insert B2-N } \\
\hline 1 & 6 & 0.002 & 0.0028 \\
\hline 5 & 30 & 0.0049 & 0.0064 \\
\hline 10 & 60 & 0.0071 & 0.0086 \\
\hline 20 & 120 & 0.0106 & 0.0122 \\
\hline 30 & 180 & 0.0151 & 0.018 \\
\hline \multicolumn{4}{|l|}{ B1-X } \\
\hline 1 & 6 & 0.0019 & 0.0033 \\
\hline 5 & 30 & 0.0036 & 0.0048 \\
\hline 10 & 60 & 0.0061 & 0.0081 \\
\hline 20 & 120 & 0.0092 & 0.0122 \\
\hline 30 & 180 & 0.0133 & 0.0154 \\
\hline
\end{tabular}




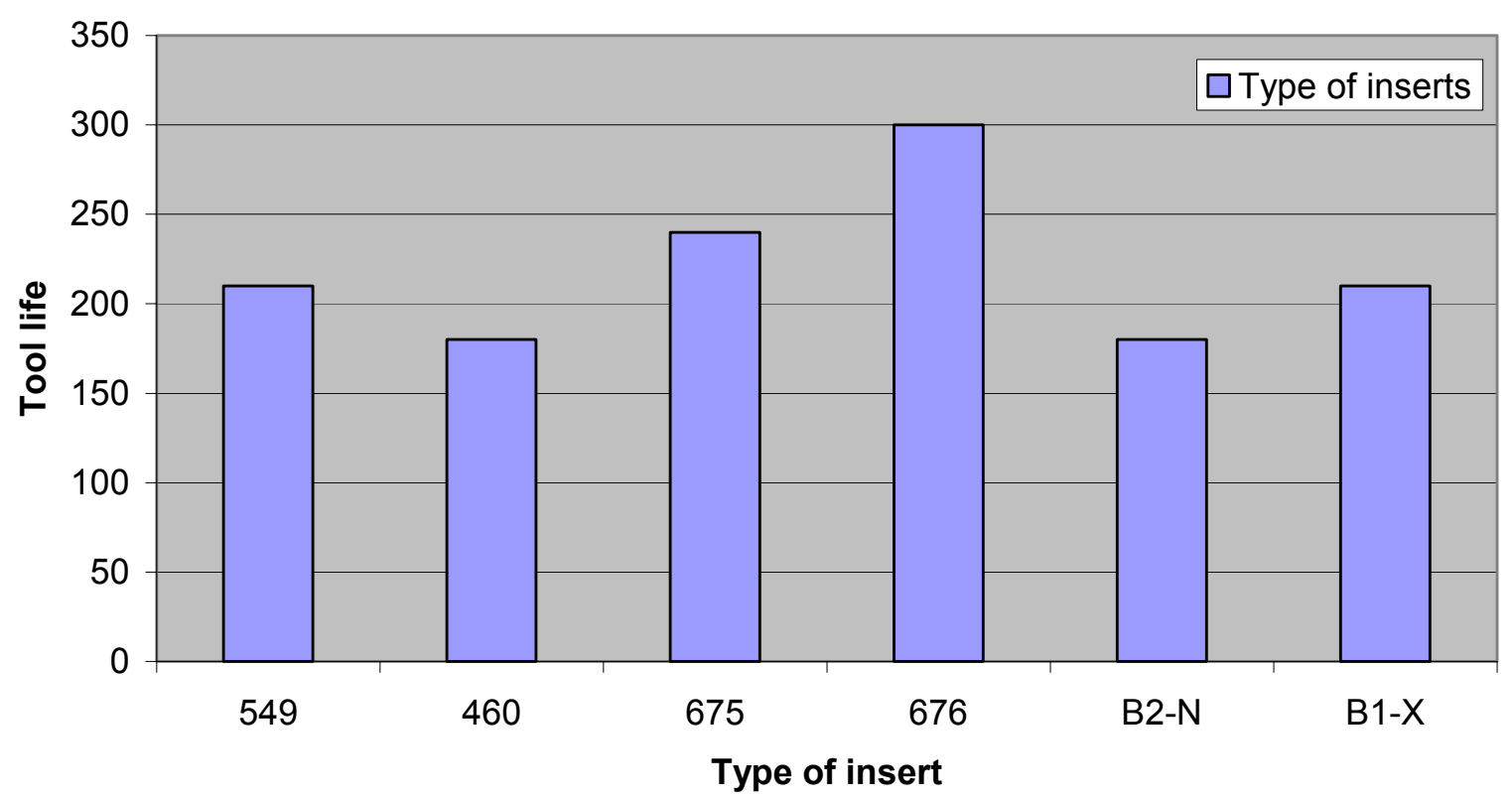

Figure 55. Tool lives of different coatings during experiments (2200 SFPM (RPM=5600), feed rate: IPT=0.01; IPM=112, 2 inserts on cutter).

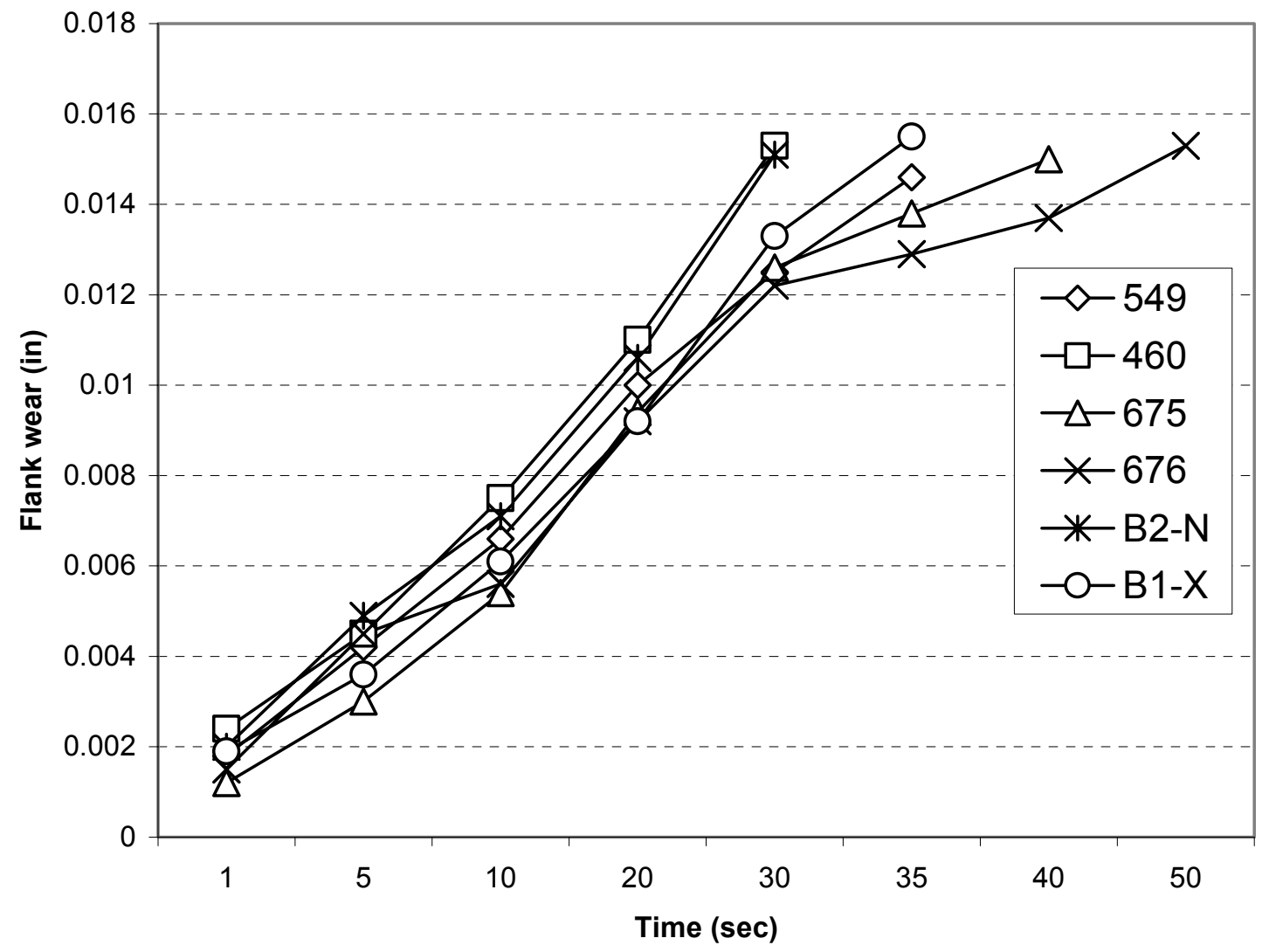

Figure 56. Progression of wear at cutting speed of 2200 SFPM (feed rate: IPT=0.01; IPM=112, 2 inserts on cutter). 
Table 19. Wear data for cutting speed of 2600 SFPM (RPM=6620), feed rate: IPT=0.01; IPM=132.4, 2 inserts on cutter

\begin{tabular}{|c|c|c|c|}
\hline No of passes & Total time (sec) & Uniform wear(in) & Max Wear(in) \\
\hline \multicolumn{4}{|l|}{ Insert 549} \\
\hline 1 & 5.1 & 0.002 & 0.003 \\
\hline 5 & 25.5 & 0.0042 & 0.0051 \\
\hline 10 & 51 & 0.0064 & 0.0086 \\
\hline 20 & 102 & 0.0111 & 0.0128 \\
\hline 30 & 153 & 0.0133 & 0.016 \\
\hline \multicolumn{4}{|l|}{ Insert 460} \\
\hline 1 & 5.1 & 0.0024 & 0.0003 \\
\hline 5 & 25.5 & 0.0047 & 0.0057 \\
\hline 10 & 51 & 0.0072 & 0.0085 \\
\hline 20 & 102 & 0.0112 & 0.013 \\
\hline 30 & 153 & 0.0133 & 0.0144 \\
\hline \multicolumn{4}{|l|}{ Insert 675} \\
\hline 1 & 5.1 & 0.001 & 0.0017 \\
\hline 5 & 25.5 & 0.0035 & 0.0043 \\
\hline 10 & 51 & 0.0061 & 0.0084 \\
\hline 20 & 102 & 0.0084 & 0.0105 \\
\hline 30 & 153 & 0.01 & 0.012 \\
\hline \multicolumn{4}{|l|}{ Insert 676} \\
\hline 1 & 5.1 & 0.0018 & 0.0025 \\
\hline 5 & 25.5 & 0.003 & 0.0042 \\
\hline 10 & 51 & 0.005 & 0.007 \\
\hline 20 & 102 & 0.0094 & 0.011 \\
\hline 30 & 153 & 0.0126 & 0.0146 \\
\hline \multicolumn{4}{|l|}{ Insert B1-X } \\
\hline 1 & 5.1 & 0.0018 & 0.0026 \\
\hline 5 & 25.5 & 0.0041 & 0.0069 \\
\hline 10 & 51 & 0.0075 & 0.0121 \\
\hline 20 & 102 & 0.0112 & 0.014 \\
\hline 30 & 153 & 0.015 & 0.0174 \\
\hline \multicolumn{4}{|l|}{$\mathrm{B} 2-\mathrm{N}$} \\
\hline 1 & 5.1 & 0.002 & 0.0025 \\
\hline 5 & 25.5 & 0.0049 & 0.0061 \\
\hline 10 & 51 & 0.007 & 0.011 \\
\hline 20 & 102 & 0.0115 & 0.014 \\
\hline 30 & 153 & 0.014 & 0.0176 \\
\hline
\end{tabular}




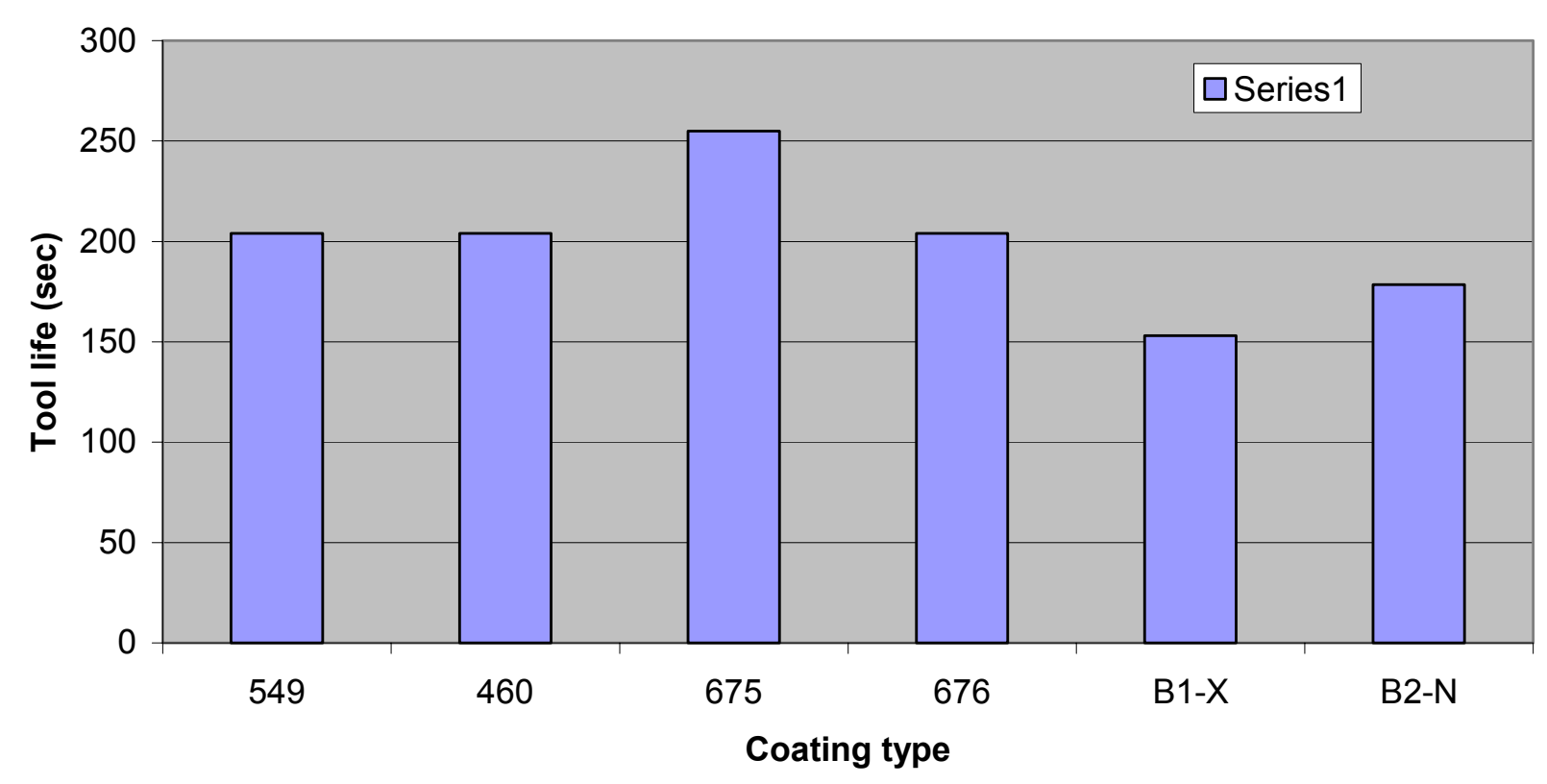

Figure 57. Tool lives of different coatings during experiments (2600 SFPM (RPM=6620), feed rate: $\mathrm{IPT}=0.01 ; \mathrm{IPM}=132.4,2$ inserts on cutter).

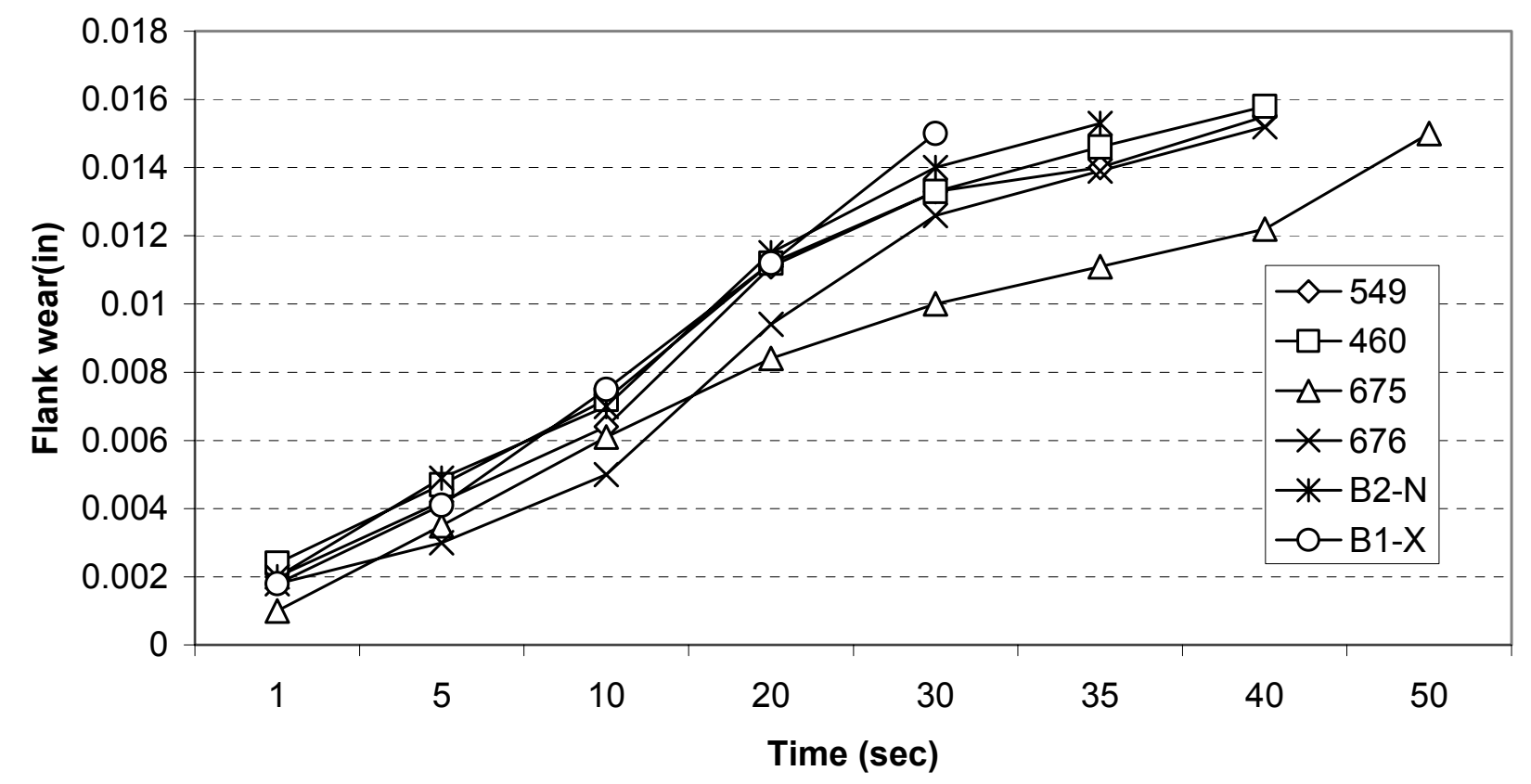

Figure 58. Progression of wear at cutting speed of 2600 SFPM (feed rate: IPT=0.01; IPM=132.4, 2 inserts on cutter).

It is observed from Figures 55 to 58 that single layer of TiBN and double layer of TiBN/TiN exhibits better resistance to the flank wear than other coatings do, with TiBN/TiN being the best at cutting speed of 2200 SFPM, while TiBN the best at cutting speed of 2600 SFPM. 


\subsubsection{FEM Analysis of Coating Behavior in Milling of Hardened Die Steel}

Face milling is similar to machining with many single-point tools moving in circles and the depth of cut is constant (see Figure 59). During the face milling process, the bottom of the insert is not in contact with the machined surface and the depth of cut is constant while the chip thickness is changing. Therefore, a 2-dimensional plane strain model can be used to simulate the face milling process to predict resultant process variables. In this study, finite element model of the face milling process that uses single insert with a straight cutting edge is used.

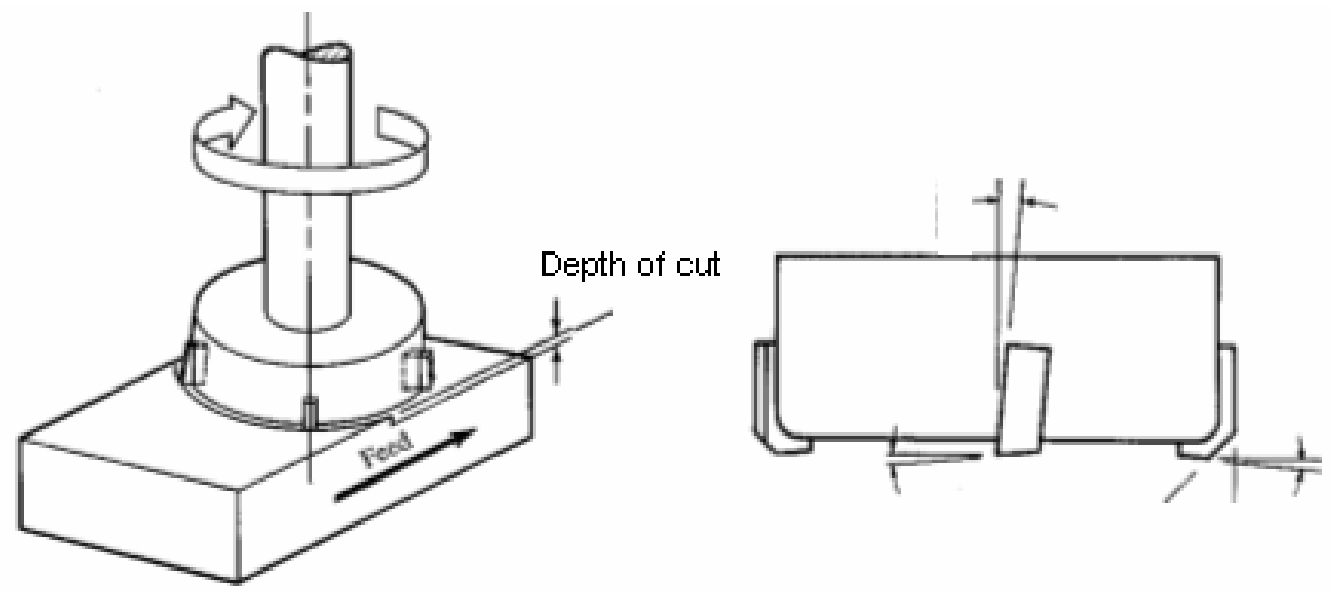

Figure 59. Face Milling Process [19,20].

\section{Development of FEM Model For End Milling}

In this project, a FEM model of TiBN and TiBN/TiN coated cutting tool in face milling of H13 steel is developed. Double-layer coating architecture is investigated with mono-layer coating used as a benchmark. Double-layering leads to better coating adhesion and toughness. It is known that stresses within a coated insert can result from three main sources: 1) the stresses taking place from the deposition process itself; 2) the residual stresses resulting from the thermal mismatch between the coating and the substrate during cooling process after the deposition process and, 3 ) the stresses generated as a result of an externally applied load. In the current study, only the last of these stresses is considered and, as a result, the insert is assumed to be initially stress-free - ignoring the influence of deposition and thermal effects. Process variables, such as temperature, pressure and stress in the coating layer as well as in the substrate are analyzed. The efficacy of the present FEM analysis is verified by conducting controlled milling experiments on AISI H-13 to collect the relevant tool life and force data.

\section{FEM Model}

Since the DEFORM-2D finite element software possesses the non-linear adaptive remeshing function, no prior assumptions regarding chip geometry or material flow were made. The whole simulation process is divided into two stages due to the dimensional incompatibility between coating layer and cutting insert and workpiece. 


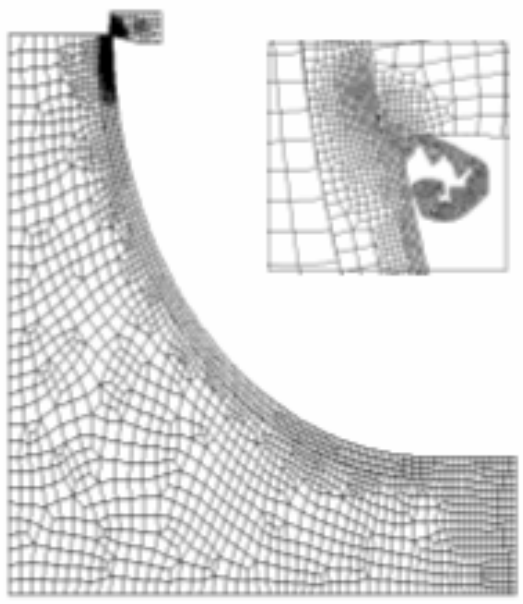

(a)

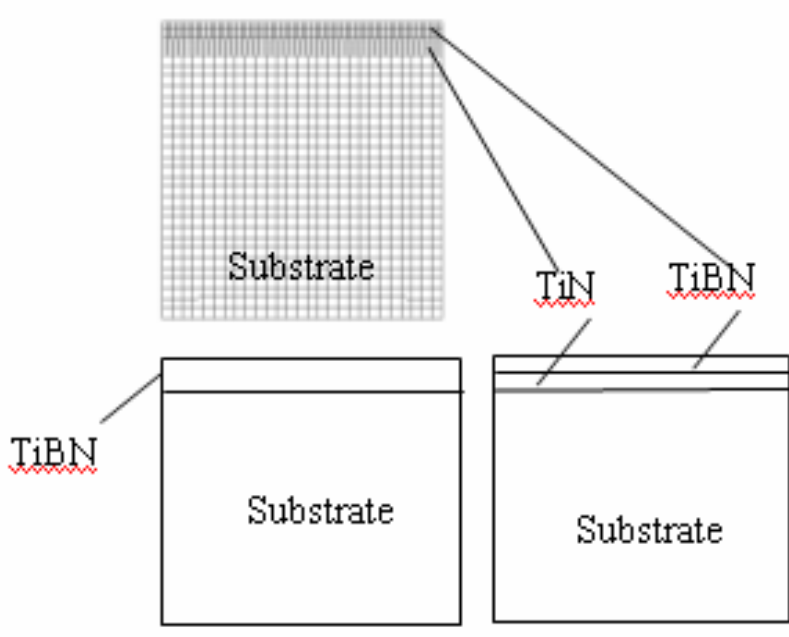

(b)

Figure 60. FEM models: a) FEM model for overall operation; b) sub-model for a interest location on cutting tool rake face.

In step 1, an orthogonal model, as shown in Figure 60a, of the cutting process is developed and the load conditions (temperature, stresses and pressure, etc.) over the tool rake face are determined. To avoid dimensional incompatibility and obtain enough number of elements for the computation, the work piece is divided into two parts: a thin arch area which is close to the tool tip path and will undergo severe deformation and, the rest portion of the work piece in which the deformation can be ignored. Due to the big difference between the sizes of substrate and coating (the thickness of coating is usually less than $10 \mu \mathrm{m}$, while size of substrate is in the order of $\mathrm{mm}$ ), the cutting tool at this stage is modeled without coating to avoid the dimensional incompatibility. Figure 60a shows the orthogonal model and small picture in Figure $60 \mathrm{a}$ zooms in the tool tip area and shows the chip formation during the simulation. In step 2, an interest point in the cutting tool rake face is taken out and modeled as shown in Figure $60 \mathrm{~b}$ to investigate the effect of different coating on the tool performance during the cutting process. In this step, coated tool is modeled with: 1) single-layer coating of TiBN and, 2) a double-layer coating of TiBN/TiN with TiBN on the top (see Figure 60b).

The cutting diameter of the tool is $38.1 \mathrm{~mm}$. The chip thickness changes from $0.203 \mathrm{~mm}$ to zero in a trochoidal manner due to the feed rate and spindle rotation. The process parameters for FEM simulation are listed in Table 20 and the material properties for tool substrate, coating and work piece are given in Table 21.

Table 20. Cutting Conditions and Tool Geometry

\begin{tabular}{cccccccc}
\hline $\begin{array}{c}\text { Cutting } \\
\begin{array}{c}\text { Speed } \\
(\mathrm{m} / \mathrm{min} .)\end{array}\end{array}$ & $\begin{array}{c}\text { Depth of } \\
\text { Cut }(\mathrm{mm})\end{array}$ & $\begin{array}{c}\text { Feed Rate } \\
(\mathrm{mm} / \text { Rev. })\end{array}$ & $\begin{array}{c}\text { Coulomb } \\
\text { friction } \\
\text { coefficient }\end{array}$ & $\begin{array}{c}\text { Cutter } \\
\text { Diameter } \\
(\mathrm{mm})\end{array}$ & $\begin{array}{c}\text { Rake } \\
\text { Angle }\left({ }^{\circ}\right)\end{array}$ & $\begin{array}{c}\text { Clearance } \\
\text { Angle }\left({ }^{\circ}\right)\end{array}$ & $\begin{array}{c}\text { Tip } \\
\text { Radius } \\
(\mathrm{mm})\end{array}$ \\
\hline $\begin{array}{c}76.2, \\
106.68,\end{array}$ & 0.7112 & 0.203 & 0.5 & 38.1 & -11 & 5 & 0.01 \\
137.16 & & & & & & \\
\hline
\end{tabular}


Table 21. Material Properties

\begin{tabular}{ccccccc}
\hline Materials & $\begin{array}{c}\text { Young's } \\
\text { modulus } \\
(\mathrm{MPa})\end{array}$ & $\begin{array}{c}\text { Poisson's } \\
\text { ratio }\end{array}$ & $\begin{array}{c}\text { Thermal } \\
\text { expansion } \\
\left(10^{-6} / \mathrm{K}\right)\end{array}$ & $\begin{array}{c}\text { Thermal } \\
\text { conductivity } \\
\left(\mathrm{W} / \mathrm{m}^{\circ} \mathrm{K}\right)\end{array}$ & $\begin{array}{c}\text { Heat } \\
\text { capacity } \\
\left(\mathrm{N} / \mathrm{mm}^{2} / \mathrm{K}\right)\end{array}$ & Emissivity \\
\hline $\begin{array}{c}\text { Workpiece } \\
\text { (AISI H13) }\end{array}$ & 210000 & 0.28 & 9.0 & 24.3 & 3.588 & 0.5 \\
\hline $\begin{array}{c}\text { Tool } \\
\begin{array}{c}\text { Substrate } \\
\text { (WC/Co) }\end{array}\end{array}$ & 558000 & 0.22 & 6.3 & 60 & 2.79 & 0.5 \\
\hline TiBN & 412500 & 0.265 & 8.05 & 29.85 & 3.99 & 0.5 \\
\hline TiN & 251000 & 0.25 & 8.0 & 32.7 & 4.25 & 0.5 \\
\hline
\end{tabular}

\section{Model Validation}

Figure 61 shows the comparison of predicted cutting force with experimental measurement. It is seen that cutting force varies with the cutting speed. Both simulation result and experimental measurement give the same trend for the cutting force variation versus cutting speed. As the cutting speed increases from $76.2 \mathrm{~m} / \mathrm{min}$. (250 SFPM) to $106.68 \mathrm{~m} / \mathrm{min}$. (350 SFPM), the cutting force decreases. However, when the cutting speed increases from 106.68 $\mathrm{m} / \mathrm{min}$. (350 SFPM) to $137.6 \mathrm{~m} / \mathrm{min}$. (450 SFPM), the cutting force increases slightly.

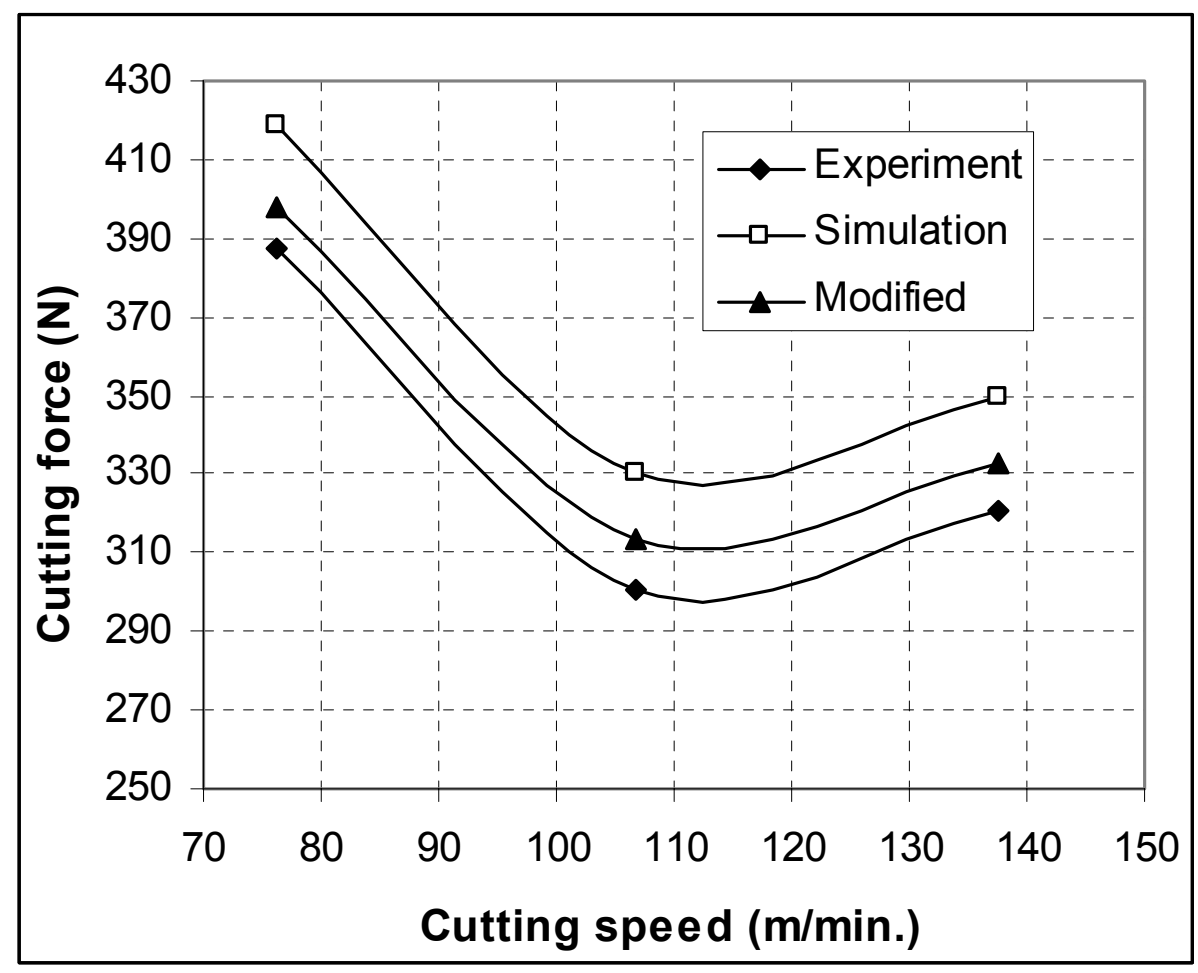

Figure 61. Comparison of Cutting Forces. 
It is shown in this picture that the predicted result is in good agreement with the experimental data and the maximum difference between predicted and experimental results is less than $10 \%$, the reason being the difference between the plane strain nature (orthogonal model) of the FEM model and the non-orthogonal behavior of milling test. The modified FEM cutting load curve shown in Figure 61, is obtained by multiplying a non-orthogonality factor $(\eta=0.95)$ to represent the limited width of the chip.

\section{FEM Simulation of H13 Milling}

The simulations of face milling of AISI H13 at three different cutting speeds are conducted from the initial state to the steady state. The effect of different coatings on the stress distribution and temperature distribution in the coating layers and in the substrate are analyzed. To investigate the effect of different coatings on the cutting tool performance, a small element of $100 \times 100 \mu \mathrm{m}$ on the tool rake face near tool tip, where the maximum temperature occurs, is selected and modeled (as shown in Figure 60b). The surface pressure and temperature of this selected small area in the simulation of step 1 are extracted and applied as boundary and initial conditions to the small element during the simulation of step 2.

\section{Stress Distribution in Coating Layer and Substrate}

The effective stress distributions under different coatings at cutting speed of $76.2 \mathrm{~m} / \mathrm{min}$. are illustrated in Figure 62. It can be seen from this figure that the maximum effective stress in the uncoated tool is $556.4 \mathrm{MPa}$, while that in the substrate of coated tool is $543.8 \mathrm{MPa}$ for singlelayer $(\mathrm{TiBN})$ and $544.8 \mathrm{MPa}$ for double-layer (TiBN/TiN) respectively. The reduction of effective stress in the substrate with coating layer is more than $10 \mathrm{MPa}$. Figure 63 shows the effective stress distributions under different coatings at cutting speed of $137.6 \mathrm{~m} / \mathrm{min}$.

It is illustrated in this figure that, as the cutting speed increases, the maximum effective stress in the substrates of coated tool is $621.4 \mathrm{MPa}$ for single-layer (TiBN) and 623.6 MPa for double-layer (TiBN/TiN) respectively. Compared to the maximum effective stress of $650.6 \mathrm{MPa}$ in uncoated substrate, there are more than $25 \mathrm{MPa}$ decreases in the tool load. This means that by applying coating to the tool substrate one can increase the load capacity of the cutting tool. A difference of stress distribution in the coating layers is also seen. At the cutting speed of 76.2 $\mathrm{m} / \mathrm{min}$., it can be seen from Figure 62 that the maximum effective stress in double-layer coating is about $30 \mathrm{MPa}$ higher $(643.4 \mathrm{MPa})$ than that in single layer coating $(613.7 \mathrm{MPa})$. At the cutting speed of $137.6 \mathrm{~m} / \mathrm{min}$.(see Figure 63 ), the maximum effective stress in double-layer is about $15 \mathrm{MPa}(760.3 \mathrm{MPa})$ higher than that in single-layer $(745.3 \mathrm{MPa})$. This indicates that the double-layer coating tends to be broken earlier than the single-layer coating. This predicted result is in good agreement with the experimental measurement illustrated in Section 3.2.6.1, where the testing results show that insert $675(\mathrm{TiBN})$ possesses longer tool life than insert 676 (TiBN/TiN). 

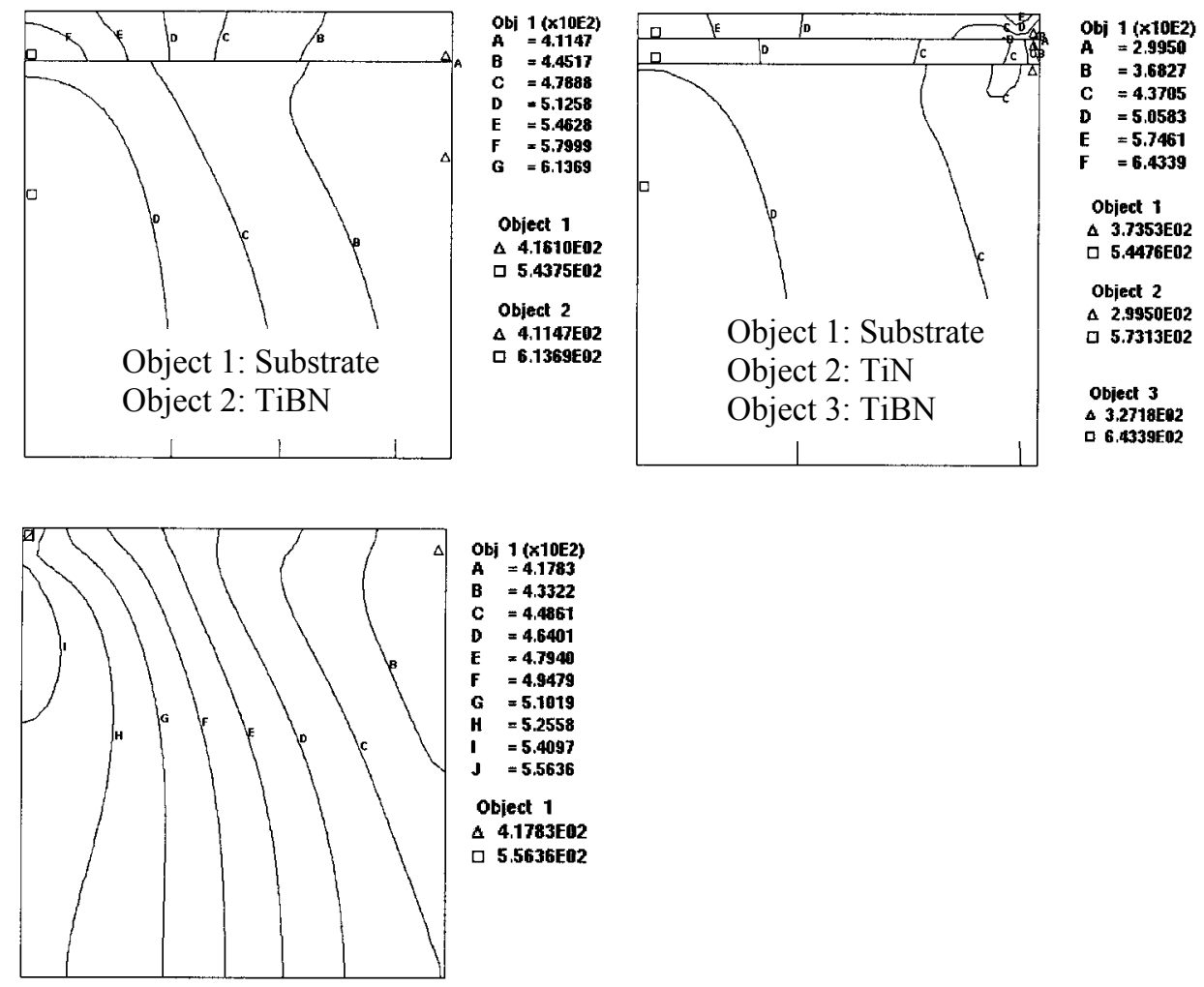

Figure 62. Stress distribution under different coatings at cutting speed of $76.2 \mathrm{~m} / \mathrm{min}(250$ SFPM). 

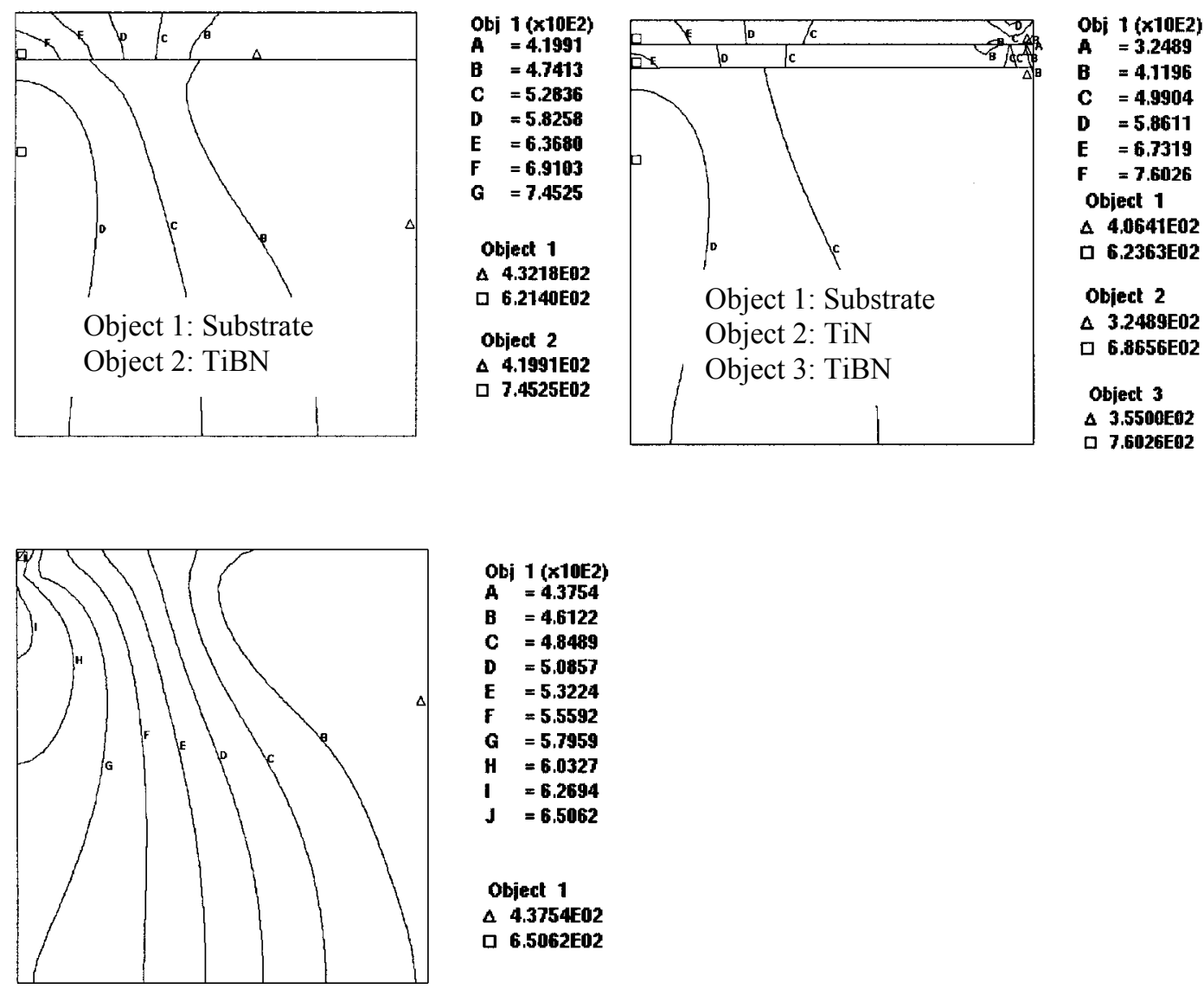

Figure 63. Stress distribution under different coatings at cutting speed of $137.6 \mathrm{~m} / \mathrm{min}(450$ SFPM).

It can be concluded based on the above analysis that tougher substrate coated with well designed hard ceramic coatings greatly help to improve tool life. A possible reason could be that surface coatings improve the tribological properties of cutting tools in an ideal way. The above observation is in good agreement with findings of other researchers [21]. Increasing the load capacity of the cutting tool may result into increase in the tool life directly through a coating induced improvement of the resistance against abrasion and tribo-chemical wear of the tool surface.

\subsubsection{Temperature Distribution in Coating Layer and Substrate}

Figures 64 and 65 show the temperature distribution in tool substrate and coating layers at different cutting speeds. When the cutting speed is low (see Figure 64), the maximum temperatures in the tool substrate for both single-layer and double-layer coating are almost the same regardless the difference of coatings. When the cutting speed increases to $137.6 \mathrm{~m} / \mathrm{min}$ (Figure 65), it can be seen that the maximum temperature of the substrate in double-layer coating case is about $13^{\circ} \mathrm{C}$ less than that in single-layer coating. This is because the thermal conductivity of double-layer coating (average of TiBN and TiN) is larger than that of single-layer coating (see Table 21) and heat from the chip can be conducted more quickly to other portion of the cutting tool other than localized on the rake face near the tool tip. This can also be explained by 
analyzing temperature distribution in the coating layers. It can be seen from Figures 64 and 65 that the maximum temperatures in the top layer (TiBN) of different coatings are the same. However, when adding TiN (with its thermal conductivity higher than that of TiBN) between TiBN and substrate, the temperature gradient increases (maximum temperature $692.6^{\circ} \mathrm{C}$ and minimum temperature $431.95^{\circ} \mathrm{C}$ ) as compared to the single-layer coating (maximum temperature $692.6^{\circ} \mathrm{C}$ and minimum temperature $440.32^{\circ} \mathrm{C}$ ). This means more heat flows within the coating layers to other part of the tool.
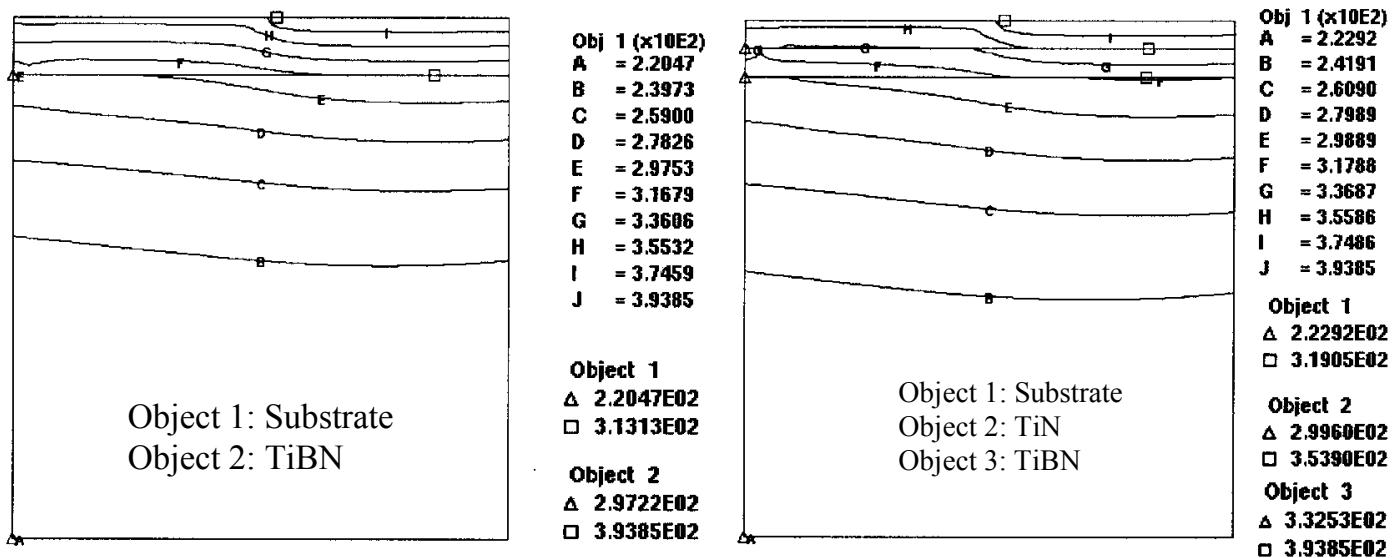

Figure 64. Temperature distribution under different coatings at cutting speed of $76.2 \mathrm{~m} / \mathrm{min}$ (250 SFPM).
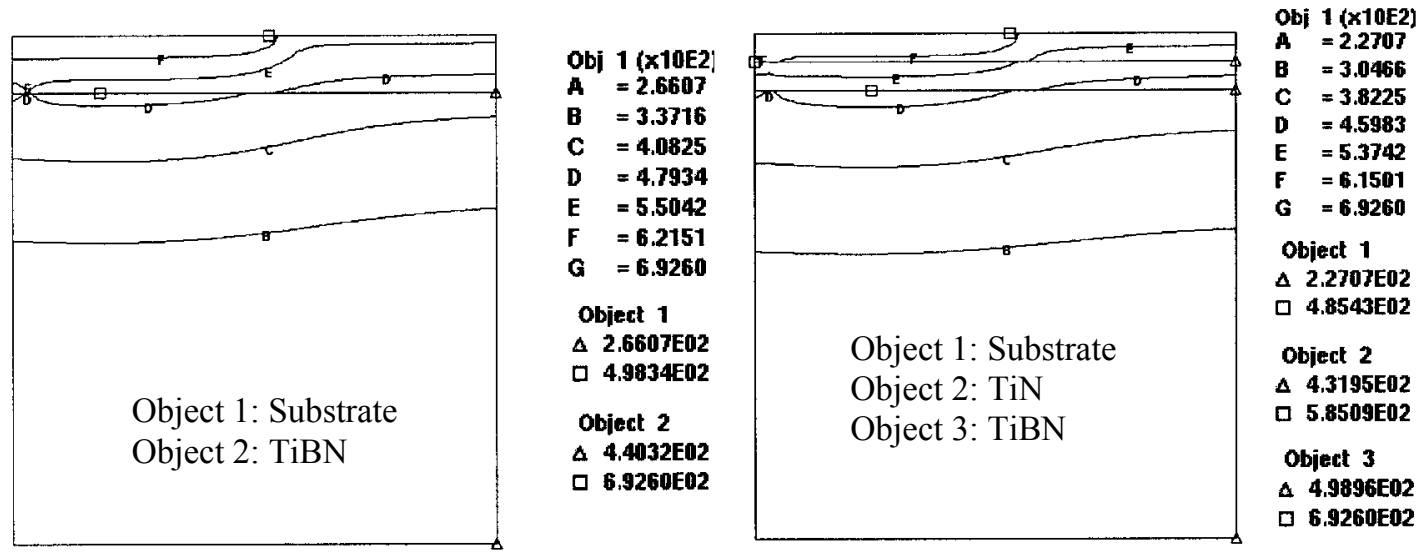

Figure 65. Temperature distribution under different coatings at cutting speed of $137.6 \mathrm{~m} / \mathrm{min}$ (450 SFPM).

This result indicates that from the thermal barrier point of view, reducing the individual coating thickness weakens neither the coating layer itself nor the substrate under it. In other words, for reducing crater wear (diffusion), the desired coating properties (for example, optimum combination of toughness and hardness) can be obtained by using multi-layer coating with the thickness of each individual layer thinner than that in single-layer coating. 


\subsubsection{Summary of FEM Simulation}

Based on the analysis of predicted results, it can be concluded that: 1) Stress in cutting tools can significantly be reduced by surface coatings that improve the tribological properties of cutting tools. In other words, cutting tool with coating induced improvement of the resistance against abrasion and tribo-chemical wear of the tool surface greatly increases loadability of cutting tool. Furthermore, the performance of single-layer coating is better than the double-layer coating to resist abrasion and tribo-chemical wear; 2) Coatings with good thermal properties also help to improve thermal behavior of cutting tool. This is even more important in high speed milling where the temperature is high and diffusion wear becomes the dominant mode of tool wear. Again, multi-layer coatings are good way to attain the optimum combination of thermal properties for resistance to diffusion wear. Therefore, multi-layer architecture is the preferred way to obtain optimal coating properties (best combination of toughness and hardness, for example) if the crater is the main concern during the cutting process.

\subsection{CONCLUSIONS}

A number of $\mathrm{B}$ and $\mathrm{C}$ based hard coatings have been developed using a combination of unique large area filtered cathodic arc and magnetron sputtering processes. The coatings have been evaluated for machining of widely used engineering alloys based on Fe, Al, and Ti. Based on the face milling experiments and FEM analysis, the following conclusions can be reached:

1. The addition of boron reduces the friction and adhesion tendency (chemical wear) of Titanium based coatings leading to reduced flank wear and increased tool lives. This is evident from its lower flank wear at higher cutting speeds during milling of the selected three different materials.

2. A tool life comparison for milling of AISI H13 is listed in Table 22, in which the benchmark coating is uncoated tungsten carbides (inserts \# 883). The values in the Table 22 represents the ratio of tool life of candidate coating to the tool life of benchmark coating. During machining of AISI H13, the single-layer TiBN coating insert (\#675) provides the best performance to resist flank wear. Double-layer TiBN/TiN coating possesses good tool life next to the single-layer TiBN coating. Uncoated tool (\#833) provides the worst performance among all inserts tested. The possible reason may be that during machining of AISI H13, the flank wear in the cutting tool is abrasive in nature. This kind of wear is mainly dependant on the strength of the tool material.

Table 22. Tool Life Comparison for Milling of H13

\begin{tabular}{|c|c|c|c|c|c|}
\hline $\begin{array}{c}\text { Cutting Speed } \\
\text { (SFPM) }\end{array}$ & $\begin{array}{c}\text { TiBN } \\
\# 675\end{array}$ & $\begin{array}{c}\text { TiBN/TiN } \\
\# 676\end{array}$ & B1 - X & B2-N & $\begin{array}{c}\text { WC } \\
\text { (Benchmark) }\end{array}$ \\
\hline 250 & 13 & 7 & 6 & 6 & 1 \\
\hline 350 & 9 & 7 & 4 & 5 & 1 \\
\hline 450 & 4.3 & 3.6 & 2.9 & 2.1 & 1 \\
\hline
\end{tabular}


3. Harder TiBCN coatings ( $35 \mathrm{GPa}$ ) perform the best at lower speeds of $660 \mathrm{~m} / \mathrm{min}$ but are only second best to $\mathrm{TiB}_{2}$ at higher speeds. This is probably due to the higher diffusion and adhesion of aluminum at higher speeds. It is possible that their performance would have been better than $\mathrm{TiB}_{2}$ for machining of aluminum with even higher Si content (25\%) or MMCs with $\mathrm{SiC}$ particulates such as directionally reinforced aluminum (DRA). However, this needs evaluation.

4 A tool life comparison for milling of Al-Si alloy is listed in Table 23, in which the benchmark coating is TiAlN (inserts \# 549). The values in Table 22 represent the ratio of tool life of candidate coating to the tool life of benchmark coating. A $25 \%$ increase in tool life over TiAlN was achieved at 2600 SFPM using a single layer of TiBN. At 2200 SFPM, multilayers performed $43 \%$ better than the benchmark coating.

Table 23. Tool Life Comparison for Milling of H13

\begin{tabular}{|c|c|c|c|c|c|c|}
\hline $\begin{array}{c}\text { Cutting } \\
\text { Speed } \\
\text { (SFPM) }\end{array}$ & $\begin{array}{c}\text { TiAlN/TiB } \\
\# 460\end{array}$ & $\begin{array}{c}\text { TiBN } \\
\# 675\end{array}$ & $\begin{array}{c}\text { TiBN/TiN } \\
\# 676\end{array}$ & B1 - X & B2-N & $\begin{array}{c}\text { TiAlN } \\
\text { (Benchmark) }\end{array}$ \\
\hline 2200 & 0.85 & 1.14 & 1.43 & 1 & 0.85 & 1 \\
\hline 2600 & 1 & 1.25 & 1 & 0.88 & 0.75 & 1 \\
\hline
\end{tabular}

\section{REFERENCES}

1. A Global Business Report on Machine Tools, Global Industry Analyst, Inc., San Francisco, Ca (June 1996); Business and Technical Outlook for Cutting Tools, Gorham Advanced Material Institute Conference, Atlanta, GA (March 1996).

2. F. Klocke and T. Krieg, Annals of the CIRP, vol 48/2, 515 (1999).

3. R. Shivpuri, NADCA Task Group Meeting Report, The Ohio State University, Columbus, OH (February 1998).

4. B.D. Barbon, L.E. Pope and T.N. Wittberg, Surf. Interf. Analysis 15, 100-106 (1990).

5. $\quad$ M.A. Tamor and W.C. Vassel, J. Appl. Phys., 76(6), 3823, (1994).

6. N. Wada, P.J. Gaczi, and S.A. Solin, J. Non-Cryst. Solids 35\&36, 543, (1980).

7. R.O. Dillon, J.A. Wollam, and V. Katkanant, Phys. Rev. B, 29, 3482, (1984).

8. H.E. Rebenne and D.G. Bhat, Review of CVD TiN Coatings for Wear-resistant Applications: Deposition Processes, Properties and Performance, Surface and Coatings Technology, $\underline{63}, 1$ (1993).

9. K. Narasimham, S. P. Boppana and D. G. Bhat, Wear, 188, 123(1995).

10. M. Halvarsson, H. Norden and S. Vuorinen, Surface and Coating Technology, 68/69, 266(1994).

11. O. Knotek, F. Löffler and G. Krämer, Int. J. Refractory Metals \& Hard Materials, $\underline{14}, 195$ (1996).

12. M. P. Groover, Fundamentals of Modern Manufacturing, Prentice-Hall Inc., 1996.

13. Gorokhovsky V. I., U. S. Patent 5,380,421 (1995). 
14. Gorokhovsky V. I., Polistchook V. P and Yartsev, Ivan M.: "Processes in a plasma arc installation for vacuum coating depositions. Part I: Plasma generation" Surface and Coatings Technology, (1993) v61 pp.101-107.

15. Vetter J. and Perry A. J., "Advances in cathodic arc technology using electrons extracted from the vacuum arc"; Surface and Coatings Technology, (1993) v61, pp. 305-308.

16. Daimler-Benz Adhesion Test, 1992, Verein Deutscher Ingenieure (VDI)-Richlinie, 3198, 7.

17. Dearnley, P. A., A. N. Grearson, Mater. Sci. Technol. 2 (1986) 47-58.

18. Hartung,P. D. B. M. Kramer, Tool wear in Titanium Machining, Annals of the CIRP, $\underline{31}(1)(1982) 75-80$.

19. Kalpakjian, S., Manufacturing Processes for Engineering Materials, Addison Wesley Longman, $3^{\text {rd }}$ Edn, Inc., 1997.

20. Schey, J. A., Introduction to Manufacturing Processes, $3^{\text {rd }}$ Edition, McGraw Hill 2000.

21. Knotek, O., Löffler, F. and Krämer, G., in R. F. Bunshah (ed.) Handbook of Hard Coatings: Deposition Technologies, Properties and Applications, William Andrew Publishing, New York, 2001. 